DOE/PC/90365-T4

(DE92010989)

\title{
FUNDAMENTAL MECHANISMS IN FLUE GAS CONDITIONING
}

Toplcal Report No. 1

Literature Review and Assembly of Theories on the Interactions of Ash and FGD Sorbents

\section{By}

Robert S. Dahlin

P. Vann Bush

Todd R. Snyder

January 9, 1992

Work Performed Under Contract No. AC22-91PC90365

For

U.S. Department of Energy

Pittsburgh Energy Technology Center

Pittsburgh, Pennsylvania

By

Southern Research Institute

Birmingham, Alabama 


\section{DISCLAIMER}

This report was prepared as an account of work sponsored by an agency of the United States Government. Neither the United States Government nor any agency thereof, nor any of their employces, makes any warranty, express or implied, or assumes any legal liability or responsibility for the accuracy, completeness, or usefulness of any information, apparatus, product, or process disclosed, or represents that its use would not infringe privately owned rights. Reference herein to any specific commercial product, process, or service by trade name, trademark, manufacturer, or otherwise does not necessarily constitute or imply its endorsement, recommendation, or favoring by the United States Government or any agency thereof. The views and opinions of authors ex. pressed herein do not necessarily state or reflect those of the United States Government or any agency thereof.

This report has been reproduced directly from the best available col v.

Available to DOE and DOE contractors from the Office of Scientific and Technical Information, P.O. Box 62, Oak Ridge, TN 37831; prices available from (615)576-8401, FTS 626-8401.

Available to the public from the National Technical Information Service, U. S. Department of Commerce, 5285 Port Royill Rd., Springfield, VA 22161. 
FUNDAMENTAL MECHANISMS IN FLUE GAS CONDITIONING

\title{
TOPICAL REPORT No. 1
}

\section{LITERATURE REVIEW AND ASSEMBLY OF THEORIES ON THE} INTERACTIONS OF ASH AND FGD SORBENTS

Contract No. DE-AC22-91PC90365

January 9, 1992

\author{
Robert S. Dahlin \\ P. Vann Bush \\ Todd R. Snyder \\ SOUTHERN RESEARCH INSTITUTE \\ 2000 NINTH AVENUE SOUTH \\ P.O. BOx 55305 \\ BIRMINGHAM, ALABAMA 35255-5305
}

Prepared for

Felixa Eskey, Project Manager

UNITED STATES DEPARTMENT OF ENERGY

Pittsburgh Energy Technology Center

Post Office Box 10940, MS 920-206

Pittsburgh, Pennsylvania 15236

SRI-ENV-92-14-7375 
INTRODUCTION..................................................................................................................................1

Specific Objectives .....................................................................................................................................

Goals of the Literature Review and Topical Reports .................................................................4

LITERATURE REVIEW METHOD .............................................................................................5

Search Procedure ............................................................................................................................................

Review Procedure .......................................................................................................................................5

SUMMARY OF THE REVIEW ......................................................................................................

Introduction and Background ..........................................................................................................

Effects of High-Temperature Sorbent Injection .......................................................................

Effect on Electrical Resistivity.............................................................................................9

Effect on Particle Size Distribution .................................................................................10

Effect on Particle Morphology, Surface Area, and Pore Structure ............................11

Effect on Particle Cohesivity......................................................................................................17

Effects of Low-Temperature Sorbent Injection......................................................................18

Specialized Forms of Low-Temperature Sorbent Injection ........................................18

Specialized Forms of In-Duct Spray Drying.......................................................................19

Specialized Forms of Dry Sorbent Injection...................................................................20

Effect on Electrical Resistivity.............................................................................................22

Effect on Particle Size Distribution .....................................................................................28

Effect on Particle Morphology, Surface Area, and Pore Structure .............................34

Effect on Particle Cohesivity.......................................................................................................36

CONCLUSIONS AND RECOMMENDATIONS.......................................................................38

High-Temperature Sorbent Injection..............................................................................................38

Low-Temperature Sorbent Injection...........................................................................................40

BIBLIOGRAPHY.....................................................................................................................................44

APPENDIX A - DETAILED DESCRIPTION OF SEARCH PROCEDURES.............. A-1

APPENDIX B - SUMMARIES OF PERTINENT ARTICLES ..............................................B-1 


\section{INTRODUCTION}

This is one of two special topical reports issued concurrently under DOE Contract No. DEAC22-91PC90365. The Department of Energy's Pittsburgh Energy Technology Center (DOE/PETC) has sponsored a number of research and development activities in fine particulate control technology. Because of this emphasis on fine particle collection, and the potential of flue gas conditioning to increase the effectiveness of this collection, DOE/PETC is funding this investigation into the fundamental mechanisms involved in the conditioning and subsequent collection of fine particles by electrostatic precipitators (ESPs) and fabric filters. An initial review of existing literature, summarized in these two topical reports, will be followed by laboratory and pilot-scale testing to evaluate the fundamental mechanisms involved in sorbent injection and flue gas conditioning processes. This report summarizes the existing literature that describes how various flue gas desulfurization systems nay affect particulate properties and the subsequent collection of fine particles. Topical Report No. 2 (issued under separate cover) contains a review of literature describing mechanisms of interparticle interactions, how flue gas conditioning may alter bulk particulate properties, and implications for fine particle collection.

A substantial body of research results has been published describing the factors that influence the effectiveness of conventionally operated electrostatic precipitators (ESPs) and fabric filters. Much of the research into the factors determining ESP and fabric filter performance has been directed toward the characterization of fly ash particles and bulk fly ash behavior. The fundamental characteristics of fly ash can be expressed in terms of particle morphology (including size distribution, shape, surface area, pore geometry and particle agglomeration), chemical makeup of the particles, and the environment immediately surrounding the particles (adsorbed water or other compounds, gaseous compounds, temperature, and the concentration of surrounding ions).

ESP performance has been shown to depend on the inlet particle size distribution, the relative dielectric constant of the ash particles, and the fly ash resistivity (White, 1963). Fly ash resistivity has, in turn, been shown to depend on coal chemistry, ion mobility, and flue gas temperature, as well as the concentration of $\mathrm{H}_{2} \mathrm{O}, \mathrm{O}_{2}$ and $\mathrm{SO}_{3}$ in the flue gas (Bickelhaupt, 1985). The wide range of sorbent injection processes currently in use are capable of modifying all of these important parameters. Various flue gas conditioning 
agents, which have been widely used to enhance ESP performance, also have the capability of modifying these parameters.

Similarly, the filtering pressure drop and collection efficiency of fabric filters have been shown to be strongly dependent on characteristics of the filtered particulate matter. The resistance of the dustcake to the passage of flue gas depends on coal and ash chemistry, flue gas temperature and viscosity, and particle size distribution and morphology (Bush, et al, 1989). Poor filtration efficiency has been associated with ashes having extremely low cohesivity (Felix and Merritt, 1986). As with ESPs, sorbent injection processes can modify all of these determining factors. Other baghouse conditioning agents, although not widely applied, have shown promise for enhancing fine particle collection in specific baghouse applications (Bush, et al, 1991).

No significant interactions between particles occur until the particles are initially collected. The concentrations of particles in typical inlet flue gases are far too low for substantial interactions between suspended particles. (There are, of course, reactions between entrained particles and various flue gas constituents.) Particles collected on the grounded electrode in an ESP or on the dustcake in a fabric filter form layers or agglomerates that exhibit characteristics that strongly influence the effectiveness of the overall particle collection process. In ESPs, bulk ash resistivity is the most important ash characteristic determining collection performance (White, 1963). The effect of resistivity on ESP performance has been extensively studied. Standardized laboratory and in situ measurement apparatus and procedures have been developed to quantify the resistivity of ash. For fabric filter applications, the cohesivity of the ash collected in the dustcake is a key determinant of collection efficiency and filter cleanability (Bush, et al, 1989). The study of the effects of cohesivity on fabric filter performance is relatively immature, and there are no standard measurements to quantify cohesivity.

Resistivity and cohesivity are derived from the characteristics of the entrained fly ash particles and the flue gas environment. In some cases the mechanisms by which these properties influence fine particle collection have been identified, while in other cases proposed mechanisms are based primarily on empirical evidence. Although many programs have successfully demonstrated the advantages of flue gas conditioning for improving particulate collection, most of the fundamental mechanisms involved in these processes remain poorly understood. The development of conditioning processes for the enhancement of fine particle collection is hampered by a lack of a comprehensive 
understanding of these mechanisms. Flue gas conditioning involves the modification of one or more of the parameters which determine the magnitude of the forces acting on the fly ash particles, and can take place through many different methods. Modification of particulate properties can alter ash resistivity or ash cohesivity and result in improved control device performance. The modification can be caused by changes to the flue gas, addition of particulate matter such as flue gas desulfurization (FGD) sorbents or the addition of reactive gases or liquids. Also it may be possible to modify the operating parameters of the ESP or fabric filter to match the characteristics of the particles to be collected. If the mechanisms by which conditioning agents and FGD sorbents react with fly ash particles can be better understood, selective application of appropriate conditioning agents may result in significantly improved fine particle collection at lower capital and operating costs.

\section{SPECIFIC OBJECTIVES}

The overall goal of this research project is to formulate a mathematical model of flue gas conditioning. This model will be based on an understanding of why ash properties, such as cohesivity and resistivity, are changed by conditioning. Such a model could serve as a component of the performance models of particulate control devices where flue gas conditioning is used. There are two specific objectives of this research project, which divide the planned research into two main parts. One part of the project is designed to determine how ash particles are modified by interactions with sorbent injection processes and to describe the mechanisms by which these interactions affect fine particle collection. The objective of the other part of the project is to identify the mechanisms by which conditioning agents, including chemically active compounds, modify the key properties of fine fly ash particles.

The study of fine particle collection in sorbent injection processes has the potential to affect the broad implementation of technologies currently available or under development to control $\mathrm{SO}_{2}$ emissions. The investigation of flue gas conditioning agents is designed to provide for the effective development of advanced approaches to flue gas conditioning of fine fly ash particles. In both cases, the focus of the research will be on an evaluation of the fundamental mechanisms that are responsible for controlling or changing the key physical properties of the particulate matter. This evaluation will require theoretical development to describe the relationships between interparticle forces and the characteristics of the particles, and empirical trials to assess the relative magnitudes of these forces. 
The literature searches, reviews of existing data, and the two topical reports are designed to provide accurate, timely information describing the state of the existing knowledge. This design ensures that the subsequent laboratory and pilot-scale studies will address those issues that are still not fully understood and that will yield the greatest benefit for the stated objectives of the project.

\section{GOALS OF THE LITERATURE REVIEW AND TOPICAL REPORTS}

The literature review was performed in order to determine the current state of knowledge with regard to the type of interactions that are likely to affect the collection of fine fly ash and/or sorbent particles. Since much of the prior research into these types of interactions was directed toward topies other than the collection of particulate matter from coal-fired sources, the literature review was not limited to this field. The literature review was designed to provide a general overview of pertinent material to the reader and to help in the development of a suitable series of tests for the investigations to be performed in the laboratory.

The two topical reports are intended both as references for use during this current project and as stand-alone documents that should be useful to other researchers working in these same areas. For this reason, some of the background information and parameters used in the literature search are presented in both topical reports. Additional articles located during the remainder of this project, but too late to be included in either of the two topical reports, will be summarized in the final report for this project. (According to the current schedule, this final report is to be issued in Septernber, 1994.) 


\section{LITERATURE REVIEW METHOD}

\section{SEARCH PROCEDURE}

An abstract search was performed through the DIALOG Information Services. This computer-based service was used to access the National Technical Information Service (NTIS), COMPENDEX PLUS, and Chemical Abstracts data bases. The NTIS data base consists of unclassified government-sponsored research, development and engineering reports, and other analyses prepared by government agencies. The COMPENDEX PLUS data base provides coverage of the worlds significant engineering and technical literature. This data base corresponds to the printed publication "Engineering Index", plus additional conference records from the Engineering Meetings file. The Chemical Abstracts data base provides the most current indexing and abstracting of the major chemical literature. Complete details of the search procedure are presented in Appendix A.

Over 35,000 abstracts were returned from this search and examined. We selected 136 articles and reports that appeared to contain information describing the factors involved in either the interactions of ashes and sorbents or in the general conditioning of ash or other fine particles. Many of these articles and reports were obtained from the holdings of Southern Research Institute's Library. The other articles and reports selected were ordered through NTIS and various interlibrary loan services.

\section{REVTEW PROCEDURE}

Thorough reviews were conducted to assemble and reconcile the theories and data applicable to the objectives of this project. The results of the labora. $r /$ studies and the articles obtained in the literature reviews performed under Contract No. DE-AC2288 PC88868 and Contract No. DE-AC22-88PC88851 were also included in this review. In addition to the information obtained through these literature reviews and abstract searches, operating experiences with ash conditioning were assembled for analysis. These field data will be especially useful in the development of meaningful test programs.

Each articie or report received was read, and a summary was written. The summaries of the articles are intended to extract the parts of the article that apply to the objectives of this project. Summaries were not written for articles or reports that were found to contain no 
information applicable to project objectives. The summaries of the articles and reports were grouped according to their applicability to sorbent or general conditioning applications. Appendix B in this report contains the complete summaries of articles dealing with flue gas desulfurization systems and their effects on particulate properties or control device performance. Articles dealing with the general modification of ash or powder properties and fundamental particle-to-particle interactions are summarized in Topical Report No. 2. In some cases the reader of the summary has been directed to access the complete article in order to obtain the full range of information and comments presented by the author(s). 


\section{SUMMARY OF THE REVIEW}

\section{INTRODUCTION AND BACKGROUND}

The foregoing discussion described the fundamental electrostatic and inertial mechanisms that are operative in particulate collection. The key particulate properties that influence these mechanisms were also identified and discussed. Particle size, shape, and chemistry were identified as key fundamental parameters. It was noted that the surface chemistry of the particles is influenced by the flue gas environment surrounding the particles. At temperatures near $300^{\circ} \mathrm{F}$, surface chemistry plays a dominant role in determining such key properties as resistivity and cohesivity. Cohesivity is also related to the number of contact points between the particles, which is determined by particle size and shape. Particle size and shape also influence the drag force on particles migrating to the plate in an ESP and the drag associated with the movement of the flue gas through a dust cake. Thus, particle chemistry, size, shape, and flue gas environment are key parameters affecting the performance of both ESPs and fabric filters.

In the following discussion, we revisw what is currently known about the effects of sorbent injection processes on particulate properties. The effects on the fundamental properties of size, shape, and chemistry are addressed, along with the effects on the flue gas environment and the bulk properties of electrical resistivity and cohesivity. Although resistivity and cohesivity are not fundamental properties, they are certainly key parameters in determining control device performance. Resistivity, in particular, is a parameter that has been measured in almost every study of sorbent injection that has been performed to date. One reason that resistivity effects have received so much attention is that the sorbent injection processes currently under development are primarily intended for the retrofit market. About $92 \%$ of the existing coal-fired generating capacity is equipped with ESPs (Barrett et $a l, 1983)$. In a recent study by the Environmental Protection Agency (EPA), information on particulate control devices was compiled for 191 boilers at the 60 power plants with the highest $\mathrm{SO}_{2}$ emissions (Emmel and Kaplan, 1988). This survey revealed that 174 out of the 191 boilers, or $91 \%$ of this population of boilers, were equipped with ESPs. Therefore, there has been relatively little research on the effects of sorbent injection on fabric filter performance. Nevertheless, the fundamental information on particulate properties obtained in the ESP-related studies is equally applicable to fabric filters, since the effects of sorbent injection on particulate properties are independent of the type of control device. 
For this discussion, it is most convenient to separate the sorbent injection processes into two categories: (1) high-temperature processes, involving injertion of calcium-based sorbents into the furnace or economizer; and (2) low-temperature processes, involving conventional lime spray drying, in-duct lime spray drying, or dry injection of hydrated lime with humidification. It is desirable to discuss these two categories of sorbent injection processes separately because the high-temperature sorbent injection processes produce fundamentally different effects on particulate properties than do the low-temperature processes. This results in different sets of concerns relative to control device performance. For example, with high-temperature sorbent injection a primary concern is high resistivity and the potential for back corona in an ESP. With low-temperature sorbent injection a primary concern is that the resistivity may become too low, resulting in electrical reentrainment in the ESP.

\section{EFFECTS OF HIGH-TEMPERATURE SORBENT INJECTION}

Injection of calcium-based sorbents (limestone or hydrated lime) into the furnace or economizer produces substantial changes in particulate properties relative to those of the baseline fly ash. At furnace temperatures, the limestone or hydrated lime is rapidly calcined, and the resulting lime $(\mathrm{CaO})$ undergoes a pozzolanic reaction with the aluminosilicates in the fly ash, forming a modified ash with cementitious qualities (Dahlin et al, 1986). (A pozzolan is any material that produces a cement when added to lime; the term "pozzolanic reaction" refers to the reaction between the pozzolan and the lime.) The mechanism of this reaction has been studied extensively in connection with the production and use of cement and is well documented (Boynton, 1966). These studies have identified the formation of ettringite $\left[\mathrm{Ca}_{6} \mathrm{Al}_{2}\left(\mathrm{SO}_{4}\right)_{3}(\mathrm{OH})_{12} \cdot 25 \mathrm{H}_{2} \mathrm{O}\right]$ as a key to the production of high-quality cement, and ettringite has been identified as a component of modified ash from furnace sorbent injection (Holcombe et al, 1990). The cementitious nature of the modified ash, along with the confirmed presence of ettringite, proves that the pozzolanic reaction does occur within the boiler. This pozzolanic reaction is one aspect of hightemperature sorbent injection that distinguishes it from low-temperature injection. At low temperatures (ca $300^{\circ} \mathrm{F}$ ), hydrated lime does not decompose, no pozzolanic reaction occurs, and the resulting ash is not significantly cementitious (Henzel and Ellison, 1990). This difference is partly responsible for the different effects of high-temperature and lowtemperature sorbent injection on the properties of the ash. 
In the following, we review the reported effects of high-temperature sorbent injection on electrical resistivity, particle size distribution, particle morphology (including surface area and pore structure), and cohesivity. Results from both limestone and hydrated lime injection are discussed. Since several studies have made use of additives to enhance the reactivity of the sorbent with $\mathrm{SO}_{2}$, the effects of the additives on particulate properties are also addressed. Since downstream humidification of the flue gas has also been used in conjunction with furnace sorbent injection (both to enhance $\mathrm{SO}_{2}$ removal and reduce resistivity), the effects of humidification on particulate properties are also discussed.

\section{Effect on Electrical Resistivity}

Numerous stidies have shown that the furnace injection of either limestone or hydrated lime produces a subctantial increase in electrical resistivity, unless this effect is controlled by flue gas humidification or conditioning with $\mathrm{SO}_{3}$. Dahlin et al (1985) showed that resistivity was increased from about $9 \times 10^{8}$ ohm-cm to about $1 \times 10^{12} \mathrm{ohm}-\mathrm{cm}$ when either Vicron limestone or Longview hydrated lime was injected at the burner at a calcium-tosulfur $(\mathrm{Ca} / \mathrm{S})$ molar ratio of $2: 1$. This result was obtained with a high-sulfur Indiana coal that produced 26 to $31 \mathrm{ppm}$ of $\mathrm{SO}_{3}$ in the absence of any sorbent. With the sorbent injection, there was virtually no $\mathrm{SO}_{3}$ left in the gas phase at $300^{\circ} \mathrm{F}$. The high resistivity of the ash/sorbent mixture was reduced to about $5 \times 10^{10} \mathrm{ohm}-\mathrm{cm}$ by injecting 30 to $40 \mathrm{ppm}$ of $\mathrm{SO}_{3}$ into the flue gas to condition the ash. When tests were done with hydrated lime injected at the furnace exit, it was found that the resistivity of this ash could not be modified with $\mathrm{SO}_{3}$ injection at concentrations up to $130 \mathrm{ppm}$. This effect was attributed to the higher specific surface area and reactivity of the hydrated lime injected at the furnace exit. In similar tests with another high-sulfur coal, Gooch et al (1987) reported that injection of the Longview hydrated lime at the furnace exit reduced the $\mathrm{SO}_{3}$ concentration from $20 \mathrm{ppm}$ to below the detection limit of $0.3 \mathrm{ppm}$, while increasing resistivity from about $10^{9} \mathrm{ohm}-\mathrm{cm}$ to about $10^{12} \mathrm{ohm}-\mathrm{cm}$. These tests confirmed that the ash/sorbent mixture was very difficult to condition with $\mathrm{SO}_{3}$, but humidification of the flue gas with a water spray, which cooled the gas from about $300^{\circ} \mathrm{F}$ to about $180^{\circ} \mathrm{F}$, reduced resistivity to about $10^{10} \mathrm{ohm}-\mathrm{cm}$. At the same time, it was noted that the humidification eliminated the severe back corona in the pilo. ESP used in the study.

At the demonstration of EPA's Limestone Injection Multistage Burner (LIMB) process at Ohio Edison's Edgewater Station, the results of the pilot studies mentioned above were 
confirmed at a scale of $100 \mathrm{MW}$. Hydrated lime injection just upstream of the superheater tubes at $\mathrm{Ca} / \mathrm{S}$ of $2: 1$ produced an increase in resistivity from $3 \times 10^{10} \mathrm{ohm}-\mathrm{cm}$ to $10^{12} \mathrm{ohm}$ $\mathrm{cm}$ (Faulkner et al, 1988). As soon as sorbent injection was initiated, the electrical operation of the first ESP field began to degrade because of severe back corona. The back corona progressed through the ESP, reaching the fifth field within three hours after the sorbent was turned on. At that point, the test had to be terminated to avoid exceeding the $20 \%$ limit on stack opacity. Pilot-scale tests suggested that the back corona problem could be avoided by humidifying the flue gas to within $50^{\circ} \mathrm{F}$ of the adiabatic saturation temperature. Later full-scale tests at the Edgewater Station showed that lowering the temperature to $100^{\circ} \mathrm{F}$ above saturation was adequate to maintain satisfactory ESP operation with stack opacity below $20 \%$ (Nolan et al, 1990). It should be noted, however, that the Edgewater ESP is unusually large, with a specific collecting area (SCA) of over 600 $\mathrm{ft}^{2} / \mathrm{kacfm}$. Smaller ESPs may not be capable of meeting the $20 \%$ opacity limit under the same conditions. Indeed, some computer model projections of ESP performance suggest that furnace sorbent injection will cause an increase in particulate emissions, even when allowance is made for the beneficial effects of humidification (DuBard et al, 1986). Other modeling efforts, however, suggest that it is possible to restore particulate emissions to the original level by the use of flue gas humidification (Helfritch et al, 1986).

\section{Effect on Particle Size Distribution}

In general, there is agreement that furnace sorbent injection produces a shift in the particle size distribution toward smaller particles (i.e., there is a reduction in the mass mean diameter of the particles). This is to be expected when hydrated lime is used as the sorbent, since the mass mean diameter of commercial hydrated lime is typically about 3 to $6 \mu \mathrm{m}$ (Boynton, 1966). The mass mean diameter of fly ash from bituminous coals is typically about $16 \mu \mathrm{m}$ (Dahlin and Altman, 1982). Limestone is available in a variety of particle sizes, depending upon the types of grinding and milling procedures used in its preparation. The smallest mean size that can be produced commercially in a dry grinciing circuit is about $10 \mu \mathrm{m}$ (Boynton, 1966). Smaller mean sizes can be produced by wet grinding, but this is generally not economical. One commercial limestone product that was tested extensively in early work on furnace sorbent injection was Vicron 45-3, a product of Pfizer, Inc., with a maximum particle size of $45 \mu \mathrm{m}$, a minimum size of $3 \mu \mathrm{m}$, and a mean size of $15 \mu \mathrm{m}$. In terms of its original size distribution, the Vicron limestone is fairly similar to fly ash. However, when subjected to rapid heating, as in furnace injection, virtually all limestones 
decrepitate (Boynton, 1966) producing a particle size distribution that is considerably finer than that of the parent material. Because of this decrepitation, limestone injection also tends to produce a shift in the size distribution toward smaller particle sizes.

Figure 1 shows particle size distributions measured in a pilot-scale combustor burning an Alabama Hallmark coal, with and without the injection of Longview hydrated lime at the furnace exit at $\mathrm{Ca} / \mathrm{S}$ of 2:1 (DuBard et al, 1986). Based on these distributions, the mass mean particle diameter was reduced from about $28 \mu \mathrm{m}$ to about $10 \mu \mathrm{m}$, and the mass loading of submicron particles was increased by over an order of magnitude. The total mass loading was increased from 2.3 to $6.3 \mathrm{gr} / \mathrm{acf}$. Thus, there was a disproportionately large increase in the loading of smaller particles. Dahlin et al (1985) give particle size distributions measured in the same combustor while burning an Indiana high-sulfur coal, with and without the injection of Vicron limestone at the furnace exit at $\mathrm{Ca} / \mathrm{S}$ of 2:1. In this case, the total mass loading was increased from about 3 to about $7 \mathrm{gr} / \mathrm{acf}$, but there was little change in the mass mean particle size. However, the loading of submicron particles was increased by a factor of about 3 . The smaller increase in fine particles with the limestone than with the hydrated lime is presumably caused by the larger size of the parent material. Thus, even though the limestone decrepitates, the fragments are still apparently larger than the hydrated ime particles, as least for these two sorbents.

At the Edgewater LIMB demonstration, hydrated lime injection at the furnace exit at $\mathrm{Ca} / \mathrm{S}$ of 2:1 increased the total mass loading from 1.9 to $3.5 \mathrm{gr} /$ acf (Faulkner et al, 1988). There was a tenfold increase in the mass loading of particles in the size range of 0.5 to $1 \mu \mathrm{m}$. Pilot ESP tests, which were done to simulate the Edgewater ESP operation with humidification, showed that this increase in the fine particle loading produced some corona quenching. While humidification dramatically improved electrical operation, it was found that the corona quenching prevented a complete restoration of the original operating conditions.

Effect on Particle Morphology, Surface Area, and Pore Structure

Particle morphology and surface area have been shown to be key parameters in determining the performance of fabric filters (Bush et al, 1989). Relatively smooth particles tend to produce a low cohesivity. In general, cohesivity increases as the particles become rougher and smaller. Ashes with low cohesivities will tend to pack tighter into smooth dust cakes. In extreme cases, very smooth particles have been known to seep 


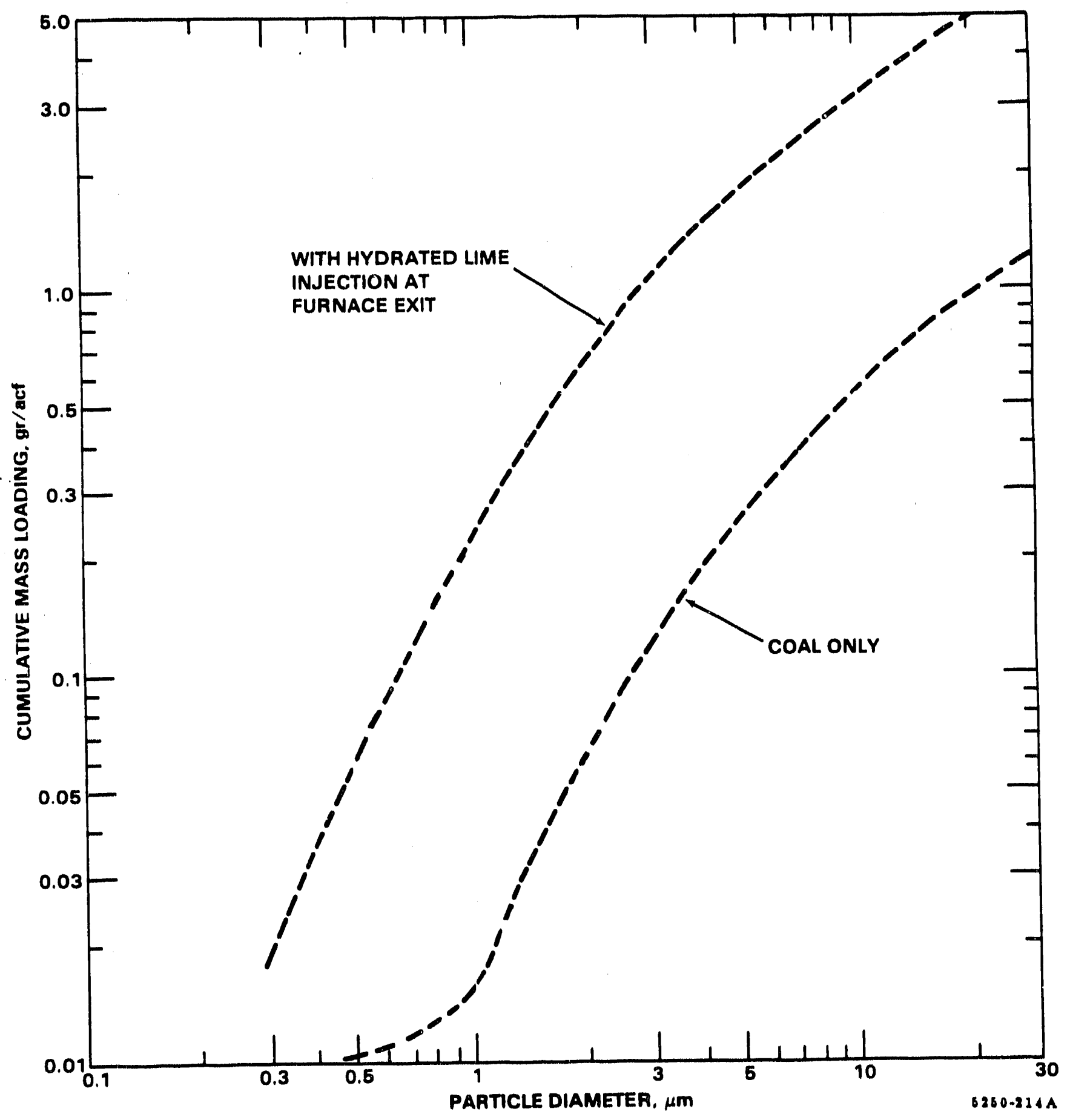

Figure 1. Effect of furnace injection of hydrated lime on the particle size distribution. (Adapted from DuBard, et al, 1986) 
through the fabric (Felix and Merritt, 1986). Particle morphology is also important in ESPs in that rougher particles are subject to greater drag forces, resulting in lower electrical migration velocities (White, 1963). Surface roughness and surface area also affect the ability of the particles to adsorb water vapor and other conditioning agents that influence the electrical resistivity of the ash (Bickelhaupt, 1975). The effects on cohesivity that are important with regard to fabric filter performance are also important in determining the tendency of the ash to be reentrained from ESP plates.

Surface area is an important factor governing the ability of the sorbent to adsorb water vapor and other potential conditioning agents. Bush et al (1989) reported BET surface areas for $18 \mathrm{fly}$ ashes and $6 \mathrm{ash} /$ sorbent mixtures from fluidized-bed combustors and spray dryers. The ash/sorbent mixtures, particularly those from the fluidized-bed combustors, generally had higher surface areas than the fly ashes that did not contain any sorbent. Ash/sorbent mixtures from furnace sorbent injection processes have also been shown to possess slightly elevated surface areas, in comparison to the baseline fly ashes (Dahlin et al, 1987). This is reasonable since commercial hydrated lime hâs an initial specific surface area of 13 to $32 \mathrm{~m}^{2} / \mathrm{g}$ (Boynton, 1966). Specialized hydration techniques and additives have been used to produce enhanced hydrated lime with surface areas as high as $80 \mathrm{~m}^{2} / \mathrm{g}$ (Gooch et al, 1986; Moran et al, 1987). Limestone typically has a specific surface area of less than 3 $\mathrm{m}^{2} / \mathrm{g}$, and fly ash from pulverized coal combustion typically has a specific surface area of less than $4 \mathrm{~m}^{2} / \mathrm{g}$.

Gullett and Bruce (1987) noted that pore structure is an important factor in the rate of loss of surface area and pore volume during the sulfation of $\mathrm{CaO}$. Over comparable extents of sulfation, calcines with cylindrical pores lost surface area and pore volume faster than calcines with slit-like pores. This was attributed to the ability of the slit-like pores to allow more expansion than cylindrical pores. The pore structure must allow expansion to accomodate the larger molar volume of $\mathrm{CaSO}_{4}$ compared to that of $\mathrm{CaO}$. Since pore structure affects the sulfation of the sorbent in this manner, then pore structure might also affect the ability of the sorbent to adsorb and react with other gases and vapors. This would, in turn, affect the surface chemistry, resistivity, and cohesivity of the ash particles.

A calcine with slit-like pores is shown in Figure 2, which is a high-resolution SEM photograph of $\mathrm{CaO}$ produced by calcining reagent-grade $\mathrm{CaCO}_{3}$ under laboratory conditions (Dahlin and Kirchgessner, 1985). The $\mathrm{CaO}$ has obviously retained the original rhombohedral crystal structure of the parent $\mathrm{CaCO}_{3}$. This is the expected result of a 

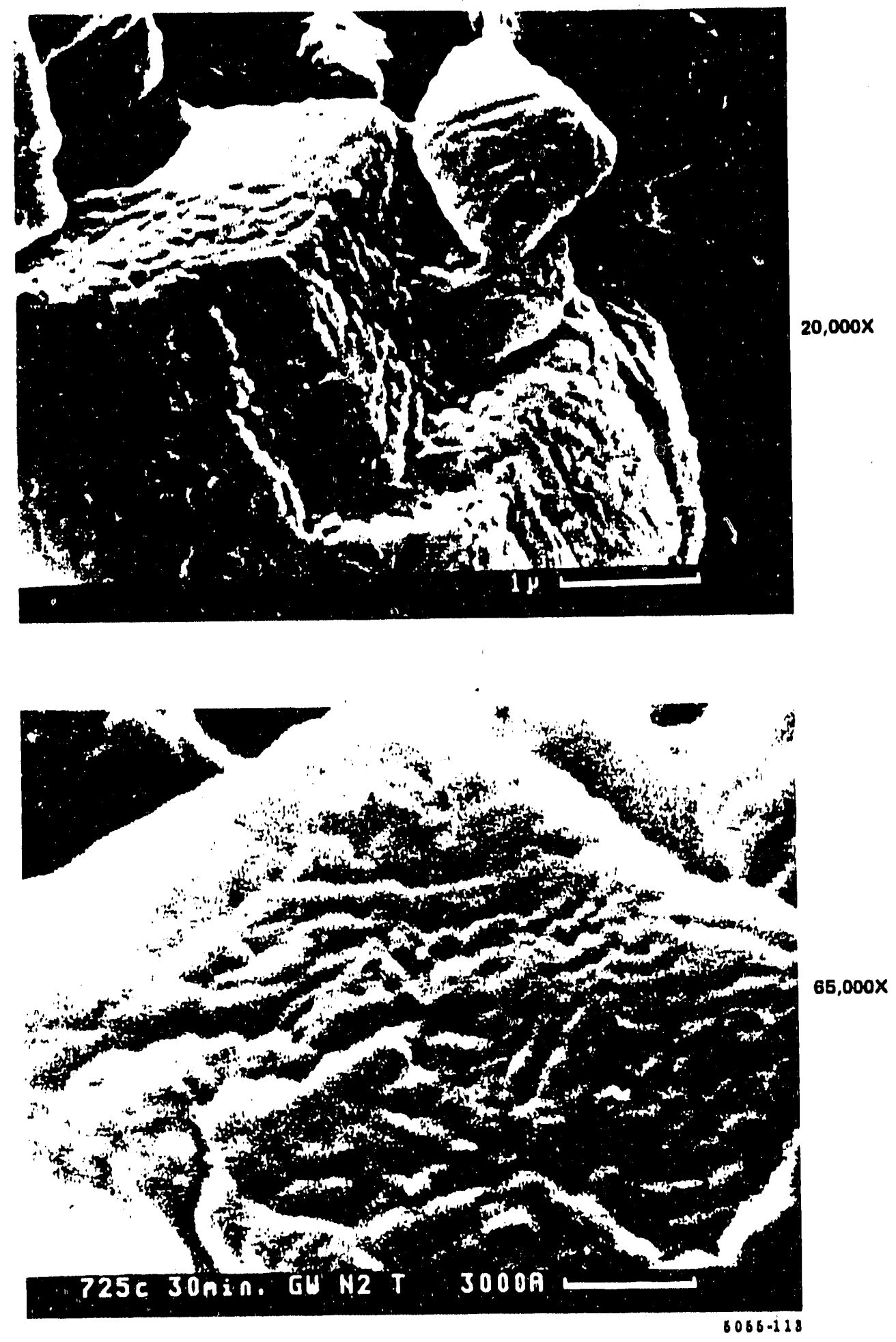

Figure 2. High-resolution SEM photographs showing the surface morphology of a calcine prepared from reagent-grade calcium carbonate. (Source: Dahlin and Kirchgessner, 1985) 
decomposition reaction that is topotactic (Volpe and Boudart, 1985). (A topotactic reaction is one in which the crystal lattice of the reaction product is spatially related to the crystal lattice of the reactant. Topotaxy invariably creates pseudomorphous products crystals converted into other substances without changing their external forms.) The $\mathrm{CaO}$ shown in this photograph had a BET surface area of $27.6 \mathrm{~m}^{2} / \mathrm{g}$, suggesting the presence of considerable pore structure. From the photograph, the pore structure detinitely appears to be slit-like. A very similar slit-like pore structure was also reported by Milne et al (1990) using a $\mathrm{CaO}$ produced by calcining commercial-grade Linwood limestone under similar conditions. The Linwood calcine had a lower surface area of only $11 \mathrm{~m}^{2} / \mathrm{g}$, but the pore structure was remarkably similar to that shown in Figure 2. Thus, the slit-like pore structure appears to be a general feature of calcines produced from limestone. Although much of the structure may be lost as the sorbent is sulfated and the pores become plugged with $\mathrm{CaSO}_{4}$, it is reasonable to expect that this basic pore structure will be retained, to some extent, in the spent sorbent.

Ca.O particles produced from hydrated lime differ from those produced from limestone in several respects. The $\mathrm{CaO}$ particles produced from hydrated lime tend to be smaller than those produced from limestone, because of the finer size of the hydrated lime. However, the $\mathrm{CaO}$ particles produced from hydrated lime have a much greater tendency to agglomerate. On the basis of in situ particle sizing and SEM photographs, Gullett and Blom (1987) documented the tendency of hydrate-derived $\mathrm{CaO}$ particles to agglomerate extensively. They showed a typical SEM photograph of a 25-mm agglomerate consisting of many primary $\mathrm{CaO}$ particles that were 1 to $2 \mu \mathrm{m}$ in size. No such agglomeration was evident in the photographs of the limestone-derived $\mathrm{CaO}$ particles.

$\mathrm{CaO}$ produced from hydrated lime also differs from limestone-derived $\mathrm{CaO}$ in terms of the distribution of pore volume with pore size. The $\mathrm{CaO}$ derived from hydrated lime tends to possess more pore volumu in larger pores than does the limestone-derived $\mathrm{CaO}$ (Gullett and Bruce, 1987). This tends to make the hydrate-derived $\mathrm{CaO}$ less susceptible to pore closure and, therefore, more reactive towards $\mathrm{SO}_{2}$ and other gases, which may explain why the ash/sorbent mixtures produced from hydrated lime tend to be more difficult to condition than those produced from limestone. The more favorable pore structure and higher specific surface area of the hydrate-derived $\mathrm{CaO}$ result in more adsorption of $\mathrm{SO}_{3}$ within the pore structure, rather than on the particle surface. With limestone-derived $\mathrm{CaO}$, the less extensive pore structure and lower surface area produce less internal adsorption, allowing more of the $\mathrm{SO}_{3}$ to be adsorbed on the particle surface. Therefore, limestone- 
derived ash/sorbent mixtures may be successfully conditioned with $\mathrm{SO}_{3}$ concentrations on the order of $30 \mathrm{ppm}$, while some hydrate-derived ash/sorbent mixtures cannot be conditioned with $\mathrm{SO}_{3}$, even with concentrations as high as $130 \mathrm{ppm}$ (Dahlin et al, 1985).

Certain additives that have been employed to promote the reactivity of sorbents have also been shown to alter morphology. A dramatic alteration of morphology has been observed when chromium oxide, $\mathrm{Cr}_{2} \mathrm{O}_{3}$, is used to promote the reactivity of limestone injected near the burner. Slaughter et al (1988) reported that the addition of $5 \mathrm{wt} \% \mathrm{Cr}_{2} \mathrm{O}_{3}$ to limestonc injected at 2150 to $2600^{\circ} \mathrm{F}$ converted the rough, angular sorbent particles to smooth spheres. The number of pores evident in SEM photographs was also severely reduced, and the specific surface area was reduced from $12 \mathrm{~m}^{2} / \mathrm{g}$ to $4 \mathrm{~m}^{2} / \mathrm{g}$. Slaughter et al suggest that the $\mathrm{Cr}_{2} \mathrm{O}_{3}$ reacts with the $\mathrm{CaO}$ to form a low-melting eutectic mixture, which would be a liquid at temperatures above about $1830^{\circ} \mathrm{F}$. The presence of this liquid phase would explain the conversion of the rough angular particles to smooth spheres. The ability of the $\mathrm{Cr}_{2} \mathrm{O}_{3}$ to promote the reaction of $\mathrm{CaO}$ with $\mathrm{SO}_{2}$ is apparently related to the more rapid diffusion through this liquid phase. While $\mathrm{Cr}_{2} \mathrm{O}_{3}$ has been shown to be an excellent promoter, analysis of the reaction products has shown that some of the chromium is converted to the hexavalent oxidation state (Dickson, 1985). Hexavalent chromium is extremely toxic, and its presence would result in classification of the ash as a hazardous waste. Therefore, research on the use of $\mathrm{Cr}_{2} \mathrm{O}_{3}$ as a promoter has been discontinued.

Less pronounced morphological effects have been noted with other promoters, particularly the alkali metals, and with dispersants and surfactants. Slaughter et al (1988) reported that the use of alkali metals as promoters of furnace $\mathrm{SO}_{2}$ capture produced large cracks on the surfaces of sorbent particles, along with a reduction in particle size. They speculated that the presence of the alkali metal in the $\mathrm{CaO}$ matrix induced a chemical sintering that closed the smaller pores, while differences in the local sintering rates between sodium-enriched and unpromoted $\mathrm{CaO}$ opened larger cracks and caused some fragmentation. The extent of crack formation and the reduction in particle size were found to increase with increasing cationic radius (i.e., potassium produced more cracking and smaller particles than did sodium, and sodium produced more cracking and smaller particles than did lithium).

Reductions in particle size and changes in pore structure have also been observed when surfactants and dispersants have been used to produce a modified hydrated lime. Kirchgessner and Lorrain (1987) prepared a modified hydrated lime by adding calcium lignosulfonate, a byproduct of the paper industry, to the water of hydration. They found 
that the modified hydrates containing calcium lignosulfonate had smaller mass mean particle sizes than the unmodified hydrates produied under the same hydration conditions. The mass mean particle size was reduced from $12 \mu \mathrm{m}$ with no lignosulfonate to $3 \mu \mathrm{m}$ with 3 wt\% lignosulfonate. In subsequent work using the same materials, Kirchgessner and Jozewicz (1989) found that the lignosulfonate also allowed the modified hydrate to retain more of its surface area and porosity than the unmodified hydrate under conditions simulating furnace injection. The presence of the lignosulfonate apparently makes the $\mathrm{CaO}$ more resistant to sintering. The presence of the large lignosulfonate molecule at the $\mathrm{Ca}(\mathrm{OH})_{2}$ grain boundaries is believed to reduce grain boundary mobility, resulting in slower sintering. The smaller particle size obtained with the lignosulfonate has been attributed to the ability of the large lignosulfonate molecule to obstruct the formation of liquid bridges between the sorbent particles, resulting in less agglomeration (Kirchgessner and Lorrain, 1987).

\section{Effect on Particle Cohesivity}

To date, there have been no studies that have examined the effect of furnace sorbent injection on ash cohesivity. The only related studies that we are aware of pertain to the cohesivity of ash from fluidized bed combustors. These studies may not be relevant, however, because the ash/sorbent mixtures produced by atmospheric fluidized-bed combustors (AFBCs) differ from those produced by furnace sorbent injection. The AFBCs operate at lower temperatures than pulverized coal-fired (pc-fired) furnaces, producing ash particles that are much rougher and more angular than those produced by pc-fired utility boilers. The ash produced by a pc-fired boiler tends to be relatively smooth and spherical because it has passed through a semi-molten state in the high-temperature regions of the furnace. The operating temperatures of the AFBCs are well below the ash fusion point, so the ash never reaches a semi-molten state, but retains the rough, angular shapes of the coal mineral inclusions. This rough, angular shape results in ash with a high angle of internal friction and a relatively high dust cake porosity, both evidences of high cohesivity (Bush et al, 1987; Cushing et al, 1991). This result may also apply to ash/sorbent mixtures from furnace injection of limestone, which tends to produce rough, angular particles. However, it is doubtful that these observations could be extrapolated to furnace injection of hydrated lime, because of the substantial difference in particle size and morphology. 


\section{EFFECTS OF LOW-TEMPERATURE SORBENT INJECTION}

Low-temperature so-bent injection processes include conventional spray drying, in-duct spray drying, dry sorbent injection with humidification, spray drying within an existing ESP casing (the E-SO $\mathrm{S}_{\mathrm{X}}$ process), and duct injection of advanced sorbents prepared by reacting lime with fly ash (Advanced silicate, or ADVACATE). The spray drying processes (conventional, in-duct, and $\mathrm{E}-\mathrm{SO}_{\mathrm{x}}$ ) use an aqueous slurry of lime that is atomized into the flue gas by either rotary atomizers or pneumatic spray nozzles. Rotary atomizers are currently used only in the conventional spray drying processes, although there has been one attempt to develop an in-duct spray drying system using a rotary atomizer (Samuel et al, 1989). The in-duct and $\mathrm{E}-\mathrm{SO}_{\mathrm{x}}$ spray drying processes use pneumatic nozzles to spray the lime slurry into the duct or ESP casing. The ADVACATE process uses a similar injection system with a modified sorbent that is prepared by reacting lime and fly ash at a temperature of about 180 to $195^{\circ} \mathrm{F}$ (Jozewicz et al, 1988).

Specialized Forms of Low-Temperature Sorbent Injection

Various corporations have developed specialized processes and additives for in-duct spray drying and dry sorbent injection with humidification. Specialized forms of in-duct spray drying include Bechtel's Confined Zone Dispersion (CZD) process, General Electric's

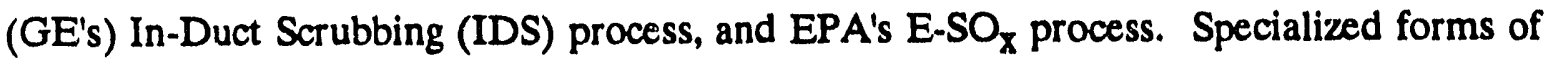
dry sorbent injection include Dravo's Hydrate Addition at Low Temperature (HALT) process, Conoco's Coolside process, Lurgi's circulating fluid bed (CFB) process, EPA's ADVACATE process, and the Electric Power Research Institute's (EPRI's) Hybrid Pollution Abatement System (HYPAS). Each of these processes has its own distinguishing features that the developer has incorporated to optimize process performance and minimize cost. These distinguishing features include the use of particular types of lime or other specially prepared sorbent, the use of particular additives, and the use of specially designed atomization systems. For this discussion, these process features are important because of their potential to produce different effects on particulate properties. Some of the most significant features of the specialized processes and their potential effects on particulate properties are discussed briefly below. After dealing with these specialized variants on the processes, the effects on particulate properties will be addressed on a more generic basis. 
The use of a slurry of pressure-hydrated dolomitic lime, atomized at a very narrow spray angle, is a feature that distinguishes Bechtel's CZD process (Abrams et al, 1986; Bechtel Corporation, 1988). The pressure-hydrated dolomitic lime is said to be a more costeffective sorbent than the more commonly used calcitic hydrated lime. The pressurehydrated dolomitic lime has a smaller primary particle size and higher specific surface area than the calcitic hydrated lime and it contains roughly equimolar amounts of calcium and magnesium (Boynton, 1966). Magnesium has long been known to enhance $\mathrm{SO}_{2}$ removal and sorbent utilization in wet flue gas des'lliurization (FGD) systems (Stowe et al, 1979). The magnesidm improves the solubility of sulfite ions in the scrubber liquor, thereby retarding the buildup of a calcium sulfite shell on the sorbent particles and increasing the effective alkalinity of the liquor (Benson, 1985). The research that has been done on tinis magnesium-enhancement effect has been applied to wet FGD systems, but there is no reason to believe that the enhancement mechanisms would not also apply to the wet stage of the CZD process. Therefore, spent sorbent particles from the CZD process may be more highly utilized than spent sorbent particles from other in-duct spray drying processes under comparable operating conditions. As mentioned earlier, the CZD sorbent particles may also be somewhat smaller and possess more surface area than the sorbent particles from other in-duct spray drying processes. Of course, they will also have a considerably differient chemical composition.

Relatively large sorbent particles are produced by GE's IDS process, which is the only induct spray drying process that uses a rotary atomizer to spray the lime slurry (Samuel et al, 1989). Although larger particle size is often considered to be undesirable from the standpoint of $\mathrm{SO}_{2}$ removal, the larger droplet size allows the sorbent to retain moisture, and thereby remain reactive, for a longer time. Given enough residence time, the IDS process performance should approach that of a conventional spray dryer. Assuming there is no change in other factors affecting ESP performance, the larger sorbent particles that result firom the IDS process would be easier to collect in an ESP than would the particles from other in-duct spray drying processes. The relatively large sorbent particles produced by the IDS process may also tend to form fabric filter dust cakes that differ from those produced with other in-duct spray drying processes. Based on the similarities between the IDS process and conventional spray drying, the effects of the IDS process on control device 
performance may be similar to those that have been observed with conventional spray dryers, which will be discussed later.

EPA's E-SO $\mathrm{x}_{\mathbf{x}}$ process is the last in-duct spray drying process to be singled out for special mention here. In the $\mathrm{E}_{-} \mathrm{SO}_{\mathrm{X}}$ process, an array of spray nozzles is retrofitted into a cavity that is created by removing the internals from the first field of an ESP (Sparks et al, 1985; Hovis et al, March 1988; Hovis et al, October 1988). Because of the relatively large cross sectional area involved, the $\mathrm{E}-\mathrm{SO}_{\mathrm{x}}$ process generally requires a larger array of spray nozzles than do other in-duct spray drying processes. However, the required capacity of each nozzle is reduced accordingly, possibly allowing the production of smaller droplets. Strict control of droplet size is essential to minimize the potential for carryover of droplets into the energized fields of the ESP. To further reduce the potential for droplet carryover, the E-SO ${ }_{\mathrm{X}}$ process has been modified to include a droplet impingment device (DID) ahead of the first energized field (Redinger et al, 1990). Although the DID is designed specifically for droplet removal, it has the potential to remove some sorbent and alter the sorbent size distribution.

In a 5-MW demonstration of an E-SO ${ }_{\mathrm{X}}$ retrofit at an existing ESP, Redinger et al (1990) reported that the DID successfully prevented droplet carryover into the first energized field, but large sorbent particles impinged on the DID and rapping was required to remove the resulting deposits. This removal of large sorbent particles by the DID, along with smaller capacity of the E-SO spray nozzles, suggest that the effective size distribution of sorbent entering the ESP may be somewhat finer than that produced by other in-duct spray drying processes. Analyses of cascade impactor samples obtained between the DID and the ESP and at the outlet of the ESP suggest that the sorbent particles also break up in the ESP (Pontius and Marchant, 1991). This breakup phenomenon, which has been attributed to electrostatic decrepitation, has not yet been documented with the other forms of in-duct spray drying.

Specialized Forms of Dry Sorbent Injection

Dravo's HALT process was one of the first attempts to commercialize the dry injection of hydrated lime with separate flue gas humidification (Forsythe and Kaiser, 1985; Babu et al, 1986; Babu et al, 1988). Dravo tested the HALT process using water sprays upstream and downstream of the sorbent injection and reported better $\mathrm{SO}_{2}$ removal with the downstream 
humidification. Downstream humidification was shown to yield more thorough sorbent wetting because of the higher rate of collisions between sorbent particles and water droplets (Beittel and Dahlin, 1988). The HALT process has been tested in a $1 \times 10^{6} \mathrm{Btu} / \mathrm{hr}$ pilot plant (Babu et al, 1986) and demonstrated at the 5-MW scale (Babu et al, 1988). Although the basic HALT process is essentially the same as the generic version of dry sorbent injection, the HALT development program included several original concepts, including injection of cold sorbent to enhance condensation effects, addition of $\mathrm{NaOH}$ to the water spray, and modification of the sorbent with methanol and sugar (Babu et al, 1986). Addition of methanol to the water of hydration has been shown to significantly increase the surface area of ':ydrated lime (Gooch et al, 1986; Moran et al, 1987). Addition of sugar to the water of hydration greatly increases the solubility of the lime (Boynton, 1966), possibly resulting in a smaller grain size in the hydrated lime.

$\mathrm{NaOH}$ is also added to the humidification water in Conocr's Coolside process (Yoon et al, 1985; Yoon et al, 1986). The Coolside process has been successfully demonstrated at the $100-\mathrm{MW}$ scale, with $\mathrm{SO}_{2}$ removals of $40 \%$ to $70 \%$ reported at calcium-to-sulfur molar ratios of 1.1:1 to 2.0:1 (Kanary et al, 1990). These results were achieved by cooling the flue gas to within 20 to $25^{\circ} \mathrm{F}$ of the adiabatic saturation temperature and using $\mathrm{NaOH}$ additive at a sodium-to-calcium molar ratio of $0.17: 1$ to $0.24: 1$. The Coolside process is very similar to the HALT process. Like Dravo, Conoco has investigated the development of improved sorbents by using additives. Several different metal chlorides have been found to improve $\mathrm{SO}_{2}$ removal, but a variety of different organic additives have been found to have little or no effect on removal (Yoon et al, 1986).

With respect to the effects on particulate properties, it is the $\mathrm{NaOH}$ addition that distinguishes the Coolside sorbent particles from the particles produced by other dry sorbent injection processes. Since the $\mathrm{NaOH}$ is dissolved in the humidification water, it probably produces very small particles of solid $\mathrm{NaOH}$ when dried. The reported ability of the $\mathrm{NaOH}$ to promote the $\mathrm{Ca}(\mathrm{OH})_{2}-\mathrm{SO}_{2}$ reaction suggests that some of the $\mathrm{NaOH}$ is incorporated into the sorbent particles. However, the limited effectiveness of the sorbentdroplet collisions suggests that much of the $\mathrm{NaOH}$ dries out and is collected as a distinct particle. Thus, to some extent, the Coolside process may produce a heterogeneous mixture of separate $\mathrm{Ca}(\mathrm{OH})_{2}$ and $\mathrm{NaOH}$ particles. Because they are so small, any separate $\mathrm{NaOH}$ particles may be difficult to collect in an ESP. The presence of these small NaOH particles may also result in a fabric filter dust cake with properties different from that produced with only $\mathrm{Ca}(\mathrm{OH})_{2}$ and fly ash. 
Lurgi's circulating fluid bed (CFB) process is one of the most advanced dry sorbent injection processes. The Lurgi CFB process has been in commercial operation on five coalfired utility boilers in Germany since 1987 (Toher et al, 1991). In the CFB process, the flue gas is first cooled to within $45^{\circ} \mathrm{F}$ of the adiabatic saturation temperature. The cooled flue gas is then passed through a circulating bed of material composed of fresh hydrated lime and recycled lime and fly ash. As much as $98 \%$ of the particulate material collected in the downstream ESP or baghouse is recycled to the CFB. This high recirculation rate provides for a very dense particulate phase in the $\mathrm{CFB}$, and provides an effective calcium residence time of up to $30 \mathrm{~min}$ (Toher et al, 1991). Abrasion between particles in the CFB reportedly removes the outer layer of reaction product, presumably $\mathrm{CaSO}_{3}$, allowing a very high degree of lime utilization. The five German installations have reported $\mathrm{SO}_{2}$ removal efficiencies of $90 \%$ to $97 \%$ at fresh calcium-to-sulfur molar ratios of 1.2:1 to 1.4:1.

The dense particulate phase that exists within the Lurgi CFB may enhance the potential for particle agglomeration, resulting in a particle size distribution that is somewhat coarser than those produced by other dry sorbent injection processes. The Lurgi CFB also generally appears to be capable of higher $\mathrm{SO}_{2}$ removals and better lime utilization than the other dry sorbent injection processes, despite the fact that it operates at a somewhat higher approach temperature $\left(45^{\circ} \mathrm{F}\right.$ versus 20 to $30^{\circ} \mathrm{F}$ for the other processes). This means that the CFB sorbent is more highly reacted than the other sorbents, resulting in potential differences in other properties such as surface area and cohesivity. Given the higher approach temperature used with the CFB, we would expect to see less adsorption of water vapor and other condensibles on the CFB sorbent. Thus, there may be less potential for the low resistivity reentrainment problems that have been reported at several spray drying and duct injection installations. The relatively low amount of vapor adsorption may also tend to make CFB dust cakes less cohesive than some other dust cakes from dry sorbent processes.

\section{Effect on Electrical Resistivity}

With regard to ESP performance, a primary concern is that the electrical resistivity of the ash/sorbent mixture may become too low. When resistivity is in the desirable range, about 1 $\times 10^{8}$ to $2 \times 10^{10} \mathrm{ohm}-\mathrm{cm}$ according to White (1963), the electrical binding force acts with adhesive and cohesive forces to hold the particles on the ESP plates. As the resistivity drops much below $1 \times 10^{8} \mathrm{ohm}-\mathrm{cm}$, the electrical force holding the particles on the ESP 
plates vanishes and then reverses direction to become a repulsive force (White, 1963). If the repulsive force becomes large enough, it can overcome the tensile strength of the particulate layer, resulting in reentrainment of the particles back into the flue gas. This effect, known as "electrical reentrainment," can drastically reduce the collection efficiency of an ESP. A theoretical development of the criterion for the onset of electrical reentrainment was recently presented by Pontius and Marchant (1991).

Brown et al (1988) suggested that the unexpectedly poor performance of a pilot ESP operated downstream from a spray dryer was attributable to reentrainment. 'They based this conclusion on the observation that ESP emissions increased as the gas velocity was increased at a constant specific collecting area (SCA). They did not report any data on resistivity, but a low value would be expected under the specified operating conditions $\left(20^{\circ} \mathrm{F}\right.$ approach temperature, calcium-to-sulfur molar ratio of 1.3:1, and coal sulfur content of $2.5 \%$ to $4 \%$ ). In later work, supporting laboratory studies showed that electrical reentrainment occurred when the resistivity of the ash/sorbent mixture from the spray dryer fell below about $1 \times 10^{8} \mathrm{ohm}-\mathrm{cm}$ (Durham, Holstein et al, 1991). As the resistivity was further reduced by lowering the temperature in the laboratory test cell, the rate of particle ejection from the grounded electrode was observed to increase. Particle ejection ceased when the temperature reached about $135^{\circ} \mathrm{F}$, presumably because of the increase in particulate cohesivity with decreasing temperature. The addition of calcium chloride to the ash/sorbent mixture was found to greatly reduce the reentrainment, presumably by increasing cohesivity.

Calcium chloride addition to the lime slurry was subsequently investigated as a means of improving the performance of the pilot ESP collecting the spray dryer effluent (Durham, Holstein et al, 1991). At an approach temperature of $18^{\circ} \mathrm{F}$, the chloride addition dramatically improved ESP performance with three different test coals, as indicated below.

\begin{tabular}{|c|c|c|c|c|}
\hline \multirow[b]{2}{*}{ Coal sulfur, \% } & \multicolumn{2}{|c|}{ ESP collection efficiency, \% } & \multicolumn{2}{|c|}{ ESP emissions, lb/10 $10^{6} \mathrm{Btu}$} \\
\hline & Baseline & With Chloride & Baseline & With Chloride \\
\hline 2.2 & 99.84 & 99.98 & 0.041 & 0.005 \\
\hline 2.7 & 99.41 & 99.95 & 0.15 & 0.01 \\
\hline 4.0 & 99.86 & 99.95 & 0.041 & 0.016 \\
\hline
\end{tabular}


With the spray dryer out of service, so that the ESP was collecting fly ash only, the collection efficiency was $99.87 \%$, and the emission rate was $0.008 \mathrm{lb} / 10^{6} \mathrm{Btu}$. When the ESP was used for collecting spray dryer effluent, the particulate emissions increased with increasing coal sulfur content, because more sorivint was required to maintain the desired calcium-to-sulfur molar ratio (1.3:1). The results suggest a decrease or a small increase in emissions with coals that are low to medium in sulfur content; a potentially large increase in emissions is suggested with a high-sulfur coal. Nevertheless, the addition of chloride is clearly beneficial, presumably because of the effect on the particulate cohesivity and reentrainment.

Landham et al (1991) observed a gradual degradation in the performance of an ESP collecting spray dryer effluent. The degradation was found to be correlated with an increase in the lime slurry feed rate. Model predictions suggested that the ESP performance should have improved with increasing slurry feed rate, as a result of the lower gas temperature, lower gas flow rate and velocity, higher SCA, lower gas viscosity, higher gas density, and higher field strength. The discrepancy between the observations and model predictions indicated the presence of a non-ideal effect such as electrical reentrainment. Resistivity measurements made in the laboratory under simulated spray dryer conditions yielded values of 4 to $6 \times 10^{7} \mathrm{ohm}-\mathrm{cm}$, which are low enough to cause electrical reentrainment. It should be noted that the coal burned during this test was extremely low in sulfur $(0.3 \%)$, resulting in a relatively low sorbent feed rate to maintain the desired calcium-to-sulfur molar ratio (1.4:1). Thus, this particular ash/sorbent mixture contained much less sorbent than did the ash/sorbent mixtures from the tests discussed previously, in which coals with sulfur contents of 2.2 to $4.0 \%$ were used. Nevertheless, the laboratory resistivity measurements and qualitative indications of electrical reentrainment were very similar at the two spray dryer installations.

There have also been indications that electrical reentrainment associated with low resistivity limits the performance of ESPs collecting effluent from dry sorbent injection. Durham, Ebner et al (1991) suggested that electrical resistivity was the primary factor limiting the performance of a pilot ESP operating downstream from hydrated lime injection with spray humidification. in their $1.7-\mathrm{MW}$ test facility, even the base line performance of the ESP, with no sorbent injection, was degraded by electrical reentrainment. This effect was attributed to inadequate insulation that allowed the gas temperature in the ESP to drop to $258^{\circ} \mathrm{F}$, producing resistivities of $10^{7}$ to $10^{8} \mathrm{ohm}-\mathrm{cm}$. 
Base line collection efficiency with an inlet fly ash loading of 1.20 to $1.57 \mathrm{gr} / \mathrm{dscf}$ was $99.87 \%$ with all eight electrical fields of the ESP in service, yielding an SCA of $590 \mathrm{ft}^{2} / \mathrm{kacfm}$. The corresponding base line emission rate varied from 0.003 to $0.004 \mathrm{lb} / 10^{6} \mathrm{Btu}$. With only two fields in service (SCA $=136 \mathrm{ft}^{2} / \mathrm{kacfm}$ ), the efficiency dropped to $67 \%$, corresponding to an emission rate of about $0.7 \mathrm{lb} / 10^{6} \mathrm{Btu}$. With hydrated lime injected and the inlet mass loading increased to $7.3 \mathrm{gr} / \mathrm{dscf}$, the collection efficiency with all fields in service was $99.93 \%$, corresponding to an emission rate of about $0.009 \mathrm{lb} / 10^{6} \mathrm{Btu}$. With only two fields in service, the efficiency with sorbent injection dropped to $92.6 \%$, corresponding to an emission rate of $1.0 \mathrm{lb} / 10^{6} \mathrm{Btu}$. With sorbent injection and recycle producing an inlet loading of $11.3 \mathrm{gr} / \mathrm{dscf}$, the efficiency was $99.95 \%$ with all fields in service. The corresponding emission rate was about $0.01 \mathrm{lb} / 10^{6} \mathrm{Btu}$. These results suggest that very small ESPs (SCA $\leq 150 \mathrm{ft}^{2} / \mathrm{kacfm}$ ) must be enlarged to adequately control the effluents from dry sorbent injection.

Other data from in-duct spray drying and dry sorbent injection tests suggest that it is possible to avoid the electrical reentrainment problem by operating the ESP at a higher gas temperature. Of course, this entails some sacrifice in $\mathrm{SO}_{2}$ capture, but operation at higher temperatures may be necessary to avoid excessive electrical reentrainment. In a $12-\mathrm{MW}$ pilot facility, Felix et al (December 1991) studied ESP performance with both in-duct spray drying and dry sorbent injection with humidification. In tests performed at approach temperatures of $35^{\circ} \mathrm{F}$ and $45^{\circ} \mathrm{F}$, no evidence of electrical reentrainment was reported with either process. At a calcium-to-sulfur molar ratio of 2:1 and an approach temperature of $35^{\circ} \mathrm{F}$, a collection efficiency of $99.96 \%$ was obtained with in-duct spray drying, and a collection efficiency of $99.94 \%$ was obtained with dry sorbent injection. The corresponding emission rates were about 0.007 and $0.01 \mathrm{lb} / 10^{6} \mathrm{Btu}$. The two sets of results are not directly comparable because the gas flow rate was about $15 \%$ higher during the dry sorbent tests than it was during the in-duct spray drying tests. The SCAs during the two tests were 402 and $336 \mathrm{ft}^{2} / \mathrm{kacfm}$. These SCAs would correspond to pre-retrofit SCAs of about 500 and $410 \mathrm{ft}^{2} / \mathrm{kacfm}$. These results suggest that a reasonably large ESP (SCA $\geq 400 \mathrm{ft}^{2} / \mathrm{kacfm}$ ) could adequately control the effluent from either an in-duct spray drying process or a dry sorbent injection process, provided that electrical reentrainment can be avoided by operation of the ESP at a suitable gas temperature.

Measurements of the collection efficiency of an ESP collecting the effluent from EPA's E$\mathrm{SO}_{\mathrm{X}}$ process have also suggested the presence of electrical reentrainment (Pontius and Marchant, 1991). Measurements of ESP collection efficiency as a function of particle size 
that were made without slurry injection (i.e., with fly ash only) were in reasonable agreement with theoretical predictions. As shown in Figure 3, the same measurements made with slurry injection yielded fractional efficiencies that were far below the theoretical predictions for that case. These results strongly suggest that some non-ideal effect (i.e., some effect that is not modeled) is responsible for the very poor performance of the ESP in the $\mathrm{E}_{-} \mathrm{SO}_{\mathbf{x}}$ mode. An extensive troubleshooting effort failed to identify any mechanical problems that might account for this poor performance. Laboratory measurements revealed that the cohesive strength of the $\mathrm{E}-\mathrm{SO}_{\mathrm{x}}$ ash/sorbent mixture was at the low end of the range measured for a large number of fly ash samples. The resistivity of the $\mathrm{E}^{-\mathrm{SO}_{\mathbf{x}}}$ solids was also shown to be extremely sensitive to temperature, dropping from $10^{10} \mathrm{ohm}-\mathrm{cm}$ at $170^{\circ} \mathrm{F}$ to $10^{8} \mathrm{ohm}-\mathrm{cm}$ at $140^{\circ} \mathrm{F}$. Although the gas temperature at the ESP inlet was 160 to $180^{\circ} \mathrm{F}$, it is possible that heat loss from the ESP may have resulted in lower temperatures within the ESP. Therefore, it appears likely that the resistivity was low enough to cause electrical reentrainment, especially considering the low cohesivity of the $\mathrm{E}_{-} \mathrm{SO}_{\mathbf{x}}$ solids. When the low values of resistivity and cohesivity are taken together with the fractional efficiency results and the absence of any mechanical problems, electrical reentrainment must be considered the most likely cause of the poor ESP performance.

The electrical resistivity of ADVACATE solids has not been determined unambiguously, because resistivity measurements have been made only with the ADVACATE solids in combination with solids from high-temperature furnace injection (EPA's LIMB process). Marchant, Dismukes et al (1990) reported resistivity values for various ash/sorbent mixtures obtained from the combined application of the ADVACATE and LIMB processes. Resistivities of $8 \times 10^{8}$ to $1 \times 10^{10} \mathrm{ohm}-\mathrm{cm}$ were obtained with ash/sorbent mixtures produced at an overall calcium-to-sulfur molar ratio of 2:1, an approach temperature of $25^{\circ} \mathrm{F}$, and varying proportions of ADVACATE and LIMB solids. However, it should be noted that these resistivity values apply to a mixture of ADVACATE and LIMB solids. Since the LIMB solids are known to be highly resistive (as discussed previously in the section on high-temperature sorbent injection), the resistivity of the ADVACATE solids alone may be lower than the values given above. 


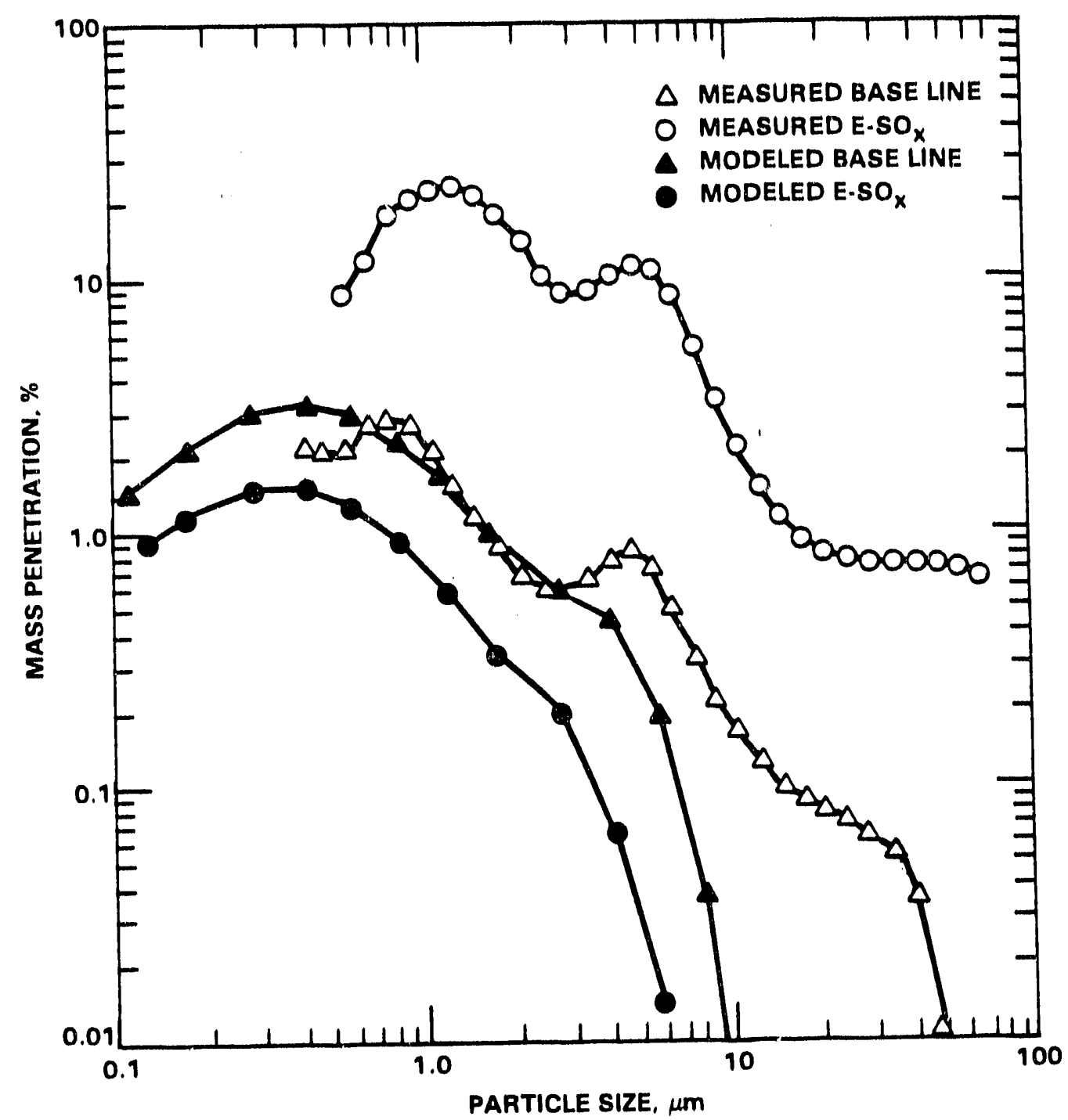

Figure 3. Comparison of measured and predicted mass penetration through the ESP under baseline and E-SO ${ }_{x}$ conditions. (Source: Pontius and Marchant, 1991) 
Effect on Particle Size Distribution

Control devices installed downstream from conventional spray dryers, or other lowtemperature sorbent injection processes, are generally subjected to much higher particulate loadings than are control devices collecting only fly ash. That is to say, the mass of particulate material contributed by the spray dryer or other sorbent injection process is usually greater than the mass of the fly ash. Yeh et al (1985) reported that a pilot spray dryer increased the particulate loading at the ESP inlet by a factor of 1.8 to 6.0, depending upon the coal sulfur and ash contents and the reagent ratio. These results were achieved with three different coals having sulfur contents of 0.7 to $1.6 \%$ and ash contents of 3.8 to 9.5\%. Calcium-to-sulfur molar ratios of $1: 1$ to $3: 1$ were tested with each coal. For higher sulfur coals, the increase in inlet loading is even greater, because of the larger amount of sorbent that must be injected. Tests performed in a 10-MW pilot spray dryer/ESP system using a coal with $4 \%$ sulfur showed a tenfold increase in the ESP inlet loading with the spray dryer operated at a calcium-to-sulfur ratio of 1.3:1 (Brown et al, 1988). With a coal containing only $0.3 \%$ sulfur and only $5 \%$ ash, the particulate mass loading at the outlet of a full-scale spray dryer was reported to be 3.7 times higher than that measured at the spray dryer inlet (Landham et al, 1991). This substantial increase in particulate mass entering the ESP was measured with a relatively low sorbent addition rate (calcium-to-sulfur ratio of $0.75: 1$ ). The unusually low ash content of this specific coal (5\%) results in a relatively low fly ash loading, making the mass ratio of sorbent-to-ash higher than otherwise expected. In any case, it appears that spray dryers generally produce at least a doubling of the particulate mass, and order of magnitude increases in particulate loading are possible with higher sulfur coals.

With in-duct spray drying using a calcium-to-sulfur molar ratio of 2:1 and approach temperature of $35^{\circ} \mathrm{F}$, particulate loadings of 8 to $10 \mathrm{gr} / \mathrm{dscf}$ have been measured at the ESP inlet of a 12-MW test facility (Felix et al, December 1991). At the same facility, comparable loadings were measured with dry sorbent injection under the same conditions. The base line fly ash loading, without sorbent injection, was about $2.2 \mathrm{gr} / \mathrm{dscf}$. Both the base line and with-sorbent loadings were measured with the flue gas diluted to reduce the inlet $\mathrm{SO}_{2}$ concentration from 3000 to $2000 \mathrm{ppm}$ for test purposes. While this dilution may affect the absolute values of the mass loadings, the ratio of sorbent-to-base line mass loadings would still be about 4:1 to 5:1. Under similar conditions, dry sorbent injection tests performed in a 1.7-MW test facility showed an increase in particulate loading from about $1.5 \mathrm{gr} / \mathrm{dscf}$ to about $7.3 \mathrm{gr} / \mathrm{dscf}$ (Durham, Ebner et al, 1991). With recycle of the ash/sorbent 
mixture to improve sorbent utilization, a mass loading of $11.3 \mathrm{gr} / \mathrm{dscf}$ was reported. These results suggest that in-duct spray drying or dry sorbent injection could increase the particulate mass loading by a factor of five to seven, for these particular coals.

Large increases in particulate mass loading have also been reported with EPA's ADVACATE process. Tests have been done in which the ADVACATE sorbent contributed an incremental mass loading of $11.5 \mathrm{gr} / \mathrm{dscf}$ above the base line mass loading (Sedman et al, 1991). Depending upon the base line loading of fly ash, the ADVACATE process could result in a total ash/sorbent mass loading of 12 to $15 \mathrm{gr} / \mathrm{dscf}$.

Low-temperature sorbent injection processes also alter the size distribution of particles entering the downstream control device. Conventional spray dryers tend to make the size distribution coarser, because of the relatively large lime agglomerates produced in this process. Dry sorbent injection plocesses tend to make the size distribution finer, because the dry hydrate particles are generally smaller than the mass mean particle size of the fly ash. The effect of in-duct spray drying lies somewhere between the effects of conventional spray drying and dry sorbent injection. The finer atomization that is used with in-duct spray drying produces sorbent agglomerates that are smaller than those produced in a conventional spray dryer, but larger than the hydrate particles that are injected in a dry state. Of course, dry injection would be expected to produce the lowest degree of sorbent agglomeration.

Figure 4 compares a particle size distribution of spray dryer sorbent to that of fly ash (Durham, Holstein et al, 1991). The size distribution of the sorbent material was obtained by subtracting the size distribution of the fly ash from that of the ash/sorbent mixture. The size distributions of the fly ash and ash/sorbent mixture were obtained from cascade impactor measurements made with the spray dryer out of service and in service. The calcium-to-sulfur ratio was 1.3:1, and the coal sulfur content was $4 \%$. Comparison of the sorbent and ash size distributions reveals that the sorbent particles are larger than the fly ash particles, and the sorbent mass is substantially larger than the mass of fly ash. Similar results were reported by Landham et al (1991) based on impactor measurements made at the inlet and outlet of a utility spray dryer, where the coal sulfur content was $0.3 \%$ and the calcium-to-sulfur ratio was $0.75: 1$. Thus, the size distribution of the sorbent appears to be relatively insensitive to coal sulfur content and calcium-to-sulfur ratio. In both of the cases discussed above, the sorbent was found to be concentrated in relatively large particles. The 


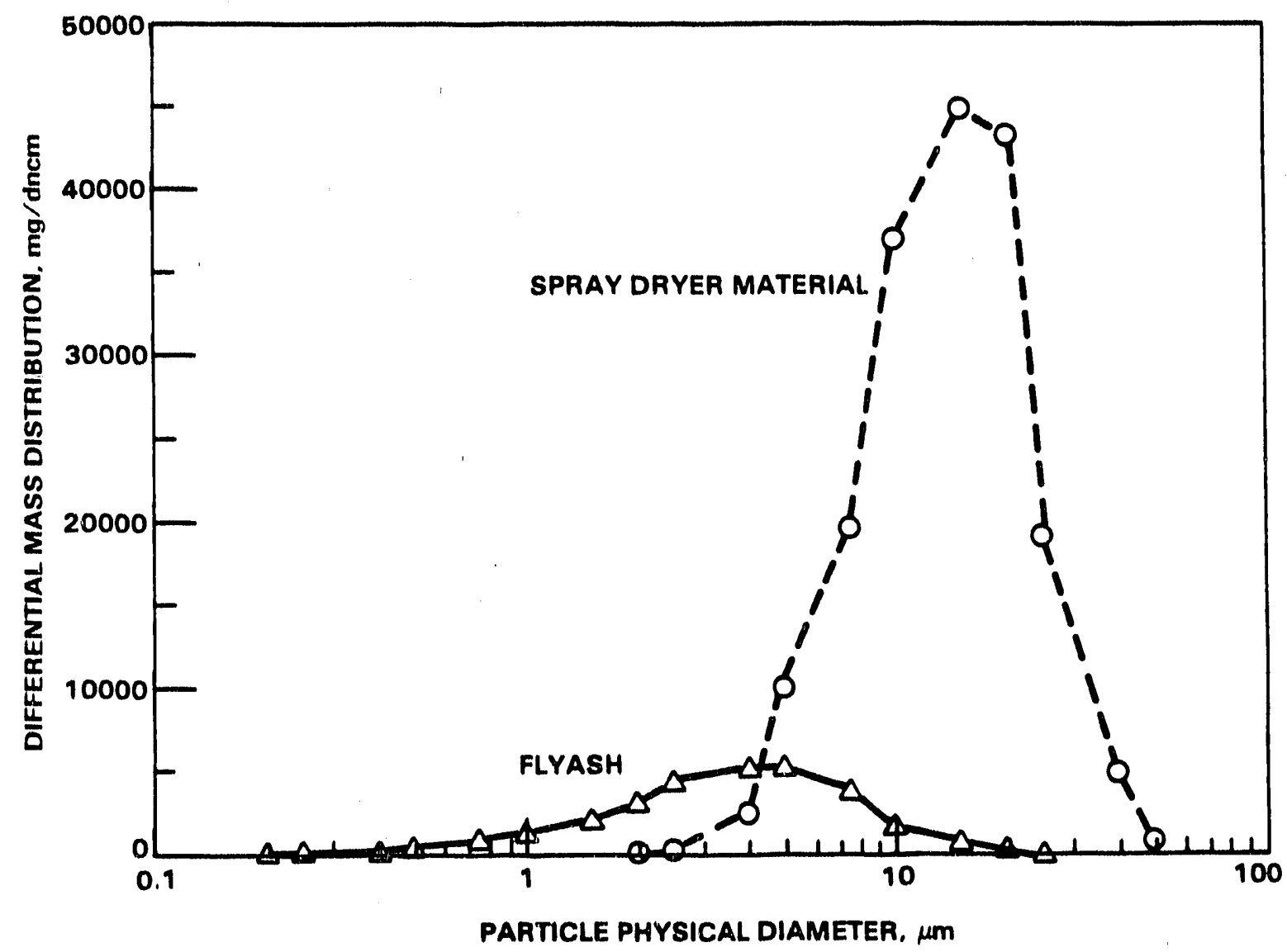

Figure 4. Comparison of the particle size distributions of the spray dryer sorbent and the fly ash contained in a spray dryer effluent. (Source: Durham, Holstein, et al, 1991) 
relatively large size of the sorbent particles tends to lessen the effect of the large increase in particulate mass on ESP performance, because the larger particles are easier to collect.

Based on cascade impactor data reported by Marchant, Gooch et al (1990), the effect of the $\mathrm{E}_{-\mathrm{SO}} \mathrm{x}_{\mathrm{X}}$ process on the particulate size distribution appears to be similar to the spray dryer effect discussed above. Their data suggest that essentially all of the $\mathrm{E}_{-} \mathrm{SO}_{\mathrm{x}}$ sorbent particles are larger than -bout $8 \mu \mathrm{m}$. This is somewhat surprising, because the pneumatic nozzles used in the $\mathrm{E}-\mathrm{SO}_{\mathrm{X}}$ process should produce smaller slurry droplets than do the rotary atomizers used in conventional spray dryers. Therefore, the dried agglomerates of $\mathrm{E}_{-} \mathrm{SO}_{\mathbf{X}}$ sorbent should be smaller than those produced in the conventional spray dryers. The unexpectedly large size of the $\mathrm{E}_{-} \mathrm{SO}_{\mathrm{x}}$ sorbent particles could be an artifact generated by the DID. Sorbent particles could be collected on the DID and then subsequently reentrained as larger agglomerates.

Analysis of cascade impactor samples taken at the ESP inlet and outlet suggests that the E$\mathrm{SO}_{\mathrm{x}}$ sorbent actually breaks up in the ESP (Pontius and Marchant, 1991). The basis for this assertion is illustrated in Figure 5, which shows the calcium-to-silicon ratio as a function of particle size. In the sample obtained at the ESP inlet, the calcium-to-silicon ratio is relatively insensitive to particle size. In the outlet sample, however, the calcium-to-silicon ratio increases dramatically with decreasing particle size. This strongly suggests that the sorbent particles were broken up into smaller particles in the ESP. Pontius and Marchant suggest that the break up occurred because the electrostatic forces acting on the sorbent agglomerates became large enough to overcome the agglomerate's tensile strength. They point out the analogy to the breakup of charged liquid droplets that occurs when electrostatic forces overcome the droplet surface tension (i.e., the Rayleigh effect). To date, this type of breakup of sorbent particles has been reported only in connection with the $\mathrm{E}^{-\mathrm{SO}_{\mathrm{X}}}$ process. However, it is possible that this breakup mechanism occurs in other lowtemperature sorbent injection processes but has not yet been recognized. An alternative explanation is that the $\mathrm{E}-\mathrm{SO}_{\mathrm{x}}$ process conditions tend to produce unusually low cohesivities and/or unusually high particle charges, leading to greater breakup of sorbent agglomerates. Given the similarity between the $\mathrm{E}_{-} \mathrm{SO}_{\mathrm{x}}$ process conditions and those used in conventional and in-duct spray drying, the latter explanation seems less plausible, but it cannot be ruled out. 


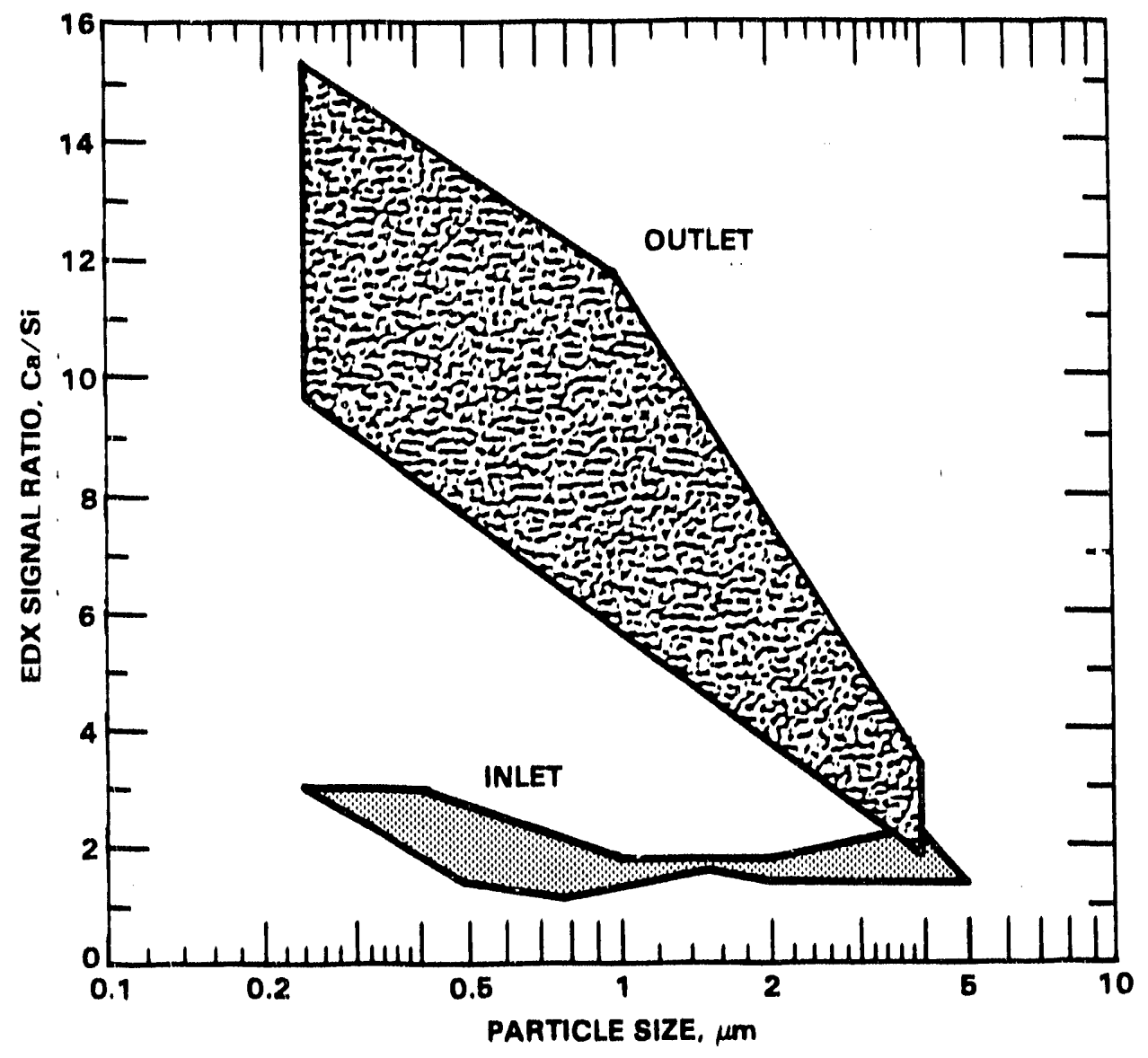

Figure 5. Concentration ratio of calcium to silicon in samples of the E-SO ${ }_{x}$ effluent obtained at the inlet and outlet of the ESP. (Source: Pontius and Marchant, 1991) 
Preparation of the ADVACATE sorbent by reaction of $\mathrm{Ca}(\mathrm{OH})_{2}$ and fly ash at elevated temperature reportedly produces a modified sorbent with a mass mean diameter of 66 to $112 \mu \mathrm{m}$ (Sedman et al, 1991). This suggests that the ADVACATE sorbent particles are much larger than the sorbent particles used in other low-temperature processes. Since the mass mean particle size of $\mathrm{Ca}(\mathrm{OH})_{2}$ is typically 2 to $6 \mu \mathrm{m}$, and that of fly ash is typically 15 to $20 \mu \mathrm{m}$, the much larger size of the ADVACATE sorbent particles suggests that this sorbent is highly agglomerated. In any case, particle dropout in the ducting would cause the mean size of the particles reaching the particulate control device to be considerably smaller than 66 to $112 \mu \mathrm{m}$. Sedman et al reported mass mein diameters of 13 to $22 \mu \mathrm{m}$ for ADVACATE sorbents sampled at the outlet of a 50-ft length of ducting in which the gas velocity was $50 \mathrm{ft} / \mathrm{sec}$. Their particle size measurements also showed that the ADVACATE sorbents contained virtually no submicron particles. If this result is substantiated at full scale, it may indicate an advantage of ADVACATE over other dry sorbent injection processes that produce increases in the submicron particulate mass.

The effect of dry sorbent injection processes on the particle size distribution appears to be dependent upon the location of the humidification sprays relative to the sorbent injection nozzles. Injection of the water upstream of the sorbent results in the formation of a sulfuric acid aerosol. Durham, Ebner et al (1991) reported that the acid aerosol formed by this mechanism caused a doubling of the mass concentration of particles smaller than $0.4 \mu \mathrm{m}$. In this size range, the acid aerosol accounted for almost all of the observed increase in particulate mass, and the increase was virtually eliminated when the water was injected downstream from the sorbent nozzles. With the downstream humidification, the $\mathrm{SO}_{3}$ vapor appears to be captured by the lime before it has a chance to condense in the water sprays. With either upstream or downstream humidification, the sorbent caused a significant increase in particle mass in the size range of 0.5 to $1 \mu \mathrm{m}$. Both this effect and the acid aerosol were observed to cause some quenching of the corona current in the inlet ESP field. The sorbent effect produced a $44 \%$ reduction in current density, while the combined effect of the sorbent and acid aerosol produced a $93 \%$ reduction, effectively shutting down the inlet field. Thus, upstream humidification is definitely not recommended for those cases where the $\mathrm{SO}_{3}$ concentration is significant.

Felix et al (July, 1991) observed the same corona quenching phenomenon discussed above with dry sorbent injection, but reported that slurry injection (i.e., in-duct spray drying) had no adverse effect on ESP electrical operation. This suggests that the acid aerosol is not formed during in-duct spray drying. It is postulated that the dense fog of slurry droplets 
created by in-duct spray drying captures the $\mathrm{SO}_{3}$ as vapor before it conden.es. In the case of dry injection with downstream humidification, the sorbent particles also appear to be capable of capturing $\mathrm{SO}_{3}$ as vapor. However, in the case of dry injection with upstream humidification, the $\mathrm{SO}_{3}$ is condensed as an ultrafine aerosol before coming into contact with the sorbent. Ultrafine acid aerosols are also produced in wet scrubbers, where the flue gas is rapidly quenched prior to entering the spray tower absorber (Dahlin and Brown, 1991). The rapid quenching prior to the absorber favors acid condensation, allowing little opportunity for capture of $\mathrm{SO}_{3}$ as vapor. The quenching of the flue gas is much slower during in-duct spray drying, resulting in more opportunity for capture of $\mathrm{SO}_{3}$ prior to condensation.

Effect on Particle Morphology, Surface Area, and Pore Structure

Like the high-temperature processes discussed earlier, low-temperature sorbent injection processes tend to significantly alier the morphology, surface area, and pore structure of the particles to be collected. An example of this effect is shown in the SEM photographs in Figure 6, which provide a comparison of particulate matter in spray dryer effluent with ordinary fly ash. As shown in the photographs, the fly ash particles are predominantly smooth spheres, with no visible pore openings that might suggest any internal porosity. The absence of intraparticle porosity is confirmed by relatively low values of BET surface area, which are generally less than $4 \mathrm{~m}^{2} / \mathrm{g}$ for fly ash (Bush et al, 1989). In contrast to the smooth, relatively non-porous fly ash particles, the sorbent particles are more irregular in a shape and are covered with many pore openings. These pore openings may actually be spaces between primary $\mathrm{Ca}(\mathrm{OH})_{2}$ particles in a sorbent agglomerate. In any case, it is obvious from the SEM photographs that the sorbent particles have more surface area and porosity than ordinary fly ash. This conclusion is consistent with measurements showing that particles in spray dryer effluents have relatively high values of BET surface area (Livenge sd et al, 1988; Jøns et al, 1986). Improper slaking of the lime used in spray dryer systems can produce relatively large particles that have relatively low surface areas, but this is not normally the case (Dantuluri et al, 1990).

The sorbent particles produced by in-duct spray drying and dry sorbent injection are generally smaller than those produced by conventional spray dryers. This is attributable to the smaller droplet sizes used in the duct injection processes. Assuming that the slurries used in the duct injection processes and in the conventional spray drying process have the 


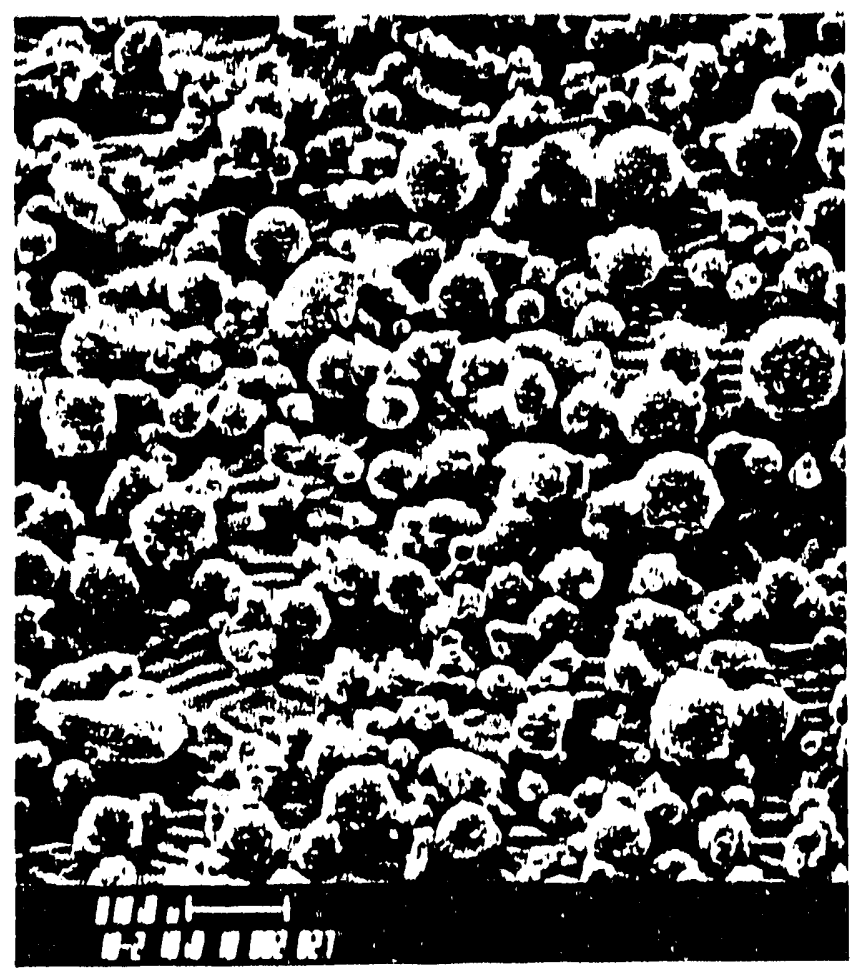

FLY ASH FROM HIGH SULFUR COAL.

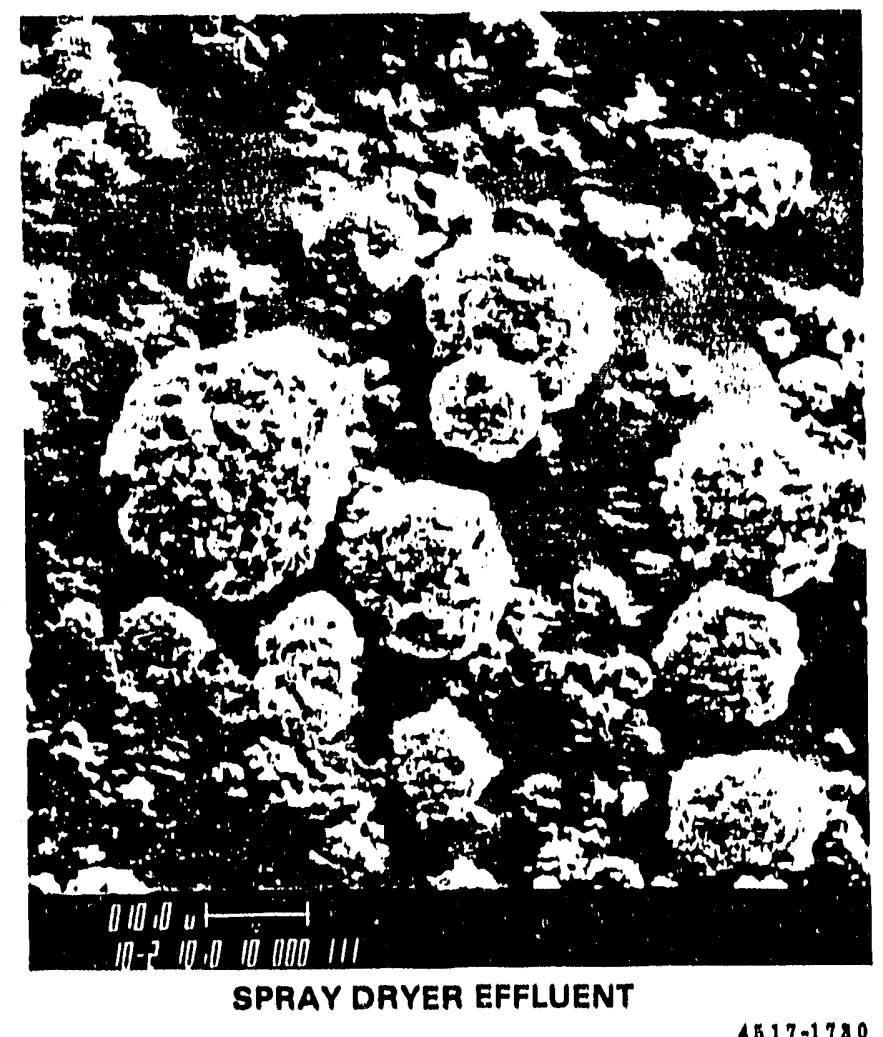

Figure 6. SEM photographs showing the contrast between spray dryer effluent and ordinary fly ash from high-sulfur coal. (Source: SRI Particle Characteristics Data Base) 
same lime content (i.e., the same solids content), the process that produces the smallest droplets should also produce the smallest sorbent particles after complete drying. Despite this difference in particle size, the surface areas of the ash/sorbent mixtures produced from conventional spray drying and duct injection appear to be comparable. Livengood at al (1988) reported surface areas of 16 to $26 \mathrm{~m}^{2} / \mathrm{g}$ for spray dryer particulate matter; Stouffer et al (1988) reported surface areas of 14 to $22 \mathrm{~m}^{2} / \mathrm{g}$ for particulate matter from the Coolside process. This similarity in surface area attests to the fact that most of the surface area is contained within pores inside the individual particles; the particle surfaces make a relatively small contribution to total surface area.

Compared to ordinary fly asin, the solid effluents from low-temperature sorbent injection exhibit elevated surface areas and porosities. This increased surface area and porosity allow greater adsorption of water vapor and other potential conditioning agents, just as these factors allow greater $\mathrm{SO}_{2}$ removal. Laboratory studies of the conversion of $\mathrm{Ca}(\mathrm{OH})_{2}$ to $\mathrm{CaSO}_{3}$ under differential reaction conditions have shown that the ultimate conversion is linearly correlated with surface area (Yoon et al, 1986; Borgwardt and Bruce, 1986; Blythe et al, 1986). Klingspor (1983) showed a direct proportionality between the BET surface area of hydrated lime and the amount of water adsorbed at a given relative humidity. It is reasonable to expect that the uptake of water vapor and other potential conditioning agents by ash/sorbent mixtures follows a similar trend with surface area. The adsorbed water and other species, such as sulfuric acid, play a key role in interparticle bonding, which is a key determinant of cohesivity or tensile strength. Therefore, electrical reentrainment in ESPs and the pressure drop across fabric filter dust cakes are ultimately affected by the elevated surface area and porosity associated with the effluents from low-temperature sorbent injection.

\section{Effect on Particle Cohesivity}

Several studies have shown that the ash/sorbent mixtures from low-temperature sorbent injection generally have lower tensile strengths (i.e., lower cohesivities) than do ordinary fly ashes (Bush et al, 1989; Pontius and Marchant, 1991). This result is contrary to what might be expected. At the lower temperatures and higher moisture levels associated with these processes, one would expect more adsorption of water vapor. With all other factors being equal, the presence of this adsorbed water should make the material more cohesive, as a result of increased liquid bridging and hydrogen bonding (Zimon, 198'2). The low 
cohesivities suggest the presence of other mechanisms that prevent or offset the expected effects of the increased adsorption of water. One possible explanation is that the water is sequestered in the sorbent particles in such a manner that it is no longer available for bridging and hydrogen bonding. Some of the water could chemically react with the sorbent to produce a hydrate such as $\mathrm{CaSO}_{3} \cdot 2 \mathrm{H}_{2} \mathrm{O}$. The water could also be drawn into pores by capillary action. This hypothesis suggests that tensile strength should decrease with increasing porosity. Miller et al (1991) reported this type of relationship between cohesivity and the bulk (interparticle) porosity. Intraparticle porosity can be important in governing the capillary movement of water into the particle interior, and thereby affect cohesivity.

In general, low cohesivity is undesirable because of the potential for electrical reentrainment in ESPs and the potential for low dust cake porosity and high pressure drop in baghouses. If necessary, cohesivity can be increased by the use of deliquescent additives that help retain water at the particle surface. Durham, Holstein et al (1991) showed that the addition of calcium chloride to a spray dryer slurry resulted in a more cohesive ash/sorbent mixture and eliminated electrical reentrainment in a ESP collecting spray dryer effluent. Doyle et al (1986) suggested that a high alkali content in the fly ash tended to make spray dryer solid effluents more cohesive. They based this hypothesis on a study of two similar spray dryer installations. The installation with the higher alkali ash produced ash/sorbent mixtures that were more highly agglomerated, stickier, and more likely to cause deposition problems than were the ash/sorbent mixtures from the low-alkali ash. Thus, the ultimate cohesivity of an ash/sorbent mixture depends on ash chemistry as well as on the operating conditions of the sorbent injection process.

J $\phi$ ns et al (1986) showed that the pressure drop across a baghouse collecting spray dryer effluent decreased and the stickiness of the solids increased as the residual moisture content of the dust cake increased. That is to say, Jøns et al confirmed thiat there is a direct relationship between surface moisture and cohesivity and an inverse relationship between cohesivity and pressure drop. As residual moisture increases, the cohesivity increases. The increased cohesivity causes particles that arrive at the dust cake surface to stick immediately upon impact. The particles do not have an opportunity to slide into a more tightly packed orientation, and the result is a more porous dust cake. The higher porosity of the cohesive dust cake results in lower pressure drop across the fabric filter. In this case, the residual moisture content of the dust cake was adjusted by manipulating the approach 
temperature. Thus, the control of process temperature and the use of deliquescent additives are two potential approaches to the control of cohesivity.

\section{CONCLUSIONS AND RECOMMENDATIONS}

High-Temperature Sorbent Injection

The effects of high-temperature sorbent injection on particulate properties are summarized below:

- Electrical resistivity is increased by two to three orders of magnitude, but flue gas humidification can be used to restore resistivity to an acceptable value.

- With highly reactive sorbents, it may not be possible to attenuate resistivity with $\mathrm{SO}_{3}$ conditioning.

- The particle size distribution is shifted toward finer particle sizes.

- Hydrated lime injection produces a greater increase in fine particles than does limestone injection, but decrepitation of the limestone also produces an increase in the number of fine particles.

- Specific surface area and porosity are increased significantly, and further enhancement is possible with additives.

- Certain surfactants and dispersants that are used to promote the capture of $\mathrm{SO}_{2}$ also reduce the effective particle size and change the pore structure.

- The ability of certain additives to prevent sorbent agglomeration has been attributed to the obstruction of liquid bridging between particles.

- There is reason to suspect that high-temperature sorbent injection may produce highly cohesive ash/sorbent mixtures, but confirming measurements are lacking. 
- There have been several good studies of ESP performance with high-temperature sorbent injection; in general, these provide a good basis for predicting the effect on ESP performance.

- Other than studies related to $\mathrm{AFBC}$, there have been no studies of fabric filter performance with high-temperature sorbent injection processes; there is no reliable basis for predicting the effects on fabric filter performance.

- There is no reliable basis for inferring the effect of high-temperature sorbent injection on ESP rapping reentrainment.

The review of literature indicates a need for additional research in the following areas:

- Additional studies are needed to assess the effects of high-temperature sorbent injection on fabric filter performance.

- Additional studies are needed to assess the effects of high-temperature sorbent injection on cohesivity and ESP rapping reentrainment.

- Additional studies are needed to investigate the ability of certain additives to prevent sorbent agglomeration by obstructing liquid bridging.

Based on the literature published to date, further research on the use of additives may also be justified. For example, transition metal compounds that might act like $\mathrm{Cr}_{2} \mathrm{O}_{3}$ should be investigated. The dramatic effects achieved with $\mathrm{Cr}_{2} \mathrm{O}_{3}$ are now of academic interest only because of the toxic nature of the reaction product. However, the use of an alternate transition metal compound might yield similar effects while producing a non-toxic product.

The effect of high-temperature sorbent injection on ESP rapping reentrainment has not been investigated systematically. Measurements of ESP collection efficiencies with and without rapping are needed to determine whether high-temperature sorbent injection increases or decreases rapping reentrainment. These measurements should be made over a range of conditions to allow the development of an empirical correlation for predicting rapping emissions with iorbent injection. The empirical correlation could then be used to adjust the ideal predictions of collection efficiency in a manner analogous to the procedures 
now used with ordinary fly ash. Previous modeling efforts have made use of the existing correlation, which was derived for fly ash applications only.

\section{Low-Temperature Sorbent Injection}

In the case of low-temperature sorbent injection, it is necessary to preface any attempt to infer general conclusions with a cautionary note concerning the many specialized processes that are currently under development. The reader is advised that each of these processes has its own unique features and effects on particulate properties. The body of this report includes a discussion of special concerns with the following processes: CZD, IDS, E-SO HALT, CFB, ADVACATE, and HYPAS. Anyone dealing with one of these processes should consult the appropriate section of the report for any caveats on the general conclusions. Subject to this limitation, the general conclusions from this literature review are listed below:

- If the process operates at a relatively close approach to saturation ( $\leq 30^{\circ} \mathrm{F}$ ), electrical resistivity is reduced substantially, and electrical reentrainment could become a problem.

- Electrical reentrainment occurs when the electrical holding force reverses direction, becoming a repulsive force large enough to overcome the tensile strength of the particulate layer.

- Ash/sorbent mixtures from low-temperature sorbent injection tend to be relatively non-cohesive compared to most types of fly ash.

- With converitional spray drying processes, the particle size distribution is shifted toward larger particle sizes.

- With in-duct spray drying and dry sorbent injection, the particle size distribution is shifted toward smaller particles.

- Dry sorbent injection with upstream humidification produces an ultrafine aerosol of sulfuric acid, because the $\mathrm{SO}_{3}$ condenses before coming into contact with lime. 
- Dry sorbent injection generally produces a greater increase in fine particles than does slurry injection.

- Specific surface area and porosity are increased significantly and further enhancement is possible with additives.

- Certain surfactants and dispersants that are used to promote $\mathrm{SO}_{2}$ capture also reduce the effective particle size and change the pore structure.

- The ability of certain additives to prevent sorbent agglomeration has been attributed to the obstruction of liquid bridging between particles.

- Low-temperature sorbent injection produces poorly cohesive ash/sorbent mixtures, but cohesivity can be increased by the use of additives such as calcium chloride.

- There have been several good studies of ESP performance with low-temperature sorbent injection; however, these do not provide a good basis for predicting the effect on ESP performance, primarily because of the inability to predict the occurrence of electrical reentrainment.

- There have been relatively few studies of fabric filter performance with lowtemperature sorbent injection processes.

- Limited information from baghouses collecting spray dryer effluent suggests that excellent fabric filter performance is possible under certain conditions.

- When the baghouse is operated at a close approach to saturation $\left(\leq 30^{\circ} \mathrm{F}\right)$, excessive pressure drop may become a problem because of the non-porous dust cakes formed by the poorly cohesive particles.

In general, the above conclusions apply to all existing low-temperature sorbent injection processes that do not use additives. The user should be aware that the use of additives may further alter particulate properties and some of the conclusions given above. An additive that is of particular interest at this time is $\mathrm{NaOH}$. The use of $\mathrm{NaOH}$ as an additive to the humidification water in a diry process probably results in a heterogeneous mixture of sorbent particles, with some of the $\mathrm{NaOH}$ incorporated into the lime sorbent. One other 
additive, magnesium, has been investigated extensively in connection with wet scrubbing. Surprisingly, magnesium-enhanced sorbents have received little attention in connection with duct injection processes.

The review of literature on low-temperature sorbent injection indicates a need for additional research in the following areas:

- Additional studies are needed to assess the effects of low-temperature sorbent injection on both ESPs and fabric filters.

- Additional studies are needed to assess the effects of low-temperature sorbent injection on cohesivity.

- Additional studies are needed to better understand the electrical reentrainment phenomenon and to develop methods for predicting when it will occur.

- Additional studies are needed to investigate the effects of additives on particulate properties, with emphasis on $\mathrm{CaCl}_{2}$ and other deliquescent salts, $\mathrm{NaOH}$, and magnesium compounds.

- Additional studies are needed to better understand the electrostatic decrepitation phenomenon and to develop methods for predicting its onset.

Based on the literature published to date, there is clearly a need for further research on the use of additives that increase cohesivity. Such materials could provide a means of overcoming the problems of electrical reentrainment and decrepitation. Calcium chloride and other deliquescent salts should be investigated. Ammonium compounds that have been shown to be effective in reducing rapping reentrainment may also be of interest in these studies. The chlorides have been shown to be effective in increasing cohesivity, but chloride stress corrosion of stainless steel components, particularly atomizer wheels, has been a problem at spray dryer installations. Therefore, the development of an alternative to the chloride additives might be justified.

In general, the foregoing discussion points to the need for a better fundamental understanding of the effects of sorbent injection on particulate properties. Much of what is known has been learned by trial-and-error on a large scale. This empirical approach 
provides some basis for predicting the effects to be expected, but it stops far short of a fundamental understanding. Testing on the large pilot scale also imposes significant limitations on the ability to vary parameters of interest and severely restricts the ability to probe the process with diagnostic tools. For example, the fear of wall wetting and duct pluggage frequently imposes a lower limit on the approach to saturation and limits the types of nozzles that can be evaluated. The design of the large-scale ESPs and baghouses also precludes internal examination during operation, so that electrical reentrainment and other problems must be inferred from indirect measurements. Well-designed, carefullycontrolled laboratory experiments could provide the fundamental information that is now needed to better understand the effects of sorbent injection on particulate properties. For example, electrical reentrainment and decrepitation phenomena could be observed directly and studied in greater detail over a wide range of conditions with and without various additives. 


\section{BIBLIOGRAPHY}

Abrams, J. Z., S. Zaczek, J. H. Blake, M. J. Davidson, and H. W. Pennline. Development of the Confined Zone Dispersion Process for the Desulfurization of Flue Gas. Presented at Coal Technology '86. Pittsburgh, PA (1986).

Albanese, V.M. Resistivity Modification for High Sulfur Coal Fired Boilers by Flue Gas Conditioning: Implications for Particulate Emissions Reduction, 75th Annual APCA Meeting (1982).

American Society of Mechanical Engineers. Determining the Properties of Fine Particulate Matter, ASME Power Test Codes (1965).

Anon. Evaluating the Use of Coal, Ash Analyses for Predicting Fabric-Filter Performance, Power 125 (1981).

Ariman, T. and DJ. Helfritch. How Relative Humidity Cuts Pressure Drop in Fabric Filters, Filtration and Separation 14 (1977).

Ash, S. G., D. H. Everett, and C. Radke. Thermodynamics of the Effects of Adsorption on Interparticle Forces, J. Chem Soc. Faraday Trans. 69 (1973).

Babu, M., J. College, R. Forsythe, R. Herbert, D. Kanary, and K. Lee. 5-MW Toronto HALT Pilot Plant. Final Report submitted to the U.S. Department of Energy. DOE Contract No. DE-AC22-85PC81012 (1988).

Babu, M., R. C. Forsythe, C. V. Runyon, E. Evans, and J. L. Thompson. Results of $1.0 \mathrm{MM}$ $\mathrm{Btu} / \mathrm{hr}$ Testing of HALT (Hydrate Addition at Low Temperature) for $\mathrm{SO}_{2}$ Control. In: Proceedings: 1986 Joint Symposium on Dry $\mathrm{SO}_{2}$ and Simultaneous $\mathrm{SO}_{2} / \mathrm{NO}_{x}$ Control Technologies, Volume 2. EPA-600/9-86-029b (NTIS PB87-120457) (1986).

Baker, J.W. and K.M. Sullivan. Developments in the Electrical Testing of Fly Ash in Relation to Electrostatic Precipitation, Proc. International Clean Air Conference, Brisbane, Australia (1978).

Barrett, W. J., J. P. Gooch, R. S. Dahlin, R. M. Riggin, J. H. Carver, A. H. Dennis, G. L. Fisher, J. E. Howes, D. C. Mays, S. E. Miller, H. D. Roth, and E. H. Pechan. Planning Studies for Measurement of Chemical Emissions in Stack Gases of Coal-Fired Power Plants. Final Report No. EA-2892. Electric Power Research Institute. Palo Alto, CA (1983).

Bechtel National, Inc. Desulfurization of Flue Gas by the Confined Zone Dispersion Process. Final Report submitted to the U.S. Department of Energy. DOE Contract No. DE-AC22-85PC81009 (1988).

Beittel, R. and R. S. Dahlin. Mechanistic Studies of Sorbent Utilization Enhancement by Humidification. Presented at the First Combir.ed FGD and Dry $\mathrm{SO}_{2}$ Control Symposium. St. Louis, MO (1988).

Benson, L. B. The Role of Magnesium in Increasing $\mathrm{SO}_{2}$ Removal and Improving Reliability in Magnesium-Enhanced FGD Systems, Presented at the Second Annual Pittsburgh Coal Conference. Pittsburgh, PA (1985). 
Benson, S.A, D.K. Rindt, G.C. Montgomery, and R.D. Sears. Microanalytical Characterization of North Dakota Fly Ash, Ind. Eng. Chem. Res. Dev. 23 (1984).

Bickelhaupt, R.E. Effect of Chemical Composition on Surface Resistivity of Fly Ash, EPA600/2-75-017 (1975).

Bickelhaupt, R.E. A Study to Improve a Technique for Predicting Fly Ash Resistivity with Emphasis on the Effect of Sulfur Trioxide, EPA-600/7-86/010 (1986).

Bickelhaupt, R.E., R.S. Dahlin, J.P. Guoch, E.C. Landham, Jr., and G.H. Marchant, Jr. Sodium Conditioning for Improved Hot-Side Precipitator Performance, Volume 1: Field and Laboratory Studies, EPRI CS-3711, vol. 1 (1984).

Blythe, G., R. Smith, M. McElroy, R. Rhudy, V. Bland, and C. Martin. EPRI Pilot Testing of $\mathrm{SO}_{2}$ Removal by Calcium Injection Upstream of a Particulate Control Device. In: Proceedings: 1986 Joint Symposium on Dry $\mathrm{SO}_{2}$ and Simultaneous $\mathrm{SO}_{2} / \mathrm{NO}_{\mathbf{x}}$ Control Technologies, Volume 2. EPA-600/9-86-029b (NTIS PB87-120457) (1986).

Borgwardt, R. H. and K. R. Bruce. EPA Study of Hydroxide Reactivity in a Differential Reactor. In: Proceedings: 1986 Joint Symposium on Dry $\mathrm{SO}_{2}$ and Simultaneous $\mathrm{SO}_{2} / \mathrm{NO}_{x}$ Control Technologies, Volume 1. EPA-600/9-86-029a (NTIS PB87-120465) (1986).

Boynton, R. S. Chemistry and Technology of Lime and Limestone, (1966)..

Briden, F.E. The Comparison of Several Standard Materials and Techniques for the Warren-Averbach Determination of Microstructure Characteristics of Calcium Hydroxide Sorbent Materials, Advances in X-ray Analysis 33 (1990).

Bridgewater, J. and I. Tranter. The Effect of Interstitial Liquid on Inter-Particle Percolation, J. of Powder \& Bulk Solids Tech. 2 (1978).

Brown, C. A., G. M. Blythe, L. R. Humphries, R. F. Robards, R. A. Runyan, and R. G. Rhudy. Results from the TVA 10-MW Spray Dryer/ESP Evaluation, Presented at the First Combined FGD and Dry $\mathrm{SO}_{2}$ Control Symposium, St. Louis, MO (1988).

Brown,T.D., G.K. Lee, J. Reeve, and N. Sekhar. Improved Electrostatic Precipitator Performance by use of Fly Ash Conditioning Agents, Journal of the Institute of Fuel $\mathbf{5 1}$ (1978).

Buck, A.D., T.B. Husbands and J.P. Burkes. Studies of the Constitution of Fly Ash Using Selective Dissolution, Army Corps of Engineers, miscellaneous paper SL-83-5 (1983).

Buckton, G. Contact Angle, Adsorption and Wettability - A Review with Respect to Powders, Powder Technology 61 (1990).

Bush, P. V., T. R. Snyder, and W. B. Smith. Filtration Properties of Fly Ash from Fluidized Bed Combustion. JAPCA 37 (1987).

Bush, P.V., T.R. Snyder, and R.L. Chang. Determination of Baghouse Performance from Coal and Ash Properties: Part I, JAPCA 39 (1989).

Bush, P.V., T.R. Snyder, and R.L. Chang. Determination of Baghouse Performance from Coal and Ash Properties: Part II, JAPCA 39 (1989). 
Carr, R.C., A.V. Conti, R.L.Merritt, D.J. Mormille, and J. Pirkey. Pilot Demonstration of a Pulse-Jet Fabric Filter for Particulate Matter Control at an Oil-Fired Utility Boiler, Proceedings of the Ninth Symposium on the Transfer and Utilization of Particulate Control Technology, Williamsburg, VA (1991).

Coelho, M.C. and N. Harnby. The Effect of Humidity on the Form of Water Retention in a Powder, Powder Technology 20 (1978).

Coelho, M.C. and N. Harnby, Moisture Bonding in Powders, Powder Technology 20 (1978).

Coluccia, S., S. Lavagnino, and L. Marchese. Adsorption and Dissociation of Ammonia on the Hydroxylated Surface of Magnesium Oxide Powders, J. Chem. Soc., Faraday Trans. 83 (1987).

Cushing, K. M., V. H. Belba, R. L. Chang, and T. J. Boyd. Fabric Filtration Experience Downstream from Atmospheric Fluidized Bed Combustion Bollers. Presented at the Ninth Particulate Control Symposium. Williamsburg, VA (1991).

Dahlin, R. S. and R. F. Altman. Prediction of Mass Loading and Particle Size Distribution for Use in a Precipitator Sizing Procedure. In: Proceedings: Conference on Electrostatic Precipitator Technology for Coal-Fired Power Plants. EPRI CS-2908. Electric Power Research Institute. Palo Alto, CA (1983).

Dahlin, R. S., R. Beittel, and J. P. Gooch. Pilot-Scale Evaluation of LIMB Technology. EPA Final Report No. EPA/600-87-019 (NTIS PB 87-224630). Environmental Protection Agency. Research Triangle Park, NC (1987).

Dahlin, R. S. and T. D. Brown. Control of Acid Mist Emissions from FGD Systems. Presented at the $1991 \mathrm{SO}_{2}$ Control Symposium. Washington, DC (1991).

Dahlin, R. S., J. P. Gooch, and J. D. Kilgroe. Effects of Furnace Sorbent Injection on Fly Ash Characteristics and Electrostatic Precipitator Performance, In: Proceedings: First Joint Symposium on Dry $\mathrm{SO}_{2}$ and Simultaneous $\mathrm{SO}_{2} / \mathrm{NO}_{x}$ Control Technologies, Vol. 2, EPA-600/9-85-020b, NTIS PB85-232361, pp. 29-3 to 29-25 (1985).

Dahlin, R.S. and D.A Kirchgessner. Surface Characterization and Microanalysis of Sorbents and Ash/Sorbent Mixtures, presented at the First Joint Symposium on Dry $\mathrm{SO}_{2}$ and Simultaneous $\mathrm{SO}_{2} / \mathrm{NO}_{x}$ Control Technologies, San Diego, CA (1984).

Dahlin, R. S., C. L. Lishawa, and N. Kaplan. Analysis of LIMB Waste Management Options. In: Proceedings: 1986 Joint Symposium on Dry $\mathrm{SO}_{2}$ and Simultaneous $\mathrm{SO}_{2} / \mathrm{NO}_{x}$ Control Technologies, Volume 2. EPA-600/9-86-029b (NTIS PB87-120457) (1986).

Dahneke, B.E. Retention Kinetics of Solid Particulates on Solid Surfaces, Special Report CRDC-SP-84021 U.S. Armament, Munitions and Chemical Command (1986).

Dalmon, J. and D. Tidy. The Cohesive Properties of Fly Ash in Electrostatic Precipitation, Atmospheric Environment 6 (1972).

Dantuluri, S. R., W. T. Davis, R. M. Counce, G. D. Reed. Mathematical Model of Sulfur Dioxide Absorption into a Calcium Hydroxide Slurry in a Spray Dryer, Separation Science and Technology 25 (1990). 
Davison, R.L., D.F.S. Natusch and J.R. Wallace. Trace Elements in Fly Ash Dependence of Concentration on Particle Size, Environmental Sclence and Technology 8 (1974).

Deryagin, B.V., V.M. Muller, Y.P. Toporov, I.N. Aleinkova and G.I. Shcherbina. Mechanism of Influence of Pressing on Adhesion of Elastic Particles, Colloid Journal of the USSR 49 (1987).

Dickson, W, R. Internal Memorandum. Southern Research Institute. Blrmingham, AL (1985).

Dismukes, E.B. Conditioning of Fly Ash with Sulfur Trioxide and Ammonia, EPA-600/2. 75-015 (1975).

Disrnukes, E.B. and J.P. Gooch. Technology for the Control of Particulates and Sulfur Oxides by Electrostatic Techniques, EPA/600/7-91/004 (1991).

Do, D.D. Effect of Surface Barrier on the Sorption of Gases in Microporous Solids, AlChE Journal 35 (1989).

Do, D. D., and P.L.J. Mayfield. A New Simplifted Model of Adsorption in a Single Particle, AIChE Journal 33 (1987).

Donsi, G. and L. Massimilla. Particle to Particle Forces in Fluidization of Fine Powders, Fluid Ses Appl, Conference (1974).

Doyle, J. B., B. J. Jankura, and R. C. Vetterick. Comparison of Dry Scrubbing Operation of Laramie River and Craig Stations. Presented at the Tenth Symposium on Flue Gas Desulfurization. Atlanta, GA (1986).

DuBard, J. L., J. P. Gooch, R. Beittel, S. L. Rakes, and G. R. Offen. Particle Properties Related to ESP Performance with Sorbent Injection and Gas Conditioning, In: Proceedings: 1986 Joint Symposium on Dry $\mathrm{SO}_{2}$ and Simultaneous $\mathrm{SO}_{2} / \mathrm{NO}_{\mathbf{x}}$ Control Technologies, Volume 2. EPA-600/9-86-029b, NTIS PB87-120457 (1986).

Duduković, M. P. Reactions of Particles with Nonuniform Distribution of Solid Reactant. The Shrinking Core Model, Ind. Eng. Chem. Process Des. Dev. 23 (1984).

Durham, M. D., T. G. Ebner, D. B. Holstein, C. A. Brown, and L. G. McGuire. Pilot Plant Investigation of ESP Performance and Upgrade Strategies for In-Duct Sorbent Injection. Presented at the Ninth Particulate Control Symposium. Williamsburg, VA (1991).

Durham, M. D., T. G. Ebner, D. B. Holstein, C. A. Brown, and L. G. McGuire. Pilot Plant Investigation of ESP Performance and Upgrade Strategies for In-Duct Sorbent Injection, Presented at the Ninth Particulate Control Symposium, Williamsburg, VA (1991).

Durham, M. D., D. B. Holstein, G. Blythe, K. A. Hieneken, R. G. Rhudy, R. F. Altman, T. A. Burnett, R.A. Barton, and C. W. Dawson. High Efficiency Electrostatic Precipitator Operation at Spray Dryer Conditions, Presented at the Ninth Particulate Control Symposium, Williamsburg, VA (1991).

Dutta, A. and L.V. Dullea. A Comparative Evaluation of Negatively and Positively Charged Particles as Flow Conditioners for a Cohesive Powder, AIChE Symposium Series 86 (1990). 
Emmel, T. E. and N. Kaplan. Lime/Limestone FGD and Sorbent Injection Technology Retrofit Difficulty at 60 Coal.Fired Utility Power Plants, Presented at the First Combined FGD and Dry $\mathrm{SO}_{2}$ Control Symposium, St. Louls, MO (1988).

Everett, D.H. The Effect of Adsorption on the Interaction Between Solid Particles, Pure and Applied Chemistry 48 (1976).

Faulkner, M. G., G. H. Marchant, Jr., E. C. Landham, Jr., and J, L. DuBard. Field and Laboratory Measurements of Fly Ash Properties and Precipitator Performance Parameters with Furnace Sorbent Injection, Presented at the First Combined FGD and Dry $\mathrm{SO}_{2}$ Control Symposium, St. Louls, MO (1988).

Felix, L. G., E. B. Dismukes, J. P. Gooch, M. G. Klett, and A. G. Demian. Scaleup Tests and Supporting Research for the Development of Duct Injection Technology - Topical Report No. 2. Draft Report submitted to the U.S. Department of Energy. DOE Contract No. DE-AC22-88PC88851 (1991).

Felix, L, G., J. P. Gooch, R. L. Merritt, M. G. Klett, J. E. Hunt, and A. G. Demian. Scaleup Tests and Supporting Research for the Development of Duct Injection Technology. Presented at the $1991 \mathrm{SO}_{2}$ Control Symposium. Washington, DC (1991).

Fellx, L. G. and R. L. Merritt, and K. Duncan. Improving Baghouse Performance at the Monticello Generating Station, J.APCA 36 (1986).

Fleer, G.J. and J.M.H.M. Scheutjens. Interaction between Adsorbed Layers of Macromolecules. J. Colloid and Interface Sci. 111 (1986).

Fletcher, H.G. Coal Selection and Dual Flue Gas Conditioning to Aid in Meeting Air Pollution Control Regulations, 78th Annual APCA Meeting paper 53.1 (1985).

Fletcher, H.R. Operating Experiences at Detroit Edison with Various Flue Gas Conditioning Systems, 75th Annual APCA Meeting (1982).

Forsythe, R. C. and R. A. Kaiser. Hydrate Addition at Low Temperature: $\mathrm{SO}_{2}$ Removal in Conjunction with a Baghouse. Presented at the Second Annual Pittsburgh Coal Conference. Pittsburgh, PA (1985).

Fraioli, A.V. Mass Transfer Mechanisms for Water Adsorbed on Sillica Gel, Report \# CONF-871234-13 ASME Winter Meeting (1987).

Fuller, E.L., Jr, and K.A. Thompson. Chemical and Geometric Factors in Physical Adsorption/Desorption of Gases and Solids, Langmuir 3 (1987).

Gillespic, T. The Contribution of Electrostatic Induction to the Long Range Forces between Solid Particles. Particulate and Multiphase Processes: Vol, 3 Colloidal and Interfacial Phenomena (1987).

Gooch, J. P., E. B. Dismukes, R. Beittel, J. L. Thompson, and S. L. Rakes. Sorbent Development and Production Studies. In: Proceedings: 1986 Joint Symposium on Dry $\mathrm{SO}_{2}$ and Simultaneous $\mathrm{SO}_{2} / \mathrm{NO}_{x}$ Control Technologies, Volume 1. EPA-600/9-86-029a (NTIS PB87-120465) (1986). 
ooch, J. P., J. L. DuBard, and R. Beittel. The Influence of Furnace Sorbent Injection on Precipitator Performance, and Methods for Improving Performance, In: Proceedings of the Third International Conference on Electrostatic Precipitation, University of Padua, Abano-Padova, Italy (1987).

Good, R.J. Fundamental Research on Surface Science of Coal in Support of Physical Beneficiation of Coal, DOE Contract No. DE-AC22-87PC79905 Quarterly Technical Progress Report \# 5 (1988).

Görner, Peter, and Josef Pich. Generalized Theory of Dispersion Forces, J. Aerosol Science 20 (1989).

Gröbner, O. Dielectric Propertles of Adsorbed Gas Molecules, Journal of Chemical Physics 46 (1967).

Gullett, B. K. and J. A. Blom. Calcium Hydroxide and Calcium Carbonate Particle Size Effects on Reactivity with Sulfur Dioxide, Reactivity of Solids 3 (1987).

Gullett, B. K., J. A. Blom, and R. T. Cunningham. Porosity, Surface Area, and Particle Size Effects of $\mathrm{CaO}$ Reacting with $\mathrm{SO}_{2}$ at $1100^{\circ} \mathrm{C}$, Reactivity of Solids 6 (1988).

Gullett, B. K. and K. R. Bruce. Pore Distribution Changes of Calcium-Based Sorbents Reacting with Sulfur Dioxide, AIC' $\imath$ E Joumal 33 (1987).

Gullett, B. K. and K. R. Bruce. Identification of $\mathrm{CaSO}_{4}$ Formed by Reaction of $\mathrm{CaO}$ and $\mathrm{SO}_{2}$, AIChE Journal 35 (1989).

Haaker, G. The Influence of Consolidation on Shear Test Results, Powder Technology 51 (1987).

Hamaker, H.C. The London-van der Waals Attraction Between Spherical Particles, Physica IV 10 (1937).

Harker, J.H. and P.M. Pimparker. The Effect of Additives on the Electrostatic Precipitation of Fly Ash, Joumal of the Institute of Energy 61 (1988).

Harrison, D. J., G. H. Newton, and D. W. Pershing. Calcination of Calcium-Based Sorbents for Control of $\mathrm{SO}_{2}$ Emissions from Coal-Fired Boilers, EPA Report No. EPA/600/D. 86/015, NTIS PB86-148145 (1986).

Helfritch, D. J., P. L. Feldman, B. Weinstein, and M. W. McElroy. Electrostatic Precipitator Upgrades for Furnace Sorbent Injection, In: Proceedings 1986 Joint Symposium on Dry $\mathrm{SO}_{2}$ and Simultaneous $\mathrm{SO}_{2} / \mathrm{NO}_{x}$ Control Technologies, Volume 2. EPA-600/9-86-029b, NTIS PB87-120457 (1986).

Hench, L. L. Characterization of Powder Surfaces - Chapter 16 of Ceramics published by Marcel Dekker (1971).

Henke, K. R. and C. J. Moretti. Chemical Characterization of Electrostatic Precipitator Ashes from Pressurized Hydrated-Lime Injection Tests, Presented at the International Conference on the Development of Alternative Energy Sources and the Lessons Learned Since the Oil Embargo, Grand Forks, ND, NTIS CONF-8605117--3 (1986). 
Henzel, D. S. and W. Ellison. Commercial Utilization of $\mathrm{SO}_{2}$ Removal Wastes in the Application of New Advanced Control Technology. Presented at the $1990 \mathrm{SO}_{2}$ Control Symposium. New Orleans, LA (1990).

Hobbel, E.F. Cohesion and Interparticle Forces. Dissertation (1988).

Holcombe, L., A. Weinberg, R. Butler, and J. Harness. Field Study of Wastes from a Lime Injection Technology. Presented at the $1990 \mathrm{SO}_{2}$ Control Symposium. New Orleans, LA (1990).

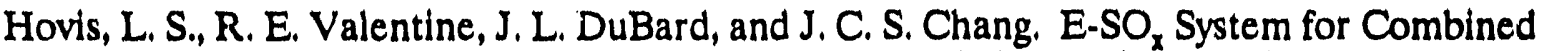
Particulate and $\mathrm{SO}_{2}$ Control. Presented at the Seventh Symposium on the Transfer and Utilization of Particulate Control Technology. Nashville, TN (1988).

Hovis, L. S., R. E. Valentine, B. J. Jankura, P. Chu, and J. C. S. Chang. E-SO Pilot Evaluation, Presented at the First Combined FGD and Dry $\mathrm{SO}_{2}$ Control Symposium, St. Louis, MO (1988).

Jayasinghe, S.S. The Cohesion and Flow of Particulate Solids, Process Technology International 17 (1972).

J $\phi$ ns, E., K. Felsvang, and R. Madhok. Limestone Spray Drying Absorption for $\mathrm{SO}_{2}$ Control. Presented at the Tenth Symposium on Flue Gas Desulfurization. Atlanta, GA (1986).

Jozewicz, W. and G. T. Rochelle. Fly Ash Recycle in Dry Scrubbing, Environmental Progress 5 (1986).

Jozewicz, W., J. C. S. Chang, C. B. Sedman, and T. G. Brna. Characterization of Advanced Sorbents for Dry $\mathrm{SO}_{2}$ Control, Reactivity of Solids 6 (1988).

Jozewicz, W., C. Jorgensen, J.C.S. Chang, C. Sedman and T. Brna. Development and Pilot Plant Evaluation of Silica-Enhanced Lime Sorbents for Dry Flue Gas Desulfurization, JAPCA 38 (1988).

Jozewicz, W. and D.A. Kirchgessner. Activation and Reactivity of Novel Calcium-Based Sorbents for Dry $\mathrm{SO}_{2}$ Control in Boilers, Powder Technology 58 (1989).

Jozewicz, W., J. C. S. Chang, and C. B. Sedman. Bench-Scale Evaluation of Calcium Sorbents for Acid Gas Emission Control, Environ. Progress 9 (1990).

Kanary, D. A., R. M. Statnick, H. Yoon, D. C. McCoy, J. A. Withum, and G. A. Kudlac. Coolside Process Demonstration at the Ohio Edison Company Edgewater Unit 4 - Boiler 13. Presented at the $1990 \mathrm{SO}_{2}$ Control Symposium. New Orleans, LA (1990).

Kanellopoulos, N.K., J.K. Petrou, and J.H. Petropoulos. Realistic Modeling of the Interaction of Vapors with Densely Packed Spherical Particles (Parts I and II), Joumal of Colloid and Interface Science 96 (1983).

Karra, V.K. and D.W. Fuerstenau. The Effect of Humidity on the Trace Mixing Kinetics in Fine Powders, Powder Technology 16 (1977). 
Kaufherr, N., M. Shenasa, and D. Lichtman. X-ray Photoelectron Spectroscopy Studies of Coal Fly Ashes with Emphasis on Depth Profiling of Submicrometer Particle Size Fractions, Environmental Science and Technology 19 (1985).

Keller, D.V., Jr. et al. Investigation of Physics of Adhesion of Coal Aerosols, Bureau of Mines Report 16-75 (1973).

Khan, F. and N. Pilpel. The Effect of Particle Size and Moisture on the Tensile Strength of Microcrystalline Cellulose Powder, Powder Technology 48 (1986).

Kirchgessner, D. A. and W. Jozewicz. Structural Changes in Surfactant-Modified Sorbents During Furnace Injection, AIChE Journal 35 (1989).

Kirchgessner, D. A. and W. Jozewicz. Enhancement of Reactivity in Surfactant-Modified Sorbents for Sulfur Dioxide Control, Ind. Eng. Chem. Res. 28 (1989).

Kirchgessner, D. A. and J. M. Lorrain. Lignosulfonate-Modified Calcium Hydroxide for Sulfur Dioxide Control, Ind. Eng. Chem. Res. 26 (1987).

Klein, D.H. et al. Pathways of Thirt,-seven Trace Elements Through Coal-Fired Power Plant, Environmental Science and Technology 9 (1975).

Klingspor, J. Kinetic and Engineering Aspects of the Wet-Dry FGD Process. Licenciate Thesis. Lund Institute of Technology. Lund, Sweden (1983).

Knight, P.C. and S.H. Johnson. Measurement of Powder Cohesive Strength with a Penetration Test, Powder Technology 54 (1988).

Kono, H.O., C.C. Huang and M. Xi. The Effect of Flow Conditioners on the Tensile Strength of Cohesive Powder Structures, AIChE Symposium Series 85 (1989).

Kono, H.O., C.C. Huang, and M. Xi. Function and Mechanism of Flow Conditioners Under Various Loading Pressure Conditions in Bulk Powders, Powder Technology 63(1990).

H. Krupp, W. Schnabel, and G. Walter. The Lifshitz-Van der Waals Constant: Computation of the Lifshitz-Van der Waals Constant on the Basis of Optical Data, J. Colloid and Interface Sci. 39 (1972).

Landham, E. C., K. M. Cushing, R. F. Altman, B. D. Larson, and J. B. Doyle. Effects of Spray Dryer Effluent on the Performance of the Laramie River Unit 3 ESP, Presented at the Ninth Particulate Control Symposium, Williamsburg, VA (1991).

Lauga, C., J. Chaouki, D. Klvana and C. Chavarie. Improvement of the Fluidisability of $\mathrm{Ni} / \mathrm{SiO}_{2}$ Aerogels by Reducing Interparticle Forces, Powder Technology 65 (1991).

I.eong, K.H., J.J. Stukel, and P.K. Hopke. Effects of Surface Properties of Collectors on the Removal of Charged and Uncharged Particles from Aerosol Suspensions, EPA Report EPA-600/7-82-006 (1981).

Liberti, A., D. Brocco and M. Possanzini. Adsorption and Oxidation of Sulfur Dioxide on Particles, Atmospheric Environment 12 (1978). 
Livengood, C. D., H. S. Huang, J. W. Allen, and P. S. Farber. Combined $\mathrm{SO}_{\mathrm{x}} / \mathrm{NO}_{\mathrm{x}}$ Removal in a High-Sulfur Spray-Dryer/Fabric-Filter System, Presented at the First Combined FGD and Dry $\mathrm{SO}_{2}$ Control Symposium, St. Louis, MO, NTIS DE89-007266 (1988).

Lu, G.Q. and D.D. Do. Adsorption Properties of Fly Ash Particles for $\mathrm{NO}_{\mathbf{x}}$ Removal from Flue Gases, Fuel Processing Technology 27 (1991).

Luckham, P.F. The Measurement of Interparticle Forces. (An Invited Review), Powder Technology 58 (1989).

Malabrel, C.A., P. Somasundaran, and N.J. Turro. In Situ Kinetics Measurements of the Surfactant Adsorption on Colloidal Alumina using ESR Spectroscopy, J. Colloid and Interface Sci. 137 (1990).

Mamane, Y., J.L. Miller and T.G. Dzubay. Characterization of Individual Fly Ash Particles Emitted from Coal- and Oil-Fired Power Plants, Atmospheric Environment 20 (1986).

Mamantov, G. and E. L. Wehry. Chemical Reactivity of Polycyclic Organic Compounds Adsorbed on Coal Fly Ash and Related Solid Surfaces, Progress Report for May 1985 to April 1986, submitted by the University of Tennessee to the U.S. Department of Energy, NTIS DE86-010293 (1986).

Mann, R.M., R.A. Magee, R.V. Collins, M.R. Fuchs and F.G. Mesich. Trace Elements of Fly Ash: Emissions from Coal-Fired Steam Plants Equipped With Hot-Side and ColdSide Electrostatic Precipitators for Particulate Control, EPA/908/4-78/008 (1978).

Marchant, G. H., E. B. Dismukes, and J. P. Gooch. Pilot-Scale Investigation of the ADVACATE Process for the Removal of $\mathrm{SO}_{2}$ from Flue Gas. Draft Final Report submitted to the Environmental Protection Agency. EPA Cooperative Agreement No. CR-812811 (1990).

Marchant, G. H., J. P. Gooch, M. G. Faulkner, and L. S. Hovis. Effects of E-SO, Technology on ESP Performance. Presented at the Eighth Symposium on the Transfer and Utilization of Particulate Control Technology. San Diego, CA (1990).

Martin, C.M., M. Ghadiri, U. Tüzün and B. Formisani. Effect of the Electrical Clamping Forces on the Mechanics of Particulate Solids, Powder Technology 65 (1991).

McKay, G., S. McKee, and H.R.J. Walters. Solid-Liquid Adsorption Based on External Mass Transfer, Macropore and Micropore Diffusion, Chemical Engineering Science 42 (1987).

McLean. KJ. Cohesion of Precipitated Dust Layer in Electrostatic Precipitators, JAPCA 27 (1977).

Merritt, R.I. P.V. Bush, N.H. Wagner, PJ. Knapp, and R.L. Chang. Demonstration of Strategies for Improved Baghouse Performance, Proceedings of the Ninth Symposium on the Transfer and Utilization of Particulate Control Technology, Williamsburg, VA (1991).

Midkiff, L.A. Flue Gas Conditioning Upgrades Performance, Cuts Down Size of Precipitators, Power 123 (1979). 
Miller, S.J. and D.L. Laudal. Flue Gas Conditioning for Improved Fine Particle Capture in Fabric Filters: Comparative Technical and Economic Assessment, DOE/MC/10637-2414, vol. 2 (1987).

Miller, S. J., D. L. Laudal, and R. Chang. Flue Gas Conditioning for Improved Pulse-Jet Baghouse Performance. Presented at the Ninth Particulate Control Symposium. Williamsburg, VA (1991).

Milne, C. R., G. D. Silcox, D. W. Pershing, and D. A. Kirchgessner. High-Temperature, Short-Time Sulfation of Calcium-Based Sorbents. 1. Theoretical Sulfation Model, Ind. Eng. Chem. Res. 29 (1990).

Milne, C. R., G. D. Silcox, D. W. Pershing, and D. A. Kirchgessner. High-Temperature, Short-Time Sulfation of Calcium-Based Sorbents. 2. Experimental Data and Theoretical Model Predictions, Ind. Eng. Chem. Res. 29 (1990).

Moore, D. and M. Pilat. Pilot-Scale $\mathrm{HCl}$ Control by Dry Alkaline Injection for Emissions from Refuse Incinerators, EPA/600/9-89/040 (1988).

Moran, D. L., M. Rostam-Abadi, R. D. Harvey, R. R. Frost, and G. C. Sresty. Sulfur Dioxide Sorption Reactivity of Hydrated Lime: Effect of Hydration Method, Am. Chem. Soc. Div. Fuel Chem. Preprints 32 (1987).

Müller, H. and W. Brenig. Kinetic Theory of Gas-Surface Interaction, Z. Physik (34) (1979).

Natusch, D.F.S. Characterization of Fly Ash from Coal Combustion, NTIS \# COO-4347-4 Workshop on measurement technology and characterization of primary sulfur oxides emission from combustion sources, Southern Pines, NC, USA (1978).

Natusch, D.F.S., E.R. Denoyer, T.R. Keyser, S.E. Kirton, D.R. Taylor, and M.V. Zeller. Surface Analysis of Particles Emitted to the Atmosphere, AIChE Symposium 201 (1980).

Neimark, A. V. Theory of Adsorption and Capillary Condensation in Porous Bodies of Corpuscular Structure. Adsorption and Capillary Condensation at the Site of Particle Contact, Kolloidnyi Zhumal 47 (1985).

Neumann, A.W., S.N. Omenyi, and C.J. van Oss. Attraction and Repulsion of Solid Particles by Solidification Fronts. 3. van der Waals Interactions, J. Phys. Chem. 86 (1982).

Newton, G. H., S. L. Chen, and J. C. Kramlich. Role of Porosity Loss in Limiting $\mathrm{SO}_{2}$ Capture by Calcium Based Sorbents, AIChE Journal 35 (1989).

Nolan, P. S., T. J. Purdon, M. E. Peruski, M. T. Santucci, M. J. DePero, R. V. Hendriks, and D. G. LaChapelle. Results of the EPA LIMB Demonstration at Edgewater. Presented at the $1990 \mathrm{SO}_{2}$ Control Symposium. New Orleans, LA (1990).

Ondov, J.M., A.H. Biermen, R.E. Hefi, and R.F. Koszykowski. Elemental Composition of Atmospheric Fine Particles Emitted from Coal Burned in a Modern Electric Power Plant Equipped with a Flue Gas Desulfurization System, American Chemical Society Meeting (1980).

Otsuka, A. Recent Advances in Research on Powder Mechanical Properties in Japan, Society of Powder Technology Conference (1981). 
Otsuka, A. and K. Danjo. Influence of Humidity on Compaction of Quartz Powder, Journal of Powder and Bulk Solids Technology 3 (1979).

Pahl, M.H. and B. Bogenschneider. Forces of Adhesion in Compacted Bulk Materials, Aufbereitungs Technik 7 (1988).

Peterson, J. R. and G. T. Rochelle. Aqueous Reaction of Fly Ash and $\mathrm{Ca}(\mathrm{OH})_{2}$ to Produce Calcium Silicate Absorbent for Flue Gas Desulfurization, Environ. Sci. Technol. 22 (1988).

Pontius, D. H. and G. H. Marchant, Jr. Laboratory and Field Studies of Electrical Reentrainment Associated with Calcium-Based Sorbents, Presented at the Ninth Particulate Control Symposium, Williamsburg, VA (1991).

Pope, M.I. The Physical Adsorption of Gases on Solids. Calculation of Physico-Chemical Data from Sorption Measurements, Education in Chemistry 3 (1966).

Radford, C.D. and R.T. Fowler. A Review of Variables Affecting the Flowability of Bulk Granular Solids: Part 2 - The Effect of Moisture upon the Adhesive and Cohesive Properties, Australian Chemical Engineering 13 (1972).

Redinger, K. E., L. S. Hovis, J. C. S. Chang, F. C. Owens, and J. M. Wilkinson. Results from the E-SO $\mathrm{S}_{\mathbf{1}}$-MW Pilot Demonstration. Presented at the $1990 \mathrm{SO}_{2}$ Control Symposium. New Orleans, LA (1990).

Rendall, H. M. and A. L. Smith. The Adsorption of Ionic Surface Active Agents, Surface Active Agents, a Symposium (1979).

Rietma, K. Powders, What Are They?, Powder Technology 37 (1984).

Robens, E. The Measurement of Specific Surface Area and Pore Size Distribution of Powders, Powder Metallurgy International 18 (1986).

Rothenberg, SJ. Coal Combustion Fly Ash Characterization: Adsorption of Nitrogen and Water, Atmospheric Environment 14 (1980).

Samuel, E. A., K. R. Murphy, and A. Demian. A 12-MW Pilot Study of In-Duct Scrubbing (IDS) Using a Rotary Atomizer. Final Report submitted to the U.S. Department of Energy. DOE Contract No. DE-AC22-85PC81010 (1989).

Schmeits, M., and A.A. Lucas. Physisorption by Small Solid Particles, Chem. Phys. Letters 35 (1975).

Schubert, H. Principles of Agglomeration, Interiational Chemical Engineering 21 (1981).

Schubert, H. Capillary Forces - Modeling and Application in Particulate Technology, Powder Technology 37 (1984).

Seaverson, L.M., J.F. McClelland, G. Burnet, J.W. Anderegg, and M.K. Iles. Investigation of Water and Hydroxyl Groups Associated with Coal Fly Ash by Thermal Desorption and Fourier Transform Infrared Photoacoustic Spectroscopies, Applied Spectroscopy 39 (1985). 
Sedman, C. B., R. E. Valentine, and N. Plaks. Evaluation of Pilot ESP Performance with Elevated Loadings from Sorbent Injection Processes, Presented at the Ninth Particulate Control Symposium, Williamsburg, VA (1991).

Shinohara, K. and T. Tanaka. Ultimate Tensile Strength of Cohesive Powders Based on Non-Uniform Packing Model, Journal of Chemical Engineering of Japan 8 (1975).

Sing, K.S.W. Surface Characterization: Physical Characteristics of Powder Surfaces, Conference (1976).

Slaughter, D. M., S. L. Chen, W. R. Seeker, D. W. Pershing, and D. A. Kirchgessner. Increased $\mathrm{SO}_{2}$ Removal with the Addition of Alkali Metals and Chromium to Calcium. Based Sorbents, Twenty-Second Symposium (International) on Combustion/The Combustion Institute (1988).

Smith, D.M., G.P. Johnston, and A.J. Hurd. Structural Studies of Vapor-Phase Aggregates via Mercury Porosimetry, Journal of Colloid and Interface Science 135 (1990).

Sparks, L. E., N. Plaks, G. H. Ramsey, and R. E. Valentine. Investigation of Combined Particulate and $\mathrm{SO}_{2}$ Removal Using E-SO ${ }_{x}$. In: Proceedings of the Ninth Symposium on Flue Gas Desulfurization, Volume 2. EPA-600/9-85-033b (NTIS PB86-138658) (1985).

Snyder, T.R., P.V. Bush, and M.S. Robinson. Characterization and Modification of Particulate Properties to Enhance Filtration Performance, DOE/PC/88868-T5 (1990).

Stouffer, M. R., H. Yoon, and F. P. Burke. An Investigation of Flue Gas Desulfurization by In -Duct Dry Sorbent Injection, Ind. Eng. Chem. Res. 28 (1989).

Stowe, D. H., D. S. Henzel, and D. C. Hoffman. Flue Gas Desulfurization Reagent Comparison - Lime, Limestone, or Thiosorbic Lime. Presented at the 1979 EPA Symposium on Flue Gas Desulfurization. Las Vegas, NV (1979).

Tagawa, M., K. Gotoh, M. Yokokura, A. Syutoh, and S. Takechi. Influence of Surface Properties of Particles on their Adhesion and Removal, Colloid Polymer Science 267 (1989).

Terashita, K., T. Kimura, H. Kimura, and K. Miyanami. Computer-Aided Measurement of Breakup Processes and Tensile Strengths of Powder Beds, Bulletin of the University of Osaka Prefecture Series A 37 (1988).

Tidy, D. A Leaching Technique for Determining the Surface Composition of Pulverized Fuel Ash (PFA), Joumal of the Institute of Energy 59 (1986).

Toher, J. G., G. D. Lanois, and H. Sauer. High Efficiency, Dry Flue Gas $\mathrm{SO}_{x}$ and Combined $\mathrm{SO}_{\mathrm{x}} / \mathrm{NO}_{\mathrm{x}}$ Removal Experience with the Lurgi Circulating Fluid Bed Dry Scrubber. Presented at the $1991 \mathrm{SO}_{2}$ Control Symposium. Washington, DC (1991).

van Oss, C. J. and R. J. Good. On the Mechanism of "Hydrophobic" Interactions, J. Dispersion Science and Technology 9 (1988).

Visser, J. Adhesion of Colloidal Particles, Manuscript for Surface and Colloid Science.

Volpe, L. and M. Boudart. Topotactic Preparation of Powders with High Specific Surface Area, Catal. Rev. - Sci. Eng. 27 (1985). 
Weinstein, B. The Evaporation Times of Drop Distributions and their Impact on Costs of In-Duct Humidification Systems for Retrofitting Electrostatic Precipitators, Environmental Progress 7 (1988).

White, H.J. Industrial Electrostatic Precipitation, (1963).

Williams, R. and R.W. Nosker. Adherent Dust Particles, RCA Engineer 28 (1983).

Wood, P.A. Fundamentals of Bulk Solids Flow, IEA Coal Research Report \# ICTIS/TR31 (1986).

Yamamoto, H. Relationship Between Adhesive Force and Dispersability of Sub-Micron Particles, ICHEME 5th International Symposium on Agglomeration (1989).

Yeh, J. T., C. J. Drummond, J. I. Joubert, D. M. Tulenko, R. R. Crynack, and M. L. Hochhauser. Performance of a Spray Dryer/ESP Flue Gas Cleanup System During Testing at the Pittsburgh Energy Technology Center. Presented at the Ninth Symposium on Flue Gas Desulfurization. Cincinnati, OH (1985).

Yoon, H., M. R. Stouffer, W. A. Rosenhoover, and R. M. Statnick. Laboratory and Field Development of Coolside $\mathrm{SO}_{2}$ Abatement Technology. Presented at the Second Annual Pittsburgh Coal Conference. Pittsburgh, PA (1985).

Yoon, H., J. A. Withum, W. A. Rosenhoover, and F. P. Burke. Sorbent Improvement and Computer Modeling Studies for Coolside Desulfurization. In: Proceedings: 1986 Joint Symposium on Dry $\mathrm{SO}_{2}$ and Simultaneous $\mathrm{SO}_{2} / \mathrm{NO}_{\mathbf{x}}$ Control Technologies, Volume 2. EPA-600/9-86-029b (NTIS PB87-120457) (1986).

Zimon, A.D. Adhesion of Dust and Powder, (1982). 


\section{APPENDIX A \\ DETAILED DESCRIPTION OF SEARCH PROCEDURES}

The literature review included a search of abstracts performed through the DIALOG Information Services. This computer-based service was used to access the National Technical Information Service (NTIS), COMPENDEX PLUS, and Chemical Abstracts data bases. The search terms used are presented in table A-1. About 35,000 abstracts were returned from this search which was performed on July 29, 1991.

\section{Table A-1}

Terms Used in Abstract Search

$\begin{array}{lll}\text { Set } & \text { Items } & \text { Description } \\ 1 & 127886 & \text { powder? or particle? or particulat? or sorbent? or ash? } \\ 2 & 127886 & \begin{array}{l}\text { S1/ENG,NPT } \\ \text { S2 not (Chromatog? or extract? or soil? or virus?? ? or } \\ 3\end{array} \\ 120912 & \text { viral? or pollen? or pharmaceut? or drug?) } \\ 4 & 6789 & \text { S3 and (inject? or spray( )(dry? or drie?) or hydroxide? or } \\ 5 & 16328 & \text { reentrai? or cohesi? or adhesi? or adsor?) } \\ 6 & 21722 & \text { S3 and (propert? or interpartic?) } \\ 7 & 7195 & \text { S4-S5 } \\ 8 & 13463 & \text { S3 and (propert? or interpartic?) }\end{array}$




\section{APPENDIX B}

SUMMARIES OF PERTINENT ARTICLES

Briden, F.E. The Comparison of Several Standard Materials and Techniques for the Warren-Averbach Determination of Microstructure Characteristics of Calcium Hydroxide Sorbent Materials, Advances in X-ray Analysis 33 (1990).

In introducing his work, the author states that the reactivity of calclum hydroxide batches can be affected by many factors including the origin of the calcium carbonate material from which the hydroxide is produced, the production conditions, and the concentration of additives used for reactivity enhancement. In a summary from earlier work by the author and Natschke, microstructure factors derived from X-ray Diffraction Line Profile measurements were found to relate to the reactivities of several calcium hydroxide sources. In that study, the microstructure factor mean column length (CL) was seen to be inversely proportional to reactivity while the strain at the mean $C L$ was seen to be directly proportional to reactivity. The data presented in this work indicate that crystallite size is inversely proportional to the first order of reactivity. The root mean square strains appear to be directly proportional to reactivity with a second degree function. Attempts by the author to regress two microstructure factors at a time with reactivity are statistically unfounded due to the small number of samples examined. However the experimental techniques may be useful in further characterizations of calcium hydroxide materials.

Brown, C. A., G. M. Blythe, L. R. Humphries, R. F. Robards, R. A. Runyan, and R. G. Rhudy. Results from the TVA 10-MW Spray Dryer/ESP Evaluation, Presented at the First Combined FGD and Dry $\mathrm{SO}_{2}$ Control Symposium, St. Louis, MO, October 25-28, 1988.

This paper discusses results from TVA's 10-MW spray dryer/ESP evaluation program. The program was designed to investigate the feasibility of retrofitting a spray dryer ahead of an existing ESP at a power plant burning high-and medium-sulfur coals. All of the 15 utility spray dryer installations currently in operation in the U.S. are used in low-sulfur (less than $1.5 \%$ ) applications. Only three of these installations utilize an ESP downstream from the spray dryer. Thus, this program was designed to provide data relevant to high-and 
medium-sulfur spray dryer retrofits at plants equipped with ESPs. Spray dryer performance and ESP performance were evaluated with three different coals: a Western Kentucky coal containing $4 \%$ sulfur and $0.05 \%$ chlorine, another Western Kentucky coal containing $4 \%$ sulfur and $0.25 \%$ chlorine, and a blend of a high-sulfur Western Kentucky with a low-sulfur coal to produce a sulfur content of $2.5 \%$ with a chlorine content of $0.25 \%$. With the high-sulfur, low-chlorine coal, overall $\mathrm{SO}_{2}$ removals varied from $50 \%$ at a $1: 1$ reagent ratio, $38^{\circ} \mathrm{F}$ approach, and $290^{\circ} \mathrm{F}$ inlet temperature to $85 \%$ at 1.6 reagent ratio, $18^{\circ} \mathrm{F}$ approach, and $320^{\circ} \mathrm{F}$ inlet temperature. With the same sulfur content, but higher chlorine content, overall removal was boosted by 8 to 10 percentage points because of the fomation of deliquescent $\mathrm{CaCl}_{2}$, which allows the prolonged maintenance of a water film on the spray dryer solids, thereby promoting $\mathrm{SO}_{2}$ removal. With the lower-sulfur blend, $\mathrm{SO}_{2}$ removals were significantly higher ( $74 \%$ to $99 \%$ over the same range of conditions given previously), because of the reduced mass transfer requirements and the lower reagent ratio, which allows more recycle.

ESP particulate removal tests were run with the high-sulfur, high-chlorine coal using a 1.3 reagent ratio, $20^{\circ} \mathrm{F}$ approach, and $320^{\circ} \mathrm{F}$ inlet temperature. Under these conditions, the particulate loiding entering the ESP was 9 to $10 \mathrm{gr} / \mathrm{acf}$, which was an order of magnitude greater than the baseline loading measured with the spray dryer out of service. ESP removal efficiency was about the same as in the baseline condition (99.7\%), so emissions increased by an order of magnitude. This was unexpected in view of the beneficial effects of the gas cooling (increased SCA, reduced gas velocity, reduced gas viscosity, and higher electrical field strength resulting from increased gas density). The authors state that there was no increase in particulate resistivity over the baseline value, but they do not give any resistivity data for either condition. No space-charge quenching of the corona current was detected. The authors suggest that the unexpectedly poor ESF performance was a result of reentrainment. This was confirmed by tests that showed increased emissions at a higher gas velocity with the same SCA. 
Dahlin, R. S., J. P. Gooch, and J. D. Kilgroe. Effects of Furnace Sorbent Injection on Fly Ash Characteristics and Electrostatic Precipitator Performance, In: Proceedings: First Joint Symposium on Dry $\mathrm{SO}_{2}$ and Simultaneous $\mathrm{SO}_{2} / \mathrm{NO}_{x}$ Control Technologies, Vol. 2 , EPA-600/9-85-020b (NTIS PB85-232361), pp. 29-3 to 29-25, July 1985.

The effects of furnace sorbent injection on particulate characteristics were studied in a pilot-scale, $1 \times 10^{6} \mathrm{Btu} / \mathrm{hr}$, combustor. In situ resistivity and particle size measurements were made at a flue gas temperature of $300^{\circ} \mathrm{F}$. The in situ resistivity measurements were made with the SRI point-plane resistivity probe. The particle size measurements were made with a combination of cascade impactors, an optical counter, and an electrical aerosol size analyzer. The measurements were made with Vicron limestone and Longview hydrated lime injected at the burner and at the furnace exit. Both sorbents were injected at a rate sufficient to produce a nominal calcium-to-sulfur molar ratio of 2:1. For comparison purposes, baseline measurements were made without any sorbent injection. In all tests, the combustor was fired with an Indiana coal containing $2.3 \%$ sulfur. Tests were also run with injected $\mathrm{SO}_{3}$ to investigate the ability of $\mathrm{SO}_{3}$ conditioning to overcome the detrimental effect of the sorbent injection on resistivity. The effects of $\mathrm{SO}_{3}$ and $\mathrm{H}_{2} \mathrm{O}$ conditioning on the resistivity of the ash/sorbent particles were also studied in the laboratory.

Without any sorbent injection, the baseline in situ resistivity was in the range of $8 \times 10^{8}$ to 1 $\times 10^{9} \mathrm{ohm}-\mathrm{cm}$ in the presence of 26 to $31 \mathrm{ppm}$ of naturally occurring $\mathrm{SO}_{3}$. With either Vicron limestone or Longview hydrated lime injected at the burner, the in situ resistivity was increased to 1 to $2 \times 10^{12} \mathrm{ohm}-\mathrm{cm}$, and there was virtually no $\mathrm{SO}_{3}$ left in the gas phase at $300^{\circ} \mathrm{F}$. By increasing the excess furnace oxygen level from $2.2 \%$ to $6.5 \%$, the naturally occurring $\mathrm{SO}_{3}$ in the presence of Vicron limestone could be increased from an undetectable amount to as high as $7.9 \mathrm{ppm}$, with a corresponding in situ resistivity below $1 \times 10^{10} \mathrm{ohm}-\mathrm{cm}$. At normal levels of excess oxygen, however, the in situ resistivity remained quite high. The $\mathrm{SO}_{3}$ injection tests showed that it was necessary to inject about 30 to $40 \mathrm{ppm}$ of $\mathrm{SO}_{3}$ to reduce the in situ resistivity from $1 \times 10^{12}$ to $5 \times 10^{10} \mathrm{ohm}-\mathrm{cm}$, which was considered adequate for good electrical operation of a precipitator. With Longview hydrated lime injected at the burner, the in situ resistivity could be reduced to a comparable value with the same amount of $\mathrm{SO}_{3}$ injection. However, the in situ resistivity was 3 to $7 \times 10^{11} \mathrm{ohm}$-cm when the hydrated lime was injected at the furnace exit with the same $\mathrm{SO}_{3}$ injection rate. This suggests that the sorbent injected at the lower temperature is more difficult to condition. 
Burner injection of the Vicron limestone resulted In a factor of 3 to 4 increase in the particulate loading in the size range 0.1 to $0.6 \mu \mathrm{m}$. However, there was no change in the loading of particles smaller than $0.1 \mu \mathrm{m}$, suggesting that none of the sorbent particles were smaller than this size. With the limestone injected at the furnace exdt, there was no increase in the loading of particles smaller than $0.6 \mu \mathrm{m}$, suggesting a lesser degree of limestone decrepitation at the lower temperature. Injection of hydrated lime at the furnace exit produced results identical to those observed with limestone injection at the same location. This was surprising because the hydrated lime had a significantly finer size distribution than the limestone.

Dahlin, R.S, and D.A Kirchgessner. Surface Characterization and Microanalysis of Sorbents and Ash/Sorbent Mixtures, presented at the First Joint Symposium on Dry $\mathrm{SO}_{2}$ and Simultaneous $\mathrm{SO}_{2} / \mathrm{NO}_{\chi}$ Control Technologies, San Diego, CA, (1984).

This paper provides a good review of the usefulness of various techniques for the detailed characterization of sorbents and sorbent/ash mixtures. Although the paper deals only with samples from the EPA's LIMB program, the findings of the authors extend beyond this one application of sorbent technology. Scanning Electron Microscopy (SEM) was found to be particularly useful in elucidating the surface morphology of calcines and sulfated calcines. In several photomicrographs, the pore openings in the calcines appeared to be slit-like and the calcination appeared to be directionally controlled. Carbon replica transmission electron microscopy (TEM) was found to be tedious and unwarranted in view of the success with the SEM. Energy dispersive X-ray (EDX) analysis in conjunction with SEM was found to be quite useful in investigating the relative abundance of various elements in different samples as well as the distribution of a given element within a field of particles. Analyses performed with an electron microprobe were useful for studying variations in elemental intensities in the top $4.5 \mu \mathrm{m}$ of a $20 \mu \mathrm{m}$ region of a sample. Due to poor spatial resolution, electron spectroscopy for chemical analysis (ESCA) was found to be unsuitable for heterogeneous particulate mixtures. Elemental depth profiles in individual particles can be determined by Auger electron spectroscopy (AES) coupled with ion milling. However, the results of this approach are very sensitive to particle charging effects and particle topography. The authors also cite prior LIMB studies that indicate that sorbents should have high surface areas and relatively large pores to effectively capture $\mathrm{SO}_{2}$ without losing surface area for reaction due to the blocking of small pores by the reaction products of sulfation. Another LIMB study conclusion that provided incentive to this research was that 
certain elemental and/or mineralogic components of the mineral matter contained in the coal fuel can either enhance or retard the ability of sorbents to capture sulfur during the combustion process.

Dantuluri, S. R., W. T. Davis, R. M. Counce, G. D. Reed. Mathematical Model of Sulfur Dioxide Absorption into a Calcium Hydroxide Slurry in a Spray Dryer, Separation Science and Technology, 25 (1990).

An existing spray dryer model was modified to take into account the effect of the specific surface area of the calcium hydroxide on the rates of lime dissolution and $\mathrm{SO}_{2}$ absorption. The model applies to the constant-rate drying period and addresses the simultaneous processes of evaporation, $\mathrm{SO}_{2}$ absorption, dissolution $0: \mathrm{Ca}(\mathrm{OH})_{2}$, and reaction of $\mathrm{SO}_{2}$ with $\mathrm{Ca}(\mathrm{OH})_{2}$. The original model assumed that the $\mathrm{Ca}(\mathrm{OH})_{2}$ particles were perfect spheres with no internal surface area. Measurements have shown that this assumption is not valid. In fact, the external surface area accounts for only a very small portion of the total surface area of the $\mathrm{Ca}(\mathrm{OH})_{2}$ particles. The modified model was used to determine the sensitivity of the predicted $\mathrm{SO}_{2}$ removal to the input surface area. Calculations were made for surface areas ranging from the external value to an upper limit of $40 \mathrm{~m}^{2} / \mathrm{g}$. The calculations were done for particle sizes of $2,3,4$, and $6 \mu \mathrm{m}$. For each particle size and surface area, $\mathrm{SO}_{2}$ removal was predicted as a function of the stolchiometric ratio.

For the $6 \mu \mathrm{m}$ particle size, $\mathrm{SO}_{2}$ removal was predicted to increase rapidly as the surface area increased, up to a value of $10 \mathrm{~m}^{2} / \mathrm{g}$. Beyond $10 \mathrm{~m}^{2} / \mathrm{g}$, the predicted removal was limited to $56.6 \%$, for the input conditions used here (inlet temperature $=300^{\circ} \mathrm{F}$, inlet moisture $=$ $6 \%$, inlet $\mathrm{SO}_{2}=2000 \mathrm{ppm}$, approach temperature $=20^{\circ} \mathrm{F}$, stoichiometric ratio $=1.0$ ). As the particle size decreased, the predicted effect of the surface area became less significant. The authors suggest that this is attributable to the dissolution rate of the lime being less dependent upon the internal surface area with smaller particles. For the $2 \mu \mathrm{m}$ particle size, the $\mathrm{SO}_{2}$ removal predicted with only external surface area was $67 \%$, compared to $67.5 \%$ with a surface area of $40 \mathrm{~m}^{2} / \mathrm{g}$. The authors state that the model predictions are consistent with field observations of reduced $\mathrm{SO}_{2}$ removal efficiencies with large particle sizes produced by improper slaking of lime. They also suggest that surface area may not a significant consideration if slaking conditions can be adjusted to yield very small particles, below 2 to $3 \mu \mathrm{m}$ in size. 
Dismukes, E.B. and J.P. Gooch. Technology for the Control of Particulates and Sulfur Oxddes by Electrostatic Techniques, EPA/600/7-91/004 (1991).

This project covered two main areas in E-SOX research. E-SOX is based on the injection of spray of lime slurry into a chamber upstream of an ESP to combine with $\mathrm{SO}_{2}$ followed by the removal of the E-SOX solids and fly ash simultaneously in the ESP. Utillity ESP's were surveyed for potentlal E-SOX applications, and a technical and economic assessment of ESOX was performed. A cold-pipe precharger offered no clear advantage in the collection of the E-SOX solids, which normally have low resistivity. In pilot-scale studies, slurries prepared from slaking quicklime gave slightly better $\mathrm{SO}_{2}$ removal than slurries prepared by mixing commercial hydrated lime with water. A laboratory method was developed to measure the electrical resistivity of solids from the E-SOX process, and other sorbent processes for $\mathrm{SO}_{2}$ control, such as LIMB.

DuBard, J. L., J. P. Gooch, R. Beittel, S. L. Rakes, and G. R. Offen. Particle Properties Related to ESP Performance with Sorbent Injection and Gas Conditioning, In: Proceedings: 1986 Joint Symposium on Dry $\mathrm{SO}_{2}$ and Simultaneous $\mathrm{SO}_{2} / \mathrm{NO}_{\mathbf{x}}$ Control Technologies, Volume 2. EPA-600/9-86-029b (NTIS PB87-120457), October 1986.

The effects of furnace injection of hydrated lime on resistivity, particle size distribution, and ESP electrical operation were studied in a pilot-scale combustor equipped with a singlelane ESP. The data were used to project ESP performance for four cases: (1) baseline (no lime injection), (2) furnace lime injection at a calcium-to-sulfur molar ratio of 2:1, (3) lime injection with $\mathrm{SO}_{3}$ conditioning, and (4) lime injection with $\mathrm{H}_{2} \mathrm{O}$ conditioning. For the latter two cases, the nominal resistivity at $300^{\circ} \mathrm{F}$ was essentially the same as the baseline resistivity, $2 \times 10^{10} \mathrm{ohm}-\mathrm{cm}$. For Case (2), lime injection with no conditioning, the resistivity was $2 \times 10^{12} \mathrm{ohm}-\mathrm{cm}$. An empirical correlation was used to predict electrical operating points (voltages and current densities) corresponding to these resistivity values. For Cases (1), (3), and (4), predicted voltages for a three-field ESP were 43, 42, and $40 \mathrm{kV}$, and predicted current densities were 20,29 , and $30 \mathrm{nA} / \mathrm{cm}^{2}$. For Case (2), the highresistivity case with no conditioning, the predicted voltages were 30,29 , and $30 \mathrm{kV}$, and the predicted current densities were $0.8,1.2$, and $2.5 \mathrm{nA} / \mathrm{cm}^{2}$. For Cases (2) and (3), the particulate mass loading was increased to $6.3 \mathrm{gr} / \mathrm{acf}$, compared to the baseline value of 2.3 gr/acf. For Case (4), the loading was increased further to $7.7 \mathrm{gr} / \mathrm{acf}$ because of the effect of the gas cooling associated with the water conditioning. For Case (4), with $\mathrm{H}_{2} \mathrm{O}$ 
conditioning, there are also beneficial effects from an increased SCA (a 25\% increase upon cooling to $150^{\circ} \mathrm{F}$ ) and a decrease in flue gas viscosity (which leads to a higher electrical migration velocity in the ESP). ESP performance projections suggest that the lime injection will increase particulate emissions, even when allowance is made for all of the beneficial effects of $\mathrm{H}_{2} \mathrm{O}$ conditioning.

Duduković, M. P. Reactions of Particles with Nonuniform Distribution of Solid Reactant. The Shrinking Core Model, Ind. Eng. Chem. Process Des. Dev., 23 (1984).

This paper describes the development of a mathematical model of gas-solid reactions with various nonuniform distributions of the solid reactant within the particles. The model applies to a variety of industrial processes in which gases react with a solid reactant that is impregnated into an inert solid support matrix. Examples include the regeneration of coked catalyst pellets and the extraction of ores from rocks. The model assumes that diffusion into the solid reactant is much slower than the reaction rate, the shrinking core model applies, particle size and shape do not change with reaction, diffusion through the product layer is in the Knudsen regime, the reaction is first order with respect to the gaseous reactant, isothermal conditions exist, and the profile of the solid reactant varies in one direction only. The author gives general equations that relate the solid reactant conversion to the position of the unreacted core, which is, in turn, related to the reaction time. The author also presents specific forms of the equations that are based on specified concentration profiles of the solid reactant.

Solution of the governing equations for spherical and cylindrical geometries shows that the time required for complete conversion of the solid reactant is dependent upon the solid reactant concentration profile, even when the reaction rate is controlled by surface kinetics. With a slab geometry; the conversion is shown to be independent of the concentration profile, if surface kinetics are controlling. If diffusion through the product layer is controlling, conversion is always affected by the concentration profile, in all geometries. The calculated time required for complete conversion with a nonuniform concentration profile is shown to be many times larger or smaller than that calculated assuming a uniform profile, depending upon how the reactant is distributed. With a parabolic profile that concentrates the reactants toward the outer surface of the solid, the predicted time required for complete conversion is $5 / 9$ of that calculated with a uniform reactant concentration, if surface kinetics are controlling. If product layer diffusion is controlling, 
the required time for complete conversion with the parabolic profile is $2 / 5$ of that calculated with the uniform reactant concentration.

Durham, M. D., T. G. Ebner, D. B. Holstein, C. A. Brown, and L. G. McGuire. Pilot Plant Investigation of ESP Performance and Upgrade Strategies for In-Duct Sorbent Injection, Presented at the Ninth Particulate Control Symposium, Williamsburg, VA, October 15-18, 1991.

The effects of in-duct sorbent injection on particulate characteristics and ESP performance were studied in a 1.7-MW pilot plant. Particulate mass loadings, size distributions, resistivities, and ESP performance parameters were measured with and without the in-duct injection of commercial hydrated lime. The sorbent injection tests were run with spray humidification of the flue gas upstream and downstream of the sorbent injection point, and with and without recycle of a portion of the spent sorbent. The test facility was equipped with two identical four-field ESPs installed in series, providing a total SCA of $590 \mathrm{ft}^{2} / \mathrm{kacfm}$ with a flue gas flow rate of $6300 \mathrm{acfm}$ at $300^{\circ} \mathrm{F}$. Under baseline conditions, with no sorbent injection, the fly ash loading at the ESP inlet varied from 1.20 to $1.57 \mathrm{gr} / \mathrm{dscf}$, and resistivity was on the order of $10^{9} \mathrm{ohm}-\mathrm{cm}$ in the presence of 9 to $18 \mathrm{ppm}$ of $\mathrm{SO}_{3}$ at $300^{\circ} \mathrm{F}$. Baseline collection efficiency varied from $67 \%$ with only two fields in service $\left(\mathrm{SCA}=136 \mathrm{ft}^{2} / \mathrm{kacfm}\right)$ to $99.87 \%$ with all eight fields in service (SCA $=590 \mathrm{ft}^{2} / \mathrm{kacfm}$ ). The baseline efficiency was significantly lower than expected and lower than predicted by the EPA/SRI ESP Model. In order to obtain good agreement between the model and the measurements, it was necessary to use a value of 0.44 for the fractional sneakage/reentrainment. The authors state that it was unlikely that sneakage was a problem because the ESP was very well baffled in the hoppers, sides, and top. The authors suggest that low-resistivity reentrainment was limiting the performance, noting that the gas temperature dropped to $258^{\circ} \mathrm{F}$ at the ESP outlet, which would produce a resistivity of $10^{7}$ to $10^{8} \mathrm{ohm}-\mathrm{cm}$.

The most significant effect of the sorbent injection was found to be the increase in the inlet mass loading to $7.3 \mathrm{gr} / \mathrm{dscf}$ without recycle or $11.3 \mathrm{gr} / \mathrm{dscf}$ with recycle. The sorbent injection also suppressed the corona current in the inlet field from $90 \mathrm{nA} / \mathrm{cm} 2$ to $50 \mathrm{nA} / \mathrm{cm} 2$ with downstream humidification and to $6 \mathrm{nA} / \mathrm{cm} 2$ with upstream humidification. The severe corona quenching with upstream humidifcation was attributed to the formation of an ultrafine sulfuric acid aerosol, while the smaller degree of quenching with downstream humidification was caused by sorbent. Analysis of impactor samples revealed that sulfuric 
acid accounted for most of the particles smaller than about $0.4 \mu \mathrm{m}$, while a large increase in mass in the range of 0.4 to $1 \mu \mathrm{m}$ was caused by the sorbent. To overcome the corona quenching problem, barbed electrodes were installed in the inlet field, and corona currents were increased by 50 to $75 \%$. With the barbed electrodes in use, collection efficiency with sorbent injection and no recycle varied from $92.6 \%$ with two fields in service to $99.93 \%$ with all eight fields in service. With recycle, efficiency increased slightly to $99.95 \%$ with all eight fields in service. The recycle did not cause any additional corona quenching, and voltagecurrent curves obtained with and without recycle were very similar. Attempts to improve ESP performance by operating at higher voltages were unsuccessful, presumably because the higher voltage increased the degree of reentrainment by increasing the repulsive force on the low-resistivity particles.

Durham, M. D., D. B. Holstein, G. Blythe, K. A. Hieneken, R. G. Rhudy, R. F. Altman, T. A. Burnett, R.A. Barton, and C. W. Dawson. High Efficiency Electrostatic Precipitator Operation at Spray Dryer Conditions, Presented at the Ninth Particulate Control Symposium, Williamsburg, VA, October 15-18, 1991.

Calcium chloride addition to lime slurries was investigated as a means of increasing ash cohesivity and reducing reentrainment from an ESP collecting a spray dryer effluent. Previous work, referenced in the paper, showed that ESP performance downstream from a spray dryer was limited by reentrainment caused by the low resistivity of the ash/sorbent mixture. Supporting laboratory studies showed that ash/sorbent particles deposited on a grounded plate and subjected to an electric field could be ejected from the plate when the conditions resulted in low resistivity ( $10^{8} \mathrm{ohm}-\mathrm{cm}$ ). As the resistivity was reduced by lowering the temperature in the test coll, the degree of particle ejection was observed to increase. However, particle ejection ceased when the temperature dropped to about $135^{\circ} \mathrm{F}$. The authors suggest that this observation may be explained in terms of increased particle cohesion at the very low temperatures. At temperatures above $135^{\circ} \mathrm{F}$, the cohesive forces are apparently not adequate to prevent the ejection. Operation of a commercial ESP at temperatures below $135^{\circ} \mathrm{F}$ is not feasible, so the authors suggest the use of an additive to increase ash cohesivity.

The feasibility of using calcium chloride additive to increase ash cohesivity and reduce ESP reentrainment was investigated at the $10-\mathrm{MW}$ spray dryer/ESP test facility at TVA's Shawnee Steam Plant. The calcium chloride was added to the lime slurry to produce 
chloride levels of 0.6 to $3.7 \%$ in the dried ash/sorbent mixture. Tests were done with three different coals having sulfur contents of $2.2,2.7$ and $4.0 \%$ and chloride contents of 0.01 , 0.06 , and $0.05 \%$. Three different approach temperatures $\left(18,28\right.$, and $\left.38^{\circ} \mathrm{F}\right)$ were tested with a constant spray dryer inlet temperature of $320^{\circ} \mathrm{F}$ and a constant reagent ratio of 1.3 . The chloride addition had no measurable effect on ESP performance at the approach temperatures of 28 and $38^{\circ} \mathrm{F}$. However, at the $18^{\circ} \mathrm{F}$ approach, the chloride addition dramatically improved ESP performance with all of the coals tested. With the coal containing $2.2 \%$ sulfur, ESP collection efficiency was increased from $99.84 \%$ to $99.98 \%$, reducing emissions from 0.041 to $0.005 \mathrm{lb} / 10^{6} \mathrm{Btu}$. With the coal containing $2.7 \%$ sulfur, efficiency was increased from $99.41 \%$ to $99.95 \%$, reducing emissions from 0.15 to $0.01 \mathrm{lb} / 10^{6}$ Btu. With the high(4.0\%)-sulfur coal, efficiency increased from $99.86 \%$ to $99.95 \%$, reducing emissions from 0.041 to $0.016 \mathrm{lb} / 10^{6} \mathrm{Btu}$. For reference, operation of the ESP with the spray dryer out of service (i.e., collecting fly ash only) resulted in a collection efficiency of $99.87 \%$ and an emission rate of $0.008 \mathrm{lb} / 10^{6} \mathrm{Btu}$.

Emmel, T. E. and N. Kaplan. Lime/Limestone FGD and Sorbent Injection Technology Retrofit Difficulty at 60 Coal-Fired Utility Power Plants, Presented at the First Combined FGD and Dry $\mathrm{SO}_{2}$ Control Symposium, St. Louis, MO, October 25-28, 1988.

This paper presents simplified procedures for estimating the costs of retrofitting $\mathrm{SO}_{2}$ controls at existing coal-fired power plants. The capital cost of the retrofit is estimated by multiplying the capital cost for a comparable new plant application by a retrofit factor. The authors give a formula for calculating the retrofit factor from information on site access and requirements for new ducting, changes to the ash handling system, new chimneys, and ESP upgrades. Specific factors are tabulated for both FGD scrubbers and sorbent injection (duct spray drying and furnace sorbent injection). This procedure was used to estimate the costs of FGD scrubbers for 191 boilers at 60 power plants in Ohio, Missouri, Illinois, Pennsylvania, Kentucky, Tennessee, and Alabama. The results indicate that the retrofit capital costs are 20 to $100 \%$ higher than the costs for comparable new plant applications. For 33 of the boilers, the projected levelized cost was less than $\$ 1000 /$ ton of $\mathrm{SO}_{2}$ removed. For 83 of the boilers, the projected cost was between $\$ 1000 /$ ton and $\$ 2000 /$ ton. The projected cost exceeded $\$ 2000 /$ ton for 75 of the boilers.

At 84 of the 191 boilers studied, the levelized cost of FGD scrubbers exceeded \$1500/ton, which the authors suggest is a cutoff beyond which a sorbent injection process should be 
considered in lieu of scrubbing. The authors suggest that these units are good candidates for sorbent injection processes because they tend to be small units ( 73 are smaller than 250 $M W$ ), they tend to fire lower sulfur coal (57 fire coal containing less than $2 \%$ sulfur), and they tend to have low capacity factors ( 42 have capacity factors below $40 \%$ ). However, 42 of the units have marginal ESPs with SCAs below $250 \mathrm{ft}^{2} / \mathrm{kacfm}$. Only 10 of these units have sufficient residence time between the air heater and ESP for complete droplet evaporation. The remaining 32 units are said to be good candidates for furnace sorbent injection.

Faulkner, M. G., G. H. Marchant, Jr., E. C. Landham, Jr., and J. L. DuBard. Field and Laboratory Measurements of Fly Ash Properties and Precipitator Performance Parameters with Furnace Sorbent Injection, Presented at the First Combined FGD and Dry $\mathrm{SO}_{2}$ Control Symposium, St. Louis, MO, October 25-28, 1988.

The effect of furnace injection of hydrated lime on ESP performance was examined by a combination of full-scale field observations and measurements coupled with tests performed on a pilot-scale system. The full-scale measurements were made in conjunction with EPA's LIMB Demonstration Program at Ohio Edison's Edgewater Station. Measurements of particulate mass loading, particle size distribution, and electrical resistivity were made with and without the lime injection. ESP electrical operating conditions were also recorded during both modes of operation. The pilot-scale testing was done in a $10^{6} \mathrm{Btu} / \mathrm{hr}$ combustior pilot plant equipped with a single-lane ESP. In addition to the same measurements made during the field testing, the pilot plant studies also examined the effect of lime injection on ESP plate rapping and the ability of $\mathrm{SO}_{3}$ and $\mathrm{H}_{2} \mathrm{O}$ conditioning to improve ESP electrical operation and rapping characteristics.

At the Edgewater demonstration, hydrated lime injection at a calcium-to-sulfur molar ratio of 2:1 increased the particulate mass loading from 1.9 to $3.5 \mathrm{gr} / \mathrm{acf}$. There was a ten-fold increase in the loading of particles in the size range of 0.5 to $1 \mu \mathrm{m}$. The electrical resistivity measured at $350^{\circ} \mathrm{F}$ was increased from $3 \times 10^{10} \mathrm{ohm}-\mathrm{cm}$ to greater than $10^{12} \mathrm{ohm}-\mathrm{cm}$. The electrical operation of the ESP was drastically degraded. Degradation of electrical operation began in the inlet ESP field and progressed to the fifth field within three hours after the initiation of the lime injection. Voltage-current curves revealed progressively worsening back corona throughout the ESP. After three hours of lims injection, the tests had to be terminated to avoid exceeding the $20 \%$ limit on stack opacity. Tests performed 
in the pilot-scale system suggested that this drastic degradation could be ameliorated by the use of water conditioning. Tests on the pilot-scale ESP showed a very rapid response of electrical conditions to moisture conditioning. The results suggested that resistivity could be reduced to $10^{10} \mathrm{ohm}-\mathrm{cm}$ with a $50^{\circ} \mathrm{F}$ approach to the adiabatic saturation temperature. With a $26^{\circ} \mathrm{F}$ approach to saturation, the residual difference in electrical operating conditions was mainly attributable to corona quenching by particulate space charge. Water conditioning was also found to make the lime-containing ash easier to remove by rapping, but $\mathrm{SO}_{3}$ conditioning did not have a similar effect.

Gooch, J. P., J. L. DuBard, and R. Beittel. The Influence of Furnace Sorbent Injection on Precipitator Performance, and Methods for Improving Performance, In: Proceedings of the Third International Conference on Electrostatic Precipitation, University of Padua, Abano-Padova, Italy, October 1987.

This paper examines the effect on precipitator performance of furnace injection of hydrated lime at a temperature of 2200 to $2500^{\circ} \mathrm{F}$. In situ measurements of electrical resistivity, particulate loading, and particle size distribution were made with and without the injection of the hydrated lime into a pilot-scale, coal-fired combustor. The hydrated lime was injected at various points in the furnace at a calcium-to-sulfur molar ratio of $2: 1$, and all of the in situ measurements were made at a flue gas temperature of $300^{\circ} \mathrm{F}$. Injection of the hydrated lime reduced the $\mathrm{SO}_{3}$ concentration in the flue gas from $20 \mathrm{ppm}$ to below the detection limit of $0.3 \mathrm{ppm}$, resulting in an increase in resistivity from $10^{9}$ to $10^{12} \mathrm{ohm}-\mathrm{cm}$. The injection temperature of the hydrated lime was found to strongly influence the ability of $\mathrm{SO}_{3}$ conditioning to attenuate the high resistivity produced by lime injection. With the lime injected at $2200^{\circ} \mathrm{F}$, injection of $120 \mathrm{ppm}$ of $\mathrm{SO}_{3}$ produced only a slight reduction in resistivity to about $3 \times 10^{11} \mathrm{ohm}-\mathrm{cm}$. With the lime injected at $2500^{\circ} \mathrm{F}$, the same amount of $\mathrm{SO}_{3}$ reduced resistivity to about $10^{10}$ ohm-cm. A comparable reduction in resistivity was produced by the injection of about $10 \%$ water to cool the flue gas to about $180^{\circ} \mathrm{F}$.

Under the high-resistivity conditions produced by the lime injection, severe back corona was evident in a pilot ESP operated at $300^{\circ} \mathrm{F}$. The use of flue gas conditioning, with either $\mathrm{SO}_{3}$ or $\mathrm{H}_{2} \mathrm{O}$, eliminated the back corona, but the ESP current was stll only about $30 \%$ of its baseline value because of space-charge suppression of the corona current. The current suppression ended immediately when the lime injection was discontinued. The lime 
injection increased the particulate mass loading at the ESP inlet from 2.3 to $6.3 \mathrm{gr} / \mathrm{acf}$. The loading of submicron particles was increased from 0.02 to $0.3 \mathrm{gr} / \mathrm{acf}$.

Gullett, B. K. and J. A. Blom. Calcium Hydroxide and Calcium Carbonate Particle Size Effects on Reactivity with Sulfur Dioxide, Reactivity of Solids, 3 (1987).

The purpose of this research was to determine the effect of particle size on the reactivity of $\mathrm{Ca}(\mathrm{OH})_{2}$ and $\mathrm{CaCO}_{3}$ sorbents with $\mathrm{SO}_{2}$. Previous efforts to study the effect of particle size have been based on sedimentation or Coulter Counter analyses of samples of the unreacted sorbent. This approach is inadequate in that the sorbents have an extreme propensity to agglomerate. To determine the true effect of particle size on reactivity, the particle size must be measured in situ under the reaction conditions. In this study, reactivity is related to in situ measurements of sorbent particle size made with a cascade impactor at the outlet of an entrained-flow reactor. The sorbents were fed into the high-temperature graphiteelement furnace with a gas flow consisting of $3000 \mathrm{ppm} \mathrm{SO}_{2}, 5 \% \mathrm{O}_{2}$, and the balance $\mathrm{N}_{2}$. The sorbent feed rate was adjusted to produce a calcium-to-sulfur molar ratio of 1:9. The nominal residence time of sorbent in the reactor was $1.5 \mathrm{sec}$. The conversion of various sorbent size fractions was determined by analysis of the impactor stage catches. Tests were run for three different types of $\mathrm{Ca}(\mathrm{OH})_{2}$ and one $\mathrm{CaCO}_{3}$. The results are given in terms of $\%$ conversion versus particle size.

Conversion increased with decreasing particle size with all four sorbents tested. The $\mathrm{CaCO}_{3}$ sorbent had the lowest reactivity at all particle sizes. The reactivities of the three $\mathrm{Ca}(\mathrm{OH})_{2}$ sorbents differed significantly at a given particle size, but all showed the same trend of increasing conversion with decreasing size. The conversion was correlated with diameter raised to the -0.22 to -0.32 power. The cascade impactor measurements were found to yield much coarser size distributions and larger mean sizes than a sedimentation analysis of the feed sorbent. This was found to be true even when the impactor measurements were made at room temperature (i.e., without heating the reactor). The authors attribute this observation to the inability of the reactor feed system to redisperse the sorbent particles into their fundamental particle size. The dispersant technique used with the sedimentation analysis produces much better dispersion of the sorbent particles. The authors also compared the feeding of one $\mathrm{Ca}(\mathrm{OH})_{2}$ with a size cut of the same material consisting of particles smaller than $2 \mu \mathrm{m}$. The impactor measurements made at the reactor exit consistently showed a coarser outlet distribution and larger mean size with the fine size 
cut. This was observed at room temperature and at $1100^{\circ} \mathrm{C}$ with and without $\mathrm{SO}_{2}$ present. Apparently, the fine size cut becomes more tightly agglomerated and difficult to disperse in the feed system.

Gullett, B. K., J. A. Blom, and R. T. Cunningham. Porosity, Surface Area, and Particle Size Effects of $\mathrm{CaO}$ Reacting with $\mathrm{SO}_{2}$ at $1100^{\circ} \mathrm{C}$, Reactivity of Solids, 6 (1988).

The reaction of $\mathrm{SO}_{2}$ with $\mathrm{CaO}$ derived from $\mathrm{CaCO}$ and $\mathrm{Ca}(\mathrm{OH})_{2}$ was studied in a flow reactor to investigate the effects of porosity, surface area, and particle size on reactivity. Samples of $\mathrm{CaO}$ having a range of specific surface areas and porosities were prepared by calcining either $\mathrm{CaCO}_{3}$ or $\mathrm{Ca}(\mathrm{OH})_{2}$ at temperatures of 800 to $1000^{\circ} \mathrm{C}$ for times of $60 \mathrm{sec}$ to $6 \mathrm{hr}$. The effect of particle size was determined by analysis of size fractionated samples extracted from the reactor using a cascade impactor. The $\mathrm{CaO}$ was pneumatically injected into the flow reactor in an environment of $3000 \mathrm{ppm} \mathrm{SO}_{2}$ and $5 \% \mathrm{O}_{2}$ in nitrogen. The reactor was surrounded with graphite heating elements to maintain a constant temperature of $1100^{\circ} \mathrm{C}$. The $\mathrm{CaO}$ residence time was about $0.74 \mathrm{sec}$.

The results showed that reactivity increased with decreasing particle size for both the $\mathrm{CaO}$ derived from $\mathrm{CaCO}_{3}$ (termed $\mathrm{c}-\mathrm{CaO}$ ) and the $\mathrm{CaO}$ derived from $\mathrm{Ca}(\mathrm{OH})_{2}$ (termed h$\mathrm{CaO}$ ). Higher initial surface areas produced increased reactivity at all particle sizes for both types of $\mathrm{CaO}$. At a given initial surface area and particle size, the $\mathrm{h}-\mathrm{CaO}$ tended to be more reactive than the $\mathrm{c}-\mathrm{CaO}$, except in the case of the lowest surface area, where the two types of $\mathrm{CaO}$ showed similar reactivities. Interpretation of the results in terms of a modified Thiele modulus showed that there was a tradeoff between high surface area leading to increased reaction rate and high porosity leading to faster pore diffusion. Surface areas of 30 to $50 \mathrm{~m}^{2} / \mathrm{g}$ and porosities of 30 to $40 \%$ appear to yield optimal reactivity. The strong dependence of reactivity on both surface area and porosity suggests that the higher conversion of $\mathrm{h}-\mathrm{CaO}$ is due to greater pore volume delaying the pore blockage from product layer buildup. 
Gullett, B. K. and K. R. Bruce. Pore Distribution Changes of Calcium-Based Sorbents Reacting with Sulfur Dioxide, AIChE Journal, 33 (1987).

An experimental study was performed to investigate the effect of sulfation and sintering on the pore size distribution of $\mathrm{CaO}$ derived from $\mathrm{CaCO}_{3}$ and $\mathrm{Ca}(\mathrm{OH})_{2}$ sorbents. The carbonate-derived $\mathrm{CaO}, \mathrm{c}-\mathrm{CaO}$, was prepared by calcining $\mathrm{CaCO}_{3}$ in an isothermal, fixedbed, nitrogen-swept reactor at $800^{\circ} \mathrm{C}$ for $2 \mathrm{~min}$. The hydrate-derived $\mathrm{CaO}, \mathrm{h}-\mathrm{CaO}$, was prepared by the same procedure, except that the time was reduced to $1 \mathrm{~min}$. Reduced surface areas were produced by controlled sintering in a stagnant nitrogen atmosphere at $800^{\circ} \mathrm{C}$ in the same apparatus. The $\mathrm{CaO}$ was then sulfated by immediately switching to an atmosphere of $7000 \mathrm{ppm} \mathrm{SO} 2$ and $5 \% \mathrm{O}_{2}$ in nitrogen. After exposure to the $\mathrm{SO}_{2}$ for times of 5,25 , and $60 \mathrm{sec}$, the sulfated sample was removed, cooled under flowing nitrogen, and subjected to pore size and surface area analysis using a Micromeritics Digisorb 2600 Autoanalyzer. This procedure was repeated with the three different reaction times to study the effect of sulfation on the pore distribution in both the c-CaO and the $\mathrm{h}-\mathrm{CaO}$. The effect of sintering was also studied by analyzing the pore distribution in $\mathrm{CaO}$ samples subjected to varying degrees of sintering in the stagnant nitrogen.

From the hysteresis in the nitrogen adsorption and desorption isotherms, the authors infer that the pores in the $\mathrm{c}-\mathrm{CaO}$ are cylindrical, while those in the $\mathrm{h}-\mathrm{CaO}$ are slit-like. The smallest pores in both the $\mathrm{c}-\mathrm{CaO}$ and the $\mathrm{h}-\mathrm{CaO}$ were found to disappear when the $\mathrm{CaO}$ was sintered for times up to $10 \mathrm{~min}$. This effect was accompanied by a large reduction in surface area, since the smallest pores account for much of the surface area. However, this had little effect on the degree of sulfation, suggesting that the smallest pores did not significantly aid the sulfation reaction. With increasing extents of sulfation, the pore volume decreased throughout the entire range of pore sizes. Both the pore volume and surface area appeared to decrease linearly with the extent of sulfation. The pore volume and area of the $\mathrm{c}-\mathrm{CaO}$ declined faster than those of the $\mathrm{h}-\mathrm{CaO}$ over comparable extents of sulfation. The authors infer that the $\mathrm{c}-\mathrm{CaO}$ is more susceptible to pore closure by sulfation than is the $\mathrm{h}-\mathrm{CaO}$, probably because of the difference in pore geometry. The structure of the h- $\mathrm{CaO}$ (slit-like pores) is said to allow more expansion and subsequent retention of porosity. 
Gullett, B. K. and K. R. Bruce. Identification of $\mathrm{CaSO}_{4}$ Formed by Reaction of $\mathrm{CaO}$ and $\mathrm{SO}_{2}$, AIChE Journal, 35 (1989).

$\mathrm{X}$-ray diffraction $\left(\mathrm{XRD}\right.$ ) was used to determine the particular type of $\mathrm{CaSO}_{4}$ formed by the reaction of $\mathrm{CaCO}_{3}$ and $\mathrm{Ca}(\mathrm{OH})_{2}$ with $\mathrm{SO}_{2}$ in a fixed-bed reactor at $800^{\circ} \mathrm{C}$ in the presence of $3000 \mathrm{ppm}$ of $\mathrm{SO}_{2}$ and $5 \% \mathrm{O}_{2}$ in a nitrogen stream. With both $\mathrm{CaCO}_{3}$ and $\mathrm{Ca}(\mathrm{OH})_{2}$, the reaction product, $\mathrm{CaSO}_{4}$, was positively identified as calcium sulfate anhydrite, Joint Committee for Powder Diffraction Spectra (JCPDS) Registry No. 37-1496. This orthorhombic crystalline structure has a density of $2.995 \mathrm{~g} / \mathrm{cm}^{3}$. Thermogravimetric analysis (TGA), atomic absorption (AA), and ion chromatography (IC) were used to quantitatively analyze the reaction product for $\mathrm{CaSO}_{4}, \mathrm{CaO}, \mathrm{Ca}(\mathrm{OH})_{2}$, and $\mathrm{CaCO}_{3}$. Helium pycnometry was used to determine the density of the reaction product. From these results, the density of the $\mathrm{CaSO}_{4}$ was calculated to be $2.98 \mathrm{~g} / \mathrm{cm}^{3}$ with a standard deviation of $0.08 \mathrm{~g} / \mathrm{cm}^{3}$ based on five replicate measurements. This value is in good agreement with that reported for the calcium sulfate anhydrite. However, the authors cite 11 papers in which a value of 2.6 $\mathrm{g} / \mathrm{cm}^{3}$, taken from the Handbook of Chemistry and Physics, was used in modeling the reaction of $\mathrm{CaO}$ and $\mathrm{SO}_{2}$. Use of this lower value of density in the models has the effect of reducing the predicted $\mathrm{SO}_{2}$ capture, because the lower density, or higher molar volume, causes faster closure of the pores with $\mathrm{CaSO}_{4}$. Increasing the assumed density from 2.6 $\mathrm{g} / \mathrm{cm}^{3}$ to the correct value of $2.98 \mathrm{~g} / \mathrm{cm}^{3}$ is shown to increase the predicted maximum conversion of $\mathrm{Ca}(\mathrm{OH})_{2}$ from about $42 \%$ to $56 \%$, based on an intial $\mathrm{CaO}$ porosity of $48.9 \%$.

Harrison, D. J., G. H. Newton, and D. W. Pershing. Calcination of Calcium-Based Sorbents for Control of $\mathrm{SO}_{2}$ Emissions from Coal-Fired Boilers, EPA Report No. EPA/600/D-86/015 (NTIS PB86-148145), January 1986.

Four limestones, one dolomite, five hydrated limes, and four pressure-hydrated dolomitic limes were calcined in a nitrogen-swept, batch calciner at $700^{\circ} \mathrm{C}$ for a period of $20 \mathrm{~min}$. The same sorbents were tested for $\mathrm{SO}_{2}$ capture in a small-scale furnace at $1090^{\circ} \mathrm{C}, \mathrm{Ca} / \mathrm{S}$ ratio of $2: 1$, and residence time of $0.5 \mathrm{sec}$. The pressure-hydrated dolomitic limes produced the highest specific surface areas ( 48 to $62 \mathrm{~m}^{2} / \mathrm{g}$ ) and the highest $\mathrm{SO}_{2}$ captures (42 to $62 \%$ ) under these conditions. The limestones produced thr: lowest specific surface areas (10 to 13 $\mathrm{m}^{2} / \mathrm{g}$ ) and the lowest $\mathrm{SO}_{2}$ captures (16 to $20 \%$ ). The $\mathrm{SO}_{2}$ capture was linearly correlated with the specific surface area with a correlation coefficient of 0.9 . Thus, the authors assert that the surface area developed under inert calcination conditions can be used as a rough 
indicator of sorbent performance in an actual combustion environment. The results also suggest that variations in surface area and capture within a given class of sorbent (limestone, dolomite, hydrated lime, or pressure-hydrated dolomitic lime) are much smaller than the variations associated with different classes.

Helfritch, D. J., P. L. Feldman, B. Weinstein, and M. W. McElroy. Electrostatic Precipitator Upgrades for Furnace Sorbent Injection, In: Proceedings: 1986 Joint Symposium on Dry $\mathrm{SO}_{2}$ and Simultaneous $\mathrm{SO}_{2} / \mathrm{NO}_{x}$ Control Technologies, Volume 2. EPA-600/9-86-029b (NTIS PB87-120457), October 1986.

Various options for restoring satisfactory ESP performance after a retrofit of furnace sorbent injection (FSI) are discussed and evaluated. Performance projections are presented for a base case with no sorbent injection, a worst case with sorbent injection and no ESP upgrades, and various intermediate cases with sorbent injection and a variety of ESP upgrades. The upgrades considered include: increased plate area (alone and in conjunction with conditioning), flue gas cooling by water injection and heat exchange, pulse energization, and $\mathrm{SO}_{3}$ conditioning. The base case is a 100-MW boiler firing a 3\% Eastern bituminous coal equipped with a four-field, cold-side ESP with an SCA of $200 \mathrm{ft}^{2} / \mathrm{kacfm}$. For the base case, the inlet loading is $3 \mathrm{gr} / \mathrm{scf}$, the predicted resistivity is $3.2 \times 10^{9} \mathrm{ohm}-\mathrm{cm}$, the efficiency is $98.6 \%$, and the emission rate is $0.1 \mathrm{lb} / 10^{6} \mathrm{Btu}$. In the sorbent injection cases, it is assumed that all of the naturally occurring $\mathrm{SO}_{3}$ is removed by the sorbent, and the predicted resistivity without conditioning or cooling is $6.5 \times 10^{12} \mathrm{ohm}-\mathrm{cm}$.

The upgrade options are evaluated in terms of what is required to restore emissions to the original level of $0.1 \mathrm{lb} / 10^{6} \mathrm{Btu}$. For the addition of plate area alone, the model predictions indicate that the SCA must be increased from 200 to over $800 \mathrm{ft}^{2} / \mathrm{kacfm}$ to maintain the original emission level. In combination with conditioning, however, the required SCA is less than $400 \mathrm{ft}^{2} / \mathrm{kacfm}$. The modeling indicates that emissions can also be restored to the original level by cooling the gas to $180^{\circ} \mathrm{F}$ by humidification or to $160^{\circ} \mathrm{F}$ by heat exchange. A lower temperature is required using a heat exchanger, because there is no conditioning effect from increased moisture. The highly beneficial effect of cooling results from reduced resistivity, increased SCA, increased gas density (permitting higher electric field strengths), and reduced gas viscosity (permitting higher migration velocities). Pulse energization alone cannot restore the emissions to the original level, because, at best, it can only eliminate the resistvity limitation. Additional plate area would still be required to 
compensate for the increased inlet loading. The predictions indicate that pulsing yields a negligible improvement when applied in conjunction with gas cooling. The assumed particle size distribution of the ash/sorbent mixture is shown to have a major effect on these predictions.

Henke, K. R. and C. J. Moretti. Chemical Characterization of Electrostatic Precipitator Ashes from Pressurized Hydrated-Lime Injection Tests, Presented at the International Conference on the Development of Alternative Energy Sources and the Lessons Learned Since the Oil Embargo, Grand Forks, ND, May 23-24, 1986 (NTIS CONF-8605117--3).

The effect of pressure hydrated-lime injection on the leaching characteristics of a North Dakota lignitic fly ash was evaluated. Standard leaching tests were run on samples of ash taken from the electrostatic precipitator hoppers of a commercial power plant using pressure hydrated-lime injection for $\mathrm{SO}_{2}$ control. To evaluate the effect of the lime injection on leaching, the tests were run with both baseline ash samples and ash samples produced at three levels of lime injection, corresponding to $\mathrm{Ca} / \mathrm{S}$ ratios of $0.5: 1,1.1: 1$, and 3.5:1. The samples were characterized by $\mathrm{X}$-ray diffraction and $\mathrm{X}$-ray fluorescence and then subjected to the standard EP (Extraction Procedure) and ASTM D3978-81 batch leaching tests and non-standard, long-term column leaching tests.

$\mathrm{X}$-ray diffraction identified the following major phases in all of the samples: calcium- and silicon-rich amorphous glasses, $\mathrm{CaO}, \mathrm{MgO}, \mathrm{CaSO}_{4}, \mathrm{Ca}_{3} \mathrm{Al}_{2} \mathrm{O}_{6}, \mathrm{Na}_{2} \mathrm{SO}_{4}$, and $\mathrm{K}_{2} \mathrm{SO}_{4}$. The $\mathrm{x}$ ray diffraction also detected small concentrations of calcite, quartz, hematite, and ferrite spinels. X-ray diffraction on the leached ash revealed the formation of an ettringite phase, which is common in cementitious materials, suggesting a pozzolanic reaction between the ash and lime components. X-ray fluorescence showed the expected increase in $\mathrm{Ca}$ and $\mathrm{Mg}$ and decrease in other elements with increasing lime addition. X-ray fluorescenec on the leached ash showed a depletion of sodium, chromium, barium, and strontium, suggesting that these elements were leached from the ashes. This was confirmed by analysis of the EP and ASTM leachates. In the long-term (month-long) column leaching tests, sodium and potassium were generally completely leached out of the columns, in the form of sulfates, within a few days. After their complete extraction, the sulfate concentration in the leachate dropped considerably because of the low solubility of $\mathrm{CaSO}_{4}$. This caused $\mathrm{BaSO}_{4}$ precipitation to cease, leading to an increase in the barium concentration. The high 
concentrations of barium were not predicted by the EP or ASTM procedures, which yielded leachate concentrations below regulatory limits for all the RCRA metals.

Hovis, L. S., R. E. Valentine, B. J. Jankura, P. Chu, and J. C. S. Chang, E-SO $\mathbf{x}$ Pilot Evaluation, Presented at the First Combined FGD and Dry $\mathrm{SO}_{2}$ Control Symposium, St. Louis, MO, October 25-28, 1988.

This paper describes a pilot-scale evaluation of the EPA E-SO $x$ process. The E-SO process is a retrofit $\mathrm{SO}_{2}$ control technology in which the inlet field of an existing ESP is replaced with an array of lime slurry spray nozzles. Pilot-scale testing of this concept was conducted in a 1000-acfm test facility at EPA's Air and Energy Engineering Research Laboratory. The test ESP originally had four fields with a total SCA of $128 \mathrm{ft}^{2} / \mathrm{kacfm}$, which was reduced to three fields and $96 \mathrm{ft}^{2} / \mathrm{kacfm}$ after removal of the first field internals and installation of a Casterjet pneumatic spray nozzle. A lime slurry containing 15 to $20 \%$ solids was atomized into a spray having a Sauter mean diameter of about $30 \mu \mathrm{m}$. The space between the spray nozzle and the first electrified section provided a gas residence time of 1.5 to $2 \mathrm{sec}$. The tests were done with simulated flue gas produced by doping air with fly ash and 1500 to $2000 \mathrm{ppm}$ of $\mathrm{SO}_{2}$. Using this setup, it was found that incomplete droplet evaporation limited the lowest practical approach to saturation to about 28 to $30^{\circ} \mathrm{F}$. At this approach temperature, $50 \% \mathrm{SO}_{2}$ removal was achieved with a stoichiometric ratio of 1.3 to 1.4 .

Operation at the above conditions produced a four-fold increase in the particulate 1 ading entering the ESP. The ESP collection efficiency was tested with three fields in service (SCA $=96 \mathrm{ft}^{2} / \mathrm{kacfm}$ ) and two fields in service (SCA $\left.=64 \mathrm{ft}^{2} / \mathrm{kacfm}\right)$. At a $30^{\circ} \mathrm{F}$ approach, collection efficiency was essentially the same for both cases (98.5 to $98.6 \%$ ). The authors do not offer any explanation for this surprising result. With three fields in service and coldpipe prechargers used ahead of the first and third fields, the collection efficiency was improved to $99.5 \%$. These efficiencies may be compared to a baseline efficiency of $89.0 \%$, which was measured with the three-field unit collecting fly ash without any lime or water injection at a temperature of $285^{\circ} \mathrm{F}$. The higher collection efficiency obtained with lime injection corresponded to a factor of seven reduction in fractional penetration (i.e., $11 \%$ to $1.5 \%$ ), which was more than sufficient to offset the four-fold increase in particulate loading. The authors conclude that emissions could be maintained below $0.1 \mathrm{lb} / 10^{6} \mathrm{Btu}$ in most cases where an $\mathrm{E}-\mathrm{SO}_{\mathbf{x}}$ retrofit would be considered. 
Jozewicz, W. and G. T. Rochelle. Fly Ash Recycle in Dry Scrubbing, Environmental Progress, 5 (1986).

An experimental study was performed to investigate the enhanced $\mathrm{SO}_{2}$ capture ability of sorbents prepared by slurrying $\mathrm{Ca}(\mathrm{OH})_{2}$ with fly ash. To determine which fly ash components were involved in the reaction, sorbents were also prepared by slurrying $\mathrm{Ca}(\mathrm{OH})_{2}$ with silica, alumina, and iron oxide. The study examined the effects of the additive-to- $\mathrm{Ca}(\mathrm{OH})_{2}$ ratio (varied from 0.5 to 20 ), slurrying temperature (varied from 25 to $92^{\circ} \mathrm{C}$ ), and slurrying time (varied from 0 to $24 \mathrm{hrs}$ ) on sorbent performance. Sorbent performance was evaluated in a thermostated sand bed reactor through which a gas mixture of $500 \mathrm{ppm}$ of $\mathrm{SO}_{2}$ in humidified $\mathrm{N}_{2}$ was passed. The sorbent was exposed to the $\mathrm{SO}_{2}$-laden gas for $1 \mathrm{hr}$ and then removed from the reactor for an analysis of the $\mathrm{Ca}(\mathrm{OH})_{2}$ conversion to $\mathrm{CaSO}_{3}$. The $\mathrm{Ca}(\mathrm{OH})_{2}$ conversion was evaluated at relative humidities of $17 \%, 54 \%$, and $74 \%$, corresponding to approach temperatures of $38^{\circ} \mathrm{C}, 9.5^{\circ} \mathrm{C}$, and $4.7^{\circ} \mathrm{C}\left(68^{\circ} \mathrm{F}, 17^{\circ} \mathrm{F}\right.$, and $\left.8.5^{\circ} \mathrm{F}\right)$.

The results snowed that, at each slurrying temperature tested, there is a critical slurrying time for which $\mathrm{Ca}(\mathrm{OH})_{2}$ conversion is maximized. The time needed to reach this maximum shortens with increasing temperature. At $25^{\circ} \mathrm{C}$, a slurrying time of $16 \mathrm{hrs}$ was required to reach a maximum conversion of $40 \%$ with a sorbent prepared from a $16: 1$ ratio of fly ash to $\mathrm{Ca}(\mathrm{OH})_{2}$ and tested at a relative humidity of $54 \%$. At $92^{\circ} \mathrm{C}$, the time to reach the maximum conversion of $80 \%$ was reduced to $5 \mathrm{hrs}$ under the same conditions. Tests with four different fly ashes, added at a 4:1 mass ratio, showed that the sorbents prepared by $4 \mathrm{hrs}$ of slurrying at $65^{\circ} \mathrm{C}$ were more reactive than $\mathrm{Ca}(\mathrm{OH})_{2}$ alone at all relative humiditics. Variations in the conversion with type of fly ash could not be explained in terms of the $\mathrm{CaO}$ content of the ash. Increasing the ash-to- $\mathrm{Ca}(\mathrm{OH})_{2}$ ratio from $0.5: 1$ to $20: 1$ increased the conversion from $17 \%$ to $78 \%$. Tests with silica, alumina, and iron oxide revealed that silica was the component responsible for the enhanced reactivity. Tests at $54 \%$ relative humidity with sorbents prepared from silicic acid showed that the conversion was increased from $22 \%$ to $90 \%$ as the mass ratio was increased from $0.125: 1$ to $20: 1$. Comparison of the results achieved with silicic acid and fly ash clearly shows that the silicic acid is more effective in promoting the $\mathrm{Ca}(\mathrm{OH})_{2}$. The authors suggest that the silica in fly ash dissolves in the heated slurry and reacts with the $\mathrm{Ca}(\mathrm{OH})_{2}$ to form calcium silicate hydrates, which then precipitate onto the fly ash particles. In effect, this converts the inert fly ash particles into sites for $\mathrm{SO}_{2}$ capture. The authors present SEM photographs that support their 
hypothesis by showing the conversion of smooth fly ash particles into particles with welldeveloped surface areas.

Jozewicz, W., J. C. S. Chang, C. B. Sedman, and T. G. Brna. Characterization of Advanced Sorbents for $\mathrm{Dry} \mathrm{SO}_{2}$ Control, Reactivity of Solids, 6 (1988).

Bench-scale studies were performed to examine the ability of fly ash, sillica, and clay minerals to enhance the reactivity of $\mathrm{Ca}(\mathrm{OH})_{2}$ under conditions simulating duct injection. Samples of the enhanced sorbents were prepared by slurrying the additive with the $\mathrm{Ca}(\mathrm{OH})_{2}$ at $90^{\circ} \mathrm{C}\left(194^{\circ} \mathrm{F}\right)$ for $8 \mathrm{hr}$. The samples were then dried and tested for $\mathrm{SO}_{2}$ reactivity in a sand-bed reactor that contained $1 \mathrm{~g}$ of the sorbent mixed with $40 \mathrm{~g}$ of sand. The sand-bed reactor was operated at a temperature of $64^{\circ} \mathrm{C}\left(147^{\circ} \mathrm{F}\right)$ and $60 \%$ relative humidity, simulating an approach temperature of $10^{\circ} \mathrm{C}\left(18^{\circ} \mathrm{F}\right)$. The bed of sorbent and sand was exposed to a gas stream containing $500 \mathrm{ppm}$ of $\mathrm{SO}_{2}$ at these conditions for a period of 1 hr. Under these conditions, the conversion of the baseline $\mathrm{Ca}(\mathrm{OH})_{2}$ sorbent, with no additive, was $17 \%$. Fly ash-to- $\mathrm{Ca}(\mathrm{OH})_{2}$ weight ratios ranging from $1: 1$ to $10: 1$ were used in preparing the fly ash $/ \mathrm{Ca}(\mathrm{OH})_{2}$ sorbent. Various forms of sillica (diatomaceous earth, pumice, and tripoli) and various clay minerals (Bentonite, kaolinite, and montmorillonite) were screened for reactivity enhancement at a weight ratio of $1: 1$ with the $\mathrm{Ca}(\mathrm{OH})_{2}$. Samples prepared with diatomaceous earth and bentonite were then tested at various levels of the additive ranging from $5 \%$ to $100 \%$.

Sorbent conversion was found to increase with increasing fly ash-to-Ca(OH $)_{2}$ ratio. A contomitant increase in BET surface area was also noted. No significant difference in reactivity was noted between sorbents produced using an Eastern bituminous ash and those produced using a Texas lignite ash. The authors suggest that weight ratios above 2.3:1 may not be practical because of the effect of the increased mass loading on an electrostatic precipitator. At the 2.3:1 ratio, the improvement in reactivity was about $25 \%$, relative. Further improvement was achieved by the use of $\mathrm{NaOH}$ additive, which is known to speed the dissolution of fly ash. A maximum in conversion (55\%) was found at an addition level of 4 mole\%. The beneficial effect of the $\mathrm{NaOH}$ additive became more pronounced at higher humidity levels, with conversions as high as $76 \%$ at $80 \%$ relative humidity, corresponding to an approach temperature of $4^{\circ} \mathrm{C}\left(7^{\circ} \mathrm{F}\right)$. Diatomaceous earth was found to he the most effective additive tested, producing a maximum conversion of $84 \%$ at $60 \%$ relative humidity. The reactivity of sorbents produced from diatomaceous earth was found 
to be proportional to the BET surface area of the sorbent. The correlation with BET surface area was not evident with the clay minerals, possibly due to the unstable structure of the clay minerals upon contact with moisture. Bentonite and kaolinite yielded maximum conversions of $76 \%$ and $54 \%$ at $60 \%$ relative humidity. The peak conversion was achieved at a weight ratio of $1: 1$ with both the bentonite and the diatomaceous earth.

Jozewicz, W., C. Jorgensen, J.C.S. Chang, C. Sedman and T. Brna. Development and Pilot Plant Evaluation of Silica-Enhanced Lime Sorbents for Dry Flue Gas Desulfurization, JAPCA 38 (1988).

The authors successfully increased the effectiveness of $\mathrm{Ca}(\mathrm{OH})_{2}$ in several experiments. Excerpts and brief summaries from the article follow. The conversion of $\mathrm{Ca}(\mathrm{OH})_{2}$ with $\mathrm{SO}_{2}$ increased several-fold compared with $\mathrm{Ca}(\mathrm{OH})_{2}$ alone when $\mathrm{Ca}(\mathrm{OH})_{2}$ was slurried with fly ash first and later exposed to $\mathrm{SO}_{2}$ in a laboratory packed bed reactor. $\mathrm{Ca}(\mathrm{OH})_{2}$ enhancement increased with increased fly ash amount. Diatmaceous earths were very effective reactivity promoters of lime-based sorbents. Differential scanning calorimetry of the promoted sorbents revealed the formation of a new phase (calcium silicate hydrates) after hydration, which may be the basis for the observed improved $\mathrm{SO}_{2}$ capture. The reactivity of fly ash and its ability to combine with lime to form highly reactive species were found to increase with slurrying temperature. It is believed that the dissolution rate of silica (in fly ash) is the rate limiting step for the formation of the calcium silicate hydrates. The authors point out that some of the problems that the recycling of partially spent sorbent/fly ash mixtures poses for ESP operation (due to increased particulate loading) can be offset by increasing the $\mathrm{pH}$ of the slurry with $\mathrm{NaOH}$. The authors propose the following mechanism for the formation of calcium silicate:

$$
\mathrm{Ca}(\mathrm{OH})_{2}+\mathrm{SiO}_{2} \rightarrow \mathrm{CaSiO}_{3}+\mathrm{H}_{2} \mathrm{O}
$$

About three times as much fly ash was needed to generate this reaction than diatomaceous earth, probably due to the higher content of $\mathrm{SiO}_{2}$ in diatomaceous earth compared with fly ash. Pilot plant work demonstrated that injection of the dry sorbent at an approach to saturation of $20-30^{\circ} \mathrm{F}$ does not result in any powder handling problems in the duct or fabric filter. 
Jozewicz, W. and D.A. Kirchgessner. Activation and Reactivity of Novel Calcium-Based Sorbents for Dry $\mathrm{SO}_{2}$ Control in Boilers, Powder Technology, 58 (1989).

The LIMB process starts with hydrated lime $\left(\mathrm{Ca}(\mathrm{OH})_{2}\right)$, that decomposes to produce active quicklime ( $\mathrm{CaO}$ ), which, in turn simultaneously reacts with $\mathrm{SO}_{2}$ and is silitered. The authors cite this sintering as a primary cause of differences in reactivity of surbents. In prior research, the authors experimented with chemically modified calcitic sorbents. The reactivities of these sorbents were also apparently influenced by sintering rates. Prior work by the authors also demonstrated that the presence of $\mathrm{SO}_{2}$ during calcination (the conversion of $\mathrm{CaCO}_{3}$ to $\mathrm{CaO}$ ) allowed sorbents to retain higher pore volumes than in the absence of $\mathrm{SO}_{2}$. This article covers the investigation of the activation of surfactantmodified sorbents (calcination without $\mathrm{SO}_{2}$ present) and the characterization of the structure of sorbents as a function of particle size. The authors also studied the changes in the pore structure of $\mathrm{CaO}$ reacting to varying degrees of $\mathrm{SO}_{2}$ while simultaneously decoupling the effects of thermal sintering. The authors mention the work of Kirchgessner and Lorrain that identified a 1 wt.\% calcium lignosulfate mixture with $\mathrm{Ca}(\mathrm{OH})_{2}$ as optimal for $\mathrm{SO}_{2}$ capture. The calcium utilization of reacted sorbents was calculated based on atomic absorption spectrophotometry (for calcium) and ion chromatography (for sulfate). The authors state that some effect other than particle size decrease must be responsible for the enhanced reactivity of surfactant-modified sorbent. They state that the properties of nascent (freshly formed) $\mathrm{CaO}$ that determine its reactivity towards $\mathrm{SO}_{2}$ are surface area, porosity, pore size distribution, and resistance to sintering. Surfactant-modified sorbent has the capability to retard sintering.

Jozewicz, W., J. C. S. Chang, and C. B. Sedman. Bench-Scale Evaluation of Calcium Sorbents for Acid Gas Emission Control, Environ. Progress, 9 (1990).

A bench-scale, fixed-bed reactor system was used to study the effectiveness of $\mathrm{Ca}(\mathrm{OH})_{2}$ and silica-enhanced $\mathrm{Ca}(\mathrm{OH})_{2}$ as sorbents for the removal of $\mathrm{HCl}, \mathrm{SO}_{2}$, and $\mathrm{NO}$ from simulated flue gas. The electrically heated reactor was maintained at constant temperatures ranging from 54 to $177^{\circ} \mathrm{C}\left(130\right.$ to $350^{\circ} \mathrm{F}$ ) to study the effect of the approach to adiabatic saturation on sorbent reactivity. Because of the effect of $\mathrm{HCl}$ on $\mathrm{SO}_{2}$ removal, experiments were done with simulated flue gas containing $\mathrm{HCl}$ only $(1000 \mathrm{ppm}), \mathrm{SO}_{2}$ only $(500 \mathrm{ppm})$, and $\mathrm{HCl}$ $(1000 \mathrm{ppm})$ in combination with $\mathrm{SO} 2(500 \mathrm{ppm})$. Because the $\mathrm{SO}_{2}$-to-NO ratio has also been reported to affect $\mathrm{NO}$ removal, the reactivity with $\mathrm{NO}$ was evaluated with no $\mathrm{SO}_{2}$ 
present and with $\mathrm{SO}_{2}$ present in a 1:1 ratio with NO. The effects of five different additives ( $\mathrm{NaCl}, \mathrm{NaOH}, \mathrm{CaCl}_{2}, \mathrm{Mg}(\mathrm{OH})_{2}$, and $\mathrm{Na}_{2} \mathrm{HPO}_{4}$ ) on sorbent reactivity with $\mathrm{SO}_{2}$ and $\mathrm{NO}$ were also evaluated. The additives were slurried with the $\mathrm{Ca}(\mathrm{OH})_{2}$ to produce a product containing 10 mole percent of the additive. Each of the additive-modified hydrates was evaluated in the fixed-bed reactor system at an approach temperature of $35^{\circ} \mathrm{C}$ with $400 \mathrm{ppm}$ $\mathrm{SO}_{2}$ and $400 \mathrm{ppm} \mathrm{N}$.

The reactivity of the $\mathrm{Ca}(\mathrm{OH})_{2}$ with $\mathrm{HCl}$ was generally an order of magnitude greater than the reactivity with $\mathrm{SO}_{2}$, which was generally an order of magnitude greater than the reactivity with $\mathrm{NO}$. The $\mathrm{Ca}(\mathrm{OH})_{2}$ reactivity with $\mathrm{HCl}$ decreased gradually with increasing approach to saturation, while the reactivity with $\mathrm{SO}_{2}$ dropped more sharply and then leveled off at approach temperatures above about $35^{\circ} \mathrm{C}\left(63^{\circ} \mathrm{F}\right)$. The reactivity with NO appeared to have a maximum value at a temperature of about $94^{\circ} \mathrm{C}\left(201^{\circ} \mathrm{F}\right)$. The reactivity with $\mathrm{SO}_{2}$ was somewhat enhanced by the presence of $\mathrm{HCl}$ for approach temperatures less than about $60^{\circ} \mathrm{C}\left(108^{\circ} \mathrm{F}\right)$. The authors attribute this to promotion of the $\mathrm{Ca}(\mathrm{OH})_{2}-\mathrm{SO}_{2}$ reaction by the diliquescent product of the $\mathrm{Ca}(\mathrm{OH})_{2}-\mathrm{HCl}$ reaction. The presence of $\mathrm{SO}_{2}$ was found to significantly improve NO removal. The authors state that this is consistent with the findings of other investigators, but they do not explain the mechanism involved. The optimurn temperature for simultaneous removal of $\mathrm{SO}_{2}$ and $\mathrm{NO}$ was found to be about $90^{\circ} \mathrm{C}\left(194^{\circ} \mathrm{F}\right)$. The silica-enhanced hydrates were generally found to be more reactive toward $\mathrm{HCl}$ but less reactive toward $\mathrm{SO}_{2}$ than the conventional hydrates. The authors speculated that the $\mathrm{CaCl}_{2}$ reaction product may block the active sites on the surface of the silica-enhanced hydrates, rendering these sorbents ineffective for $\mathrm{SO}_{2}$ removal in the presence of $\mathrm{HCl}$. Of the additives tested, $\mathrm{Na}_{2} \mathrm{HPO}_{4}$ and $\mathrm{Mg}(\mathrm{OH})_{2}$ were found to be most effective in promoting $\mathrm{SO}_{2}$ and $\mathrm{NO}$ removal.

Kirchgessner, D. A. and W. Jozewicz. Structural Changes in Surfactant-Modified Sorbents During Furnace Injection, AIChE Journal, 35 (1989).

This laboratory study documents the ability of calcium lignosulfonate additive to inhibit the sintering of calcium hydroxide during furnace injection. Samples of a lignosulfonatemodified hydrate and a baseline hydrate were prepared by hydrating the same $\mathrm{CaO}$ under the same conditions, the only difference being that calcium lignosulfonate was added to the water of hydration when preparing the modified hydrate. The modified hydrate contained about 1 wt\% lignosulfonate additive, the amount shown previously to be optimal for $\mathrm{SO}_{2}$ 
capture. Sintering of the baseline and modified hydrates was studied in a flow reactor as a function of temperature and residence time. The sintering process was tracked by characterizing samples taken from the reactor after various residence times, ranging from 0.6 to $2.0 \mathrm{sec}$, at a constant temperature of either 700,800 , or $1000^{\circ} \mathrm{C}$. The samples were characterized in terms of their BET surface area, porosity, pore volume, median pore size, and extent of dehydration.

The lignosulfonate-modified hydrate was found to retain a higher surface area, porosity, and pore volume than the baseline hydrate at all residence times. This was true at all three temperatures investigated. The modified hydrate exhibited smaller median pore sizes and a greater degree of dehydration at all residence times for all three temperatures. The smaller median pore size, along with larger surface area, porosity, and pore volume, strongly suggest a lower rate of sintering in the modified hydrate. The authors point out that median pore size increases as sintering proceeds, because the smallest pores collapse first. The authors suggest that the reduced sintering may be related to the increased dehydration, because previous studies have shown that water catalyzes the sintering process. The authors also speculate that the presence of the large lignosulfonate molecules at the grain boundaries and surfaces of the $\mathrm{Ca}(\mathrm{OH})_{2}$ may reduce grain boundary mobility, which has been shown to reduce the rate of sintering.

Kirchgessner, D. A. and W. Jozewicz. Enhancement of Reactivity in Surfactant-Modified Sorbents for Sulfur Dioxide Control, Ind. Eng. Chem. Res., 28 (1989).

This study compares the characteristics of sulfated calcines produced from calcium hydroxide $\left[\mathrm{Ca}(\mathrm{OH})_{2}\right]$ and lignosulfonate-modified $\mathrm{Ca}(\mathrm{OH})_{2}$ in a flow reactor system under conditions simulating furnace injection. The primary objective is to clarify the relative roles of particle size reduction, accelerated dehydration rate, and retarded sintering rate in enhancing the $\mathrm{SO}_{2}$ capture by the lignosulfonate-modified $\mathrm{Ca}(\mathrm{OH})_{2}$. To examine the particle size effects, various size fractions of the baseline and modified calcines were compared with respect to their degree of sulfation as a function of residence time. The effect of accelerated dehydration was examined by comparing the degrees of sulfation of both baseline and modified sorbents with their precalcined (dehydrated) counterparts. The effect of retarded sintering was investigated by comparing the two calcines with respect to their changes in specific surface area, pore size, and pore volume with increasing degree of sulfation. The study also examined the effect of increasing $\mathrm{SO}_{2}$ concentration on the 
median pore size and pore size distribution of the sulfated calcines to determine if the presence of $\mathrm{SO}_{2}$ has a reinforcing effect on the ability of the lignosulfonate to retard sintering. The flow reactor used in this study is the same as that used previously to study sintering of these sorbents in the absence of $\mathrm{SO}_{2}$ as described in Reference No. 34 .

For each particle size fraction at each residence time, the degree of sulfation was found to be greater with the modified sorbent. Thus, the authors concluded that reduced particle size is not a prerequisite for enhanced reactivity in the modified sorbent. However, any reduction in particle size that may occur is an addtional benefit, since sulfation was observed to increase with decreasing particle size. The dehydrated calcine produced from the modified hydrate showed the same advantage over the dehydrated calcine produced from the baseline hydrate as did the modified hydrate over the baseline hydrate. Therefore, the authors conclude that the enhanced reactivity of the modified hydrate is not dependent on its more rapid dehydration. At a given degree of sulfation, the modified calcine was found to possess a greater pore volume than the baseline calcine. This was true at all levels of sulfation studied, which corresponded to conversions of $4 \%$ to $22 \%$. The modified calcine also possessed a higher specific surface area at conversions up to about $15 \%$. At higher conversions, there was essentially no difference in the specific surface areas of the two calcines. The authors suggest that the surface areas of the two calcines tend to converge at higher conversions because most of the surface area is in smaller pores, which are the first ones to be plugged by the sulfate. Plots of the pore size distribution as a function of $\mathrm{SO}_{2}$ level show that the presence of low levels of $\mathrm{SO}_{2}$ actually causes an increase in the volume of pores larger than about 125 , suggesting delayed sintering. At higher $\mathrm{SO}_{2}$ levels, the effects of pore plugging dominate, and there is a reduction in pore volume at all pore sizes. However, the reduction decreases with increasing pore size. These results do not offer strong evidence for a reinforcing effect between the lignosulfonate and the $\mathrm{SO}_{2}$ in retarding the rate of sintering.

Kirchgessner, D. A. and J. M. Lorrain. Lignosulfonate-Modified Calcium Hydroxide for Sulfur Dioxide Control, Ind. Eng. Chem. Res., 26 (1987).

Laboratory-scale sulfation tests were run in an isothermal flow reactor to determine the ability of calcium lignosulfonate to promote $\mathrm{SO}_{2}$ capture by $\mathrm{Ca}(\mathrm{OH})_{2}$. The lignosulfonate was incorporated into the $\mathrm{Ca}(\mathrm{OH})_{2}$ by dissolution in the water used to hydrate the $\mathrm{CaO}$. The amount of added lignosulfonate was varied to produce concentrations of $0.5,1.0,1.5$, 
2.0,3.0, and $4.0 \%$ on a mass basis of the additive in the dry $\mathrm{Ca}(\mathrm{OH})_{2}$ product. Each of these mixtures was injected into the flow reactor with a feed gas containing $3000 \mathrm{ppm} \mathrm{SO}$ at a temperature of $1000^{\circ} \mathrm{C}$ and a sorbent resicience time of $1 \mathrm{sec}$. Conversion of the sorbent to $\mathrm{CaSO}_{4}$ was determined by analysis of samples collected in a cyclone and filter after cooling of the gas.

The lignosulfonate promoted the sorbent conversion at all levels of addition, with a concentration of $1.5 \%$ being optimal. At the optimal addition rate, a $20 \%$ relative increase in calcium utilization was achieved, corresponding to an increase in $\mathrm{SO}_{2}$ capture from $50 \%$ to $60 \%$ at a $\mathrm{Ca} / \mathrm{S}$ ratio of $2: 1$. Size analyses of the modified and baseline sorbents determined by using a cascade impactor in the reactor feed stream showed a dramatic reduction in particle size with increasing lignosulfonate content. The mass median diameter was reduced from $12 \mu \mathrm{m}$ for the baseline $\mathrm{Ca}(\mathrm{OH})_{2}$ to $3 \mu \mathrm{m}$ for se $\mathrm{Ca}(\mathrm{OH})_{2}$ containing $3 \%$ lignosulfonate. The authors suggest that the hydrophobic portion of the lignosulfonate molecule prevents hydrogen bonding between adsorbed water layers on the individual hydrate particles, resulting in less agglomeration of the hydrate crystals. This effect was much less pronounced in size analyses performed using a Sedigraph, because this technique uses a dispersant that deagglomerates the particles prior to analysis. However, some size reduction was still evident in the Sedigraph results, suggesting the lignosulfonate may have also reduced the fundamental crystal size of the $\mathrm{Ca}(\mathrm{OH})_{2}$. With the $\mathrm{Ca}(\mathrm{OH})_{2}$ containing 3\% lignosulfonate, the Sedigraph gave results similar to those obtained with the cascade impactor, suggesting that this level of lignosulfonate addition was sufficient to almost completely deagglomerate the sorbent into its component crystals. To explain the optimum in calcium conversion at $1.5 \%$, the authors suggest that higher levels of lignosulfonate addition might hinder access of the $\mathrm{SO}_{2}$ molecule to reactive $\mathrm{CaO}$ sites.

Landham, E. C., K. M. Cushing, R. F. Altman, B. D. Larson, and J. B. Doyle. Effects of Spray Dryer Effluent on the Performance of the Laramie River Unit 3 ESF, Presented at the Ninth Particulate Control Symposium, Williamsburg, VA, October 15-18, 1991.

The performance of the Laramie River spray dryer and ESP were evaluated, and the effect of the spray dryer on ESP performance was evaluated based on ESP modeling using the conditions at the spray dryer inlet. Unit 3 is a 586-MWe Babcock \& Wilcox boiler fired with a Wyoming subbituminous coal containing $0.3 \%$ sulfur and $0.01 \%$ chlorine. The unit is equipped with four parallel spray dryer/ESP trains. During testing, the spray dryers 
operated at a $35^{\circ} \mathrm{F}$ approach to saturation and a nominal reagent ratio of $1.4: 1$, providing an average $\mathrm{SO}_{2}$ removal of $73 \%$. The ESPs have five electrical fields, providing a design SCA of $678 \mathrm{ft}^{2} / \mathrm{kacfm}$, with a plate spacing of $12 \mathrm{in.}$ During testing, the ESPs were operated with only four fields in service, providing an SCA of $470 \mathrm{ft}^{2} / \mathrm{kacfm}$, with a gas velocity of 4.5 $\mathrm{ft} / \mathrm{sec}$.

Comparison of the measurements made at the spray dryer inlet and the ESP inlet reveal that the effect of the spray dryer is to increase the particulate mass loading by a factor of 3.7, while reducing the gas temperature from 300 to $160^{\circ} \mathrm{F}$. The reduction in gas temperature increases the effective SCA by about $20 \%$, while reducing gas velocity by the same percentage. The concentration of $\mathrm{SO}_{3}$ in the flue gas was essentially negligible at both the spray dryer inlet and the ESP inlet. However, in situ resistivity was greatly reduced, from $3.7 \times 10^{11} \mathrm{ohm}-\mathrm{cm}$ to $5.2 \times 10^{9} \mathrm{ohm}-\mathrm{cm}$, by the cooling and increased moisture levels contributed by the spray dryer. Laboratory measurements indicated an even lower resistivity value of 4 to $6 \times 10^{7} \mathrm{ohm}-\mathrm{cm}$ under spray dryer conditions. The authors point out that, if the laboratory measurement were correct, low-resistivity reentrainment could be a source of ESP performance degradation.

During the tests, a degradation in ESP performance with time was noted and found to be correlated with an increase in the lime slurry feed rate. The model predicted that ESP performance should have improved with increased slurry feed, as a result of the lower flue gas temperatures and the associated beneficial effects. This discrepancy may suggest the presence of a non-ideal effect, such as low-resistivity reentrainment.

Livengood, C. D., H. S. Huang, J. W. Allen, and P. S. Farber. Combined $\mathrm{SO}_{x} / \mathrm{NO}_{\mathbf{x}}$ Removal in a High-Sulfur Spray-Dryer/Fabric-Filter System, Presented at the First Combined FGD and Dry $\mathrm{SO}_{2}$ Control Symposium, St. Louis, MO, October 25-28, 1988 (NTIS DE89007266).

Field tests were performed to examine the effects of approach temperature and $\mathrm{NaOH}$ addition on $\mathrm{SO}_{x}$ and $\mathrm{NO}_{x}$ removal in a spray dryer/baghouse system. The system consisted of a Niro rotary atomizing spray dryer followed by a Joy Manufacturing Company fourcompartment, pulse-jet baghouse. The system was installed on the principal steamgenerating boiler at Argonne National Laboratories, which was fired with an Illinois coal containing 3.5\% sulfur. At normal approach temperatures of 20 to $40^{\circ} \mathrm{F}$ and a baghouse 
air-to-cloth ratio of $3 \mathrm{ft} / \mathrm{min}, \mathrm{SO}_{2}$ removal across the entire system was 67 to $71 \%$, and $\mathrm{NO}_{\text {× }}$ removal was less than $5 \%$, without addition of $\mathrm{NaOH}$. As the approach temperature was gradually increased to $85^{\circ} \mathrm{F}, \mathrm{SO}_{2}$ removal steadily declined to about $60 \%$, and $\mathrm{NO}_{\mathrm{x}}$ removal steadily increased to about $18 \%$. The NO removal actually reached about $24 \%$, but overall $\mathrm{NO}_{\mathrm{x}}$ removal was lower due to the formation of $\mathrm{NO}_{2}$ across the fabric filter. The addition of $5 \mathrm{wt} \% \mathrm{NaOH}$ to the lime slurry improved $\mathrm{NO}_{x}$ removal, and the degree of improvement increased with increasing approach temperature over the range of 55 to $75^{\circ} \mathrm{F}$. Over $30 \%$ removal was achieved with the $\mathrm{NaOH}$ at a $75^{\circ} \mathrm{F}$ approach.

As the approach temperature was increased, baghouse pressure drop decreased and dustcake porosity increased. This resulted in a longer time interval between the baghouse cleaning cycles, which were automatically controlled to maintain a pressure drop of $3.5 \mathrm{in}$. $\mathrm{H}_{2} \mathrm{O}$. This allowed the buildup of thicker dustcakes, which removed more of the $\mathrm{NO}_{\mathbf{x}}$. At a $85^{\circ} \mathrm{F}$ approach, the time between filter cleaning cycles increased from a baseline value of 3 hrs without $\mathrm{NaOH}$ to $6 \mathrm{hrs}$ with $5 \mathrm{wt} \% \mathrm{NaOH}$ and to $8 \mathrm{hrs}$ with $10 \mathrm{wt} \% \mathrm{NaOH}$. The $\mathrm{NaOH}$ produced further changes in the dustcake porosity and surface area beyond those seen with increased approach temperature. At a $85^{\circ} \mathrm{F}$ approach, the addition of $5 \mathrm{wt} \% \mathrm{NaOH}$ increased the specific surface area of the dustcake from 24.4 to $26.5 \mathrm{~m}^{2} / \mathrm{g}$ and increased the volume median pore size from 4.1 to $7.8 \mu \mathrm{m}$. At a $35^{\circ} \mathrm{F}$ approach, the specific surface area and median pore size, without $\mathrm{NaOH}$ addition, were $15.9 \mathrm{~m}^{2} / \mathrm{g}$ and $3.4 \mu \mathrm{m}$.

Mamantov, G. and E. L. Wehry. Chemical Reactivity of Polycyclic Organic Compounds Adsorbed on Coal Fly Ash and Related Solid Surfaces. Progress Report for May 1985 to April 1986, submitted by the University of Tennessee to the U.S. Department of Energy, April 1986 (NTIS DE86-010293).

This is the annual progress report on a DOE contract with the University of Tennesseee to study the photodecomposition of polycyclic aromatic hydrocarbons (PAHs) adsorbed on the surface of fly ash particles. Photochemical reactivity studies were done with five PAHs (pyrene, benzo(a)pyrene, anthracene, benz(a)anthracene, and phenanthrene) adsorbed on 8 different fly ashes, silica gel, alumina, graphite, and glass. Three of the ashes showed no photochemical reactivity with any of the PAHs, and three other ashes showed moderate reactivity with only one or two of the PAHs. One ash showed moderate reactivity with three of the PAHs and extensive reactivity with one PAH. One ash showed moderate reactivity with two PAHs and extensive reactivity with three PAHs. The general trend was 
for ashes that are dark in color to be most effective in stabilizing the PAHs against photodecomposition. The silica, alumina, and glass, which were all light in color, showed extensive reactivity. Graphite, which was dark in color, showed no reactivity for any of the PAHs.

The relationship between PAH stability and ash color is being investigated further by fractionating ash samples into subsamples cortaining high leveis of carbon and iron, which are believed to be primarily responsible for the dark color. Studies with these ash fractions will help determine if the apparent effect of color is really an effect of chemical composition.

Milne, C. R., G. D. Silcox, D. W. Pershing, and D. A. Kirchgessner. High-Temperature, Short-Time Sulfation of Calcium-Based Sorbents. 1. Theoretical Sulfation Model, Ind. Eng. Chem. Res., 29 (1990).

This paper describes a model of $\mathrm{CaO}$ sulfation, in which the $\mathrm{CaO}$ particle is treated as a large number of overlapping grains. The sulfation process is modeled in terms of three mechanisms: (1) $\mathrm{SO}_{2}$ diffusion from the bulk gas, (2) diffusion within the pores of the calcine, and (3) diffusion through the product layer. Sulfation of exposed $\mathrm{CaO}$ is assumed to be instantaneous, limited only by gas-phase diffusion, until a monolayer of $\mathrm{CaSO}_{4}$ covers the surface. Subsequent to monolayer coverage, the sulfation rate is controlled by combined pore diffusion and product layer diffusion. The loss in porosity with sulfation is modeled by allowing the overlapping grains to grow in accordance with the molar volumes of the $\mathrm{CaO}$ and $\mathrm{CaSO}_{4}$ product. After the porosity is reduced to $2 \%$, it is assumed that the porosity remains at that value because of particle swelling. Particle swelling occurs because the molar volume of the $\mathrm{CaSO}_{4}$ is greater than that of the $\mathrm{CaO}$ that it replaces. The latter stages of sulfation are controlled entirely by product layer diffusion. The product layer diffusivity used in the model was determined from sulfation data for whi h the reaction was limited entirely by product layer diffusion. The grain overlap reduces the rate of product layer diffusion by accounting for limited surface area for diffusion relative to nonoverlapping grains. This results in the prediction of a lesser degree of sulfation than that predicted by the non-overlapping grain model, which was developed previously and described in earlier publications. The non-overlapping grain model is shown to be inadequate for explaining the measured porosities of calcines with very low surface areas. 
The overlapping grain model was used to predict curves of sulfation versus time for initial $\mathrm{SO}_{2}$ concentrations of 120 to $7000 \mathrm{ppm}$ and temperatures of 84.5 to $1000^{\circ} \mathrm{C}$. These curves did a reasonably good job of fitting the previously reported sulfation data of Borgwardt and Bruce for all conditions, except the lowest $\mathrm{SO}_{2}$ concentration, where the model underpredicted the sulfation. The authors stress that the model agrees well with the data obtained at all residence times, and not just during the latter stages when product layer diffusion controls. This is an important point because, in deriving the product layer diffusivity, the model was, in effect, fit to the data obtained at long residence times. The authors also acknowledge that the model development is based on data obtained at temperatures that are low relative to those used in furnace injection.

Milne, C. R., G. D. Silcox, D. W. Pershing, and D. A. Kirchgessner. High-Temperature, Short-Time Sulfation of Calcium-Based Sorbents. 2. Experimental Data and Theoretical Model Predictions, Ind. Eng. Chem. Res., 29 (1990).

The sulfation of $\mathrm{CaCO}_{3}$ and $\mathrm{Ca}(\mathrm{OH})_{2}$ derived from the same parent $\mathrm{CaCO}_{3}$ was studied experimentally in a laboratory-scale, dispersed-phase, isothermal reactor, and the results were interpreted in terms of the overlapping grain model described in Reference 8A. The reactor was a cast refractory tube with an inside diameter of 6 in. and a reaction zone length of about $6 \mathrm{ft}$. The reactor was surrounded with back-fired auxiliary heating channels that maintained the reactor under isothermal conditions $\left( \pm 20^{\circ} \mathrm{F}\right)$. Natural gas, doped with $\mathrm{SO}_{2}$, was burned at a rate of $30 \mathrm{~kW}$ to provide a gas composition of $4.3 \% \mathrm{O}_{2}, 7.5 \% \mathrm{CO}_{2}, 14.0 \%$ $\mathrm{H}_{2} \mathrm{O}, 2000$ ppm $\mathrm{SO}_{2}$, and the balance $\mathrm{N}_{2}$. Sorbents were injected through a water-cooled lance into a venturi section designed to ensure good mixing of the sorbent throughout the flue gas. Injection rates for the carbonate and hydrate were selected to produce a $\mathrm{Ca} / \mathrm{S}$ ratio of 2:1. Gas samples for continuous $\mathrm{SO}_{2}$ analysis were extracted at various points along the reactor, corresponding to reaction times of 0.04 to $0.55 \mathrm{sec}$, using a high-velocity, watercooled, phase-discrimination probe designed to quickly quench the sulfation reaction and minimize $\mathrm{SO}_{2}$ capture in the probe. This made it possible to obtain data on the extent of sulfation as a function of residence time with the reactor operated isothermally at various temperatures ranging from 1830 to $2150^{\circ} \mathrm{F}$. An evaluation of the effect of sorbent type (carbonate versus hydrate) was made possible by the direct comparison of the $\mathrm{CaCO}_{3}$ with the $\mathrm{Ca}(\mathrm{OH})_{2}$ derived from it. 
The experimental results confirmed that, even when derived from the same parent limestone, hydrated lime is clearly superior to the carbonate sorbent with respect to $\mathrm{SO}_{2}$ capture. The difference primarily results from a dramatic difference in the so-called "prompt" capture that occurs within the first $0.03 \mathrm{sec}$ of reaction time. Data obtained with narrow size cuts of the two sorbents shows that the difference in prompt capture is primarily associated with the difference in particle size distribution between the two sorbent types. The model suggests that the large decrease in prompt capture with increasing particle size results from delayed calcination and pore diffusion effects. On the basis of the data, the optimum isothermal injection temperature appears to be about $2060^{\circ} \mathrm{F}$. The model predicts a lower optimum of $1950^{\circ} \mathrm{F}$, which the authors attribute to an overestimate of the retarding effect of the equilibrium backpressure of $\mathrm{SO}_{2}$. Modeling of the effect of gas-sorbent mixing revealed that mixing delays of up to $0.2 \mathrm{sec}$ were actually beneficial in that they allowed $\mathrm{SO}_{2}$ penetration into the particle prior to the onset of sintering. The authors speculate that this mixing effect, together with the direct reaction of $\mathrm{SO}_{2}$ with $\mathrm{Ca}(\mathrm{OH})_{2}$ (without calcination), may be responsible for the model's general tendency to underpredict the prompt capture. The model predicts that pore diffusion, product-layer diffusion, and sintering are the limiting factors in $\mathrm{SO}_{2}$ capture under utility boiler conditions.

Moore, D. and M. Pilat. Pilot-Scale $\mathrm{HCl}$ Control by Dry Alkaline Injection for Emissions from Refuse Incinerators, EPA/600/9-89/040 (1988).

The authors begin with a brief review of the calcination reaction for sodium bicarbonate upon its injection into a $250^{\circ} \mathrm{F}$ gas stream and its subsequent reaction with $\mathrm{HCl}$.

$2 \mathrm{NaHCO}_{3} \rightarrow \mathrm{Na}_{2} \mathrm{CO}_{3}+\mathrm{H}_{2} \mathrm{O}+\mathrm{CO}_{2}$

Although chemically identical to mined sodium carbonate, the sodium carbonate sorbent formed through this decomposition reaction is much more porous, owing to the "popcorn" effect induced by rapidly evolving hydrogen gas. The sodium carbonate then reacts as follows:

$2 \mathrm{HCl}+\mathrm{NaCO}_{3} \rightarrow 2 \mathrm{NaCl}+\mathrm{H}_{2} \mathrm{O}+\mathrm{CO}$

In their pilot-scale studies, the authors determined that the majority of $\mathrm{HCl}$ is removed turing the first second of exposure in their test reactor. With sorbent-to-gas stoichiometric 
ratios of 1.8:1, the authors predict $95 \%$ removal of $\mathrm{HCl}$ after 4 seconds reaction time. Although the authors performed some tests with lime as a sorbent, difficulties during testing rendered the data meaningless.

Moran, D. L., M. Rostam-Abadi, R. D. Harvey, R. R. Frost, and G. C. Sresty. Sulfur Dioxide Sorption Reactivity of Hydrated Lime: Effect of Hydration Method, Am. Chem. Soc. Div. Fuel Chem. Preprints, 32 (1987).

The effect of various hydration techniques on the reactivity of $\mathrm{Ca}(\mathrm{OH})_{2}$ toward $\mathrm{SO}_{2}$ was examined. Techniques tested were: (1) dry atmospheric hydration using twice the stoichiometric water requirement, (2) wet atmospheric hydration using five times the stoichiometric water requirement, (3) hydration at elevated pressures, (4) hydration with steam, and (5) hydration with methanol additive. All of the techniques were applied to $\mathrm{CaO}$ prepared by calcining the same two limestones under the same conditions in nitrogen gas at $850^{\circ} \mathrm{C}$. The $\mathrm{Ca}(\mathrm{OH})_{2}$ prepared by the various techniques was dispersed on quartz wool, calcined at $850^{\circ} \mathrm{C}$, and then exposed to a simulated flue gas mixture containing 5000 $\mathrm{ppm} \mathrm{SO}_{2}$. The sample holder was suspended from a microbalance that allowed the weight gain from sulfation to be recorded as a function of time.

The $\mathrm{Ca}(\mathrm{OH})_{2}$ produced with methanol additive was found to be most reactive with $\mathrm{SO}_{2}$ and to possess the largest specific surface area. Surface area and reactivity increased with increasing methanol concentrations up to $50 \%$, which was the maximum concentration studied. There was a linear correlation between the surface area and the calcium utilization (i.e., reactivity). The $\mathrm{Ca}(\mathrm{OH})_{2}$ produced by pressure hydration was somewhat more reactive than the $\mathrm{Ca}(\mathrm{OH})_{2}$ produced by the other techniques without additives, but possessed a somewhat lower surface area. There did not appear to be a significant difference between the $\mathrm{Ca}(\mathrm{OH})_{2}$ produced with twice the stoichiometric water requirement and that produced with five times the requirement. The lowest surface area was produced by steam hydration, which also produced a calcium utilization that was lower than all but one of the other samples. 
Newton, G. H., S. L. Chen, and J. C. Kramlich. Role of Porosity Loss in Limiting $\mathrm{SO}_{2}$ Capture by Calcium Based Sorbents, AIChE Journal, 35 (1989).

The role of porosity loss in limiting high-temperature $\mathrm{SO}_{2}$ capture by $\mathrm{CaCO}_{3}$ and $\mathrm{Ca}(\mathrm{OH})_{2}$ was investigated in an isothermal, dispersed-phase reactor fired with $\mathrm{SO}_{2}$-doped $\mathrm{CO}$. The use of $\mathrm{CO}$ as the fuel allowed pore size distributions to be determined for calcines sampled from a combustion environment without the presence of water vapor in the sampling system. The presence of water vapor is known to alter the calcine's structure during sampling. The inlet $\mathrm{SO}_{2}$ concentration was $1400 \mathrm{ppm}$, and the sorbent injection rate was adjusted to yield a $\mathrm{Ca} / \mathrm{S}$ ratio of 2:1. Three different sorbents were tested: Linwood $\mathrm{Ca}(\mathrm{OH})_{2}$, Mississippl $\mathrm{Ca}(\mathrm{OH})_{2}$, and Vicron $\mathrm{CaCO}_{3}$. Tests were run at reactor temperatures of 970,1180 , and $1270^{\circ} \mathrm{C}$. Quenched solids samples and $\mathrm{SO}_{2}$ measurements were obtained at four points along the reactor, corresponding to residence times of 30 to $400 \mathrm{msec}$. This allowed the $\mathrm{SO}_{2}$ capture, porosity, pore size, and surface area to be determined as a function of residence time at each temperature studied.

Average pore size was found to be independent of residence time over the range of 30 to $400 \mathrm{~ms}$. This was true at all three temperatures studied. However, the average pore size was found to increase with increasing temperature at all residence times. This variation with temperature, coupled with the insensitivity to residence times beyond $30 \mathrm{msec}$, suggests that the sintering responsible for differences in pore size must occur within the first $30 \mathrm{msec}$ of residence time. At a temperature of $1180^{\circ} \mathrm{C}$, the porosity of the Linwood sorbent remained constant at a value of $20 \%$ over the first $100 \mathrm{msec}$ of residence time. In the presence of $\mathrm{SO}_{2}$, the porosity then declined to about $10 \%$ at a residence time of 350 msec. In the absence of $\mathrm{SO}_{2}$, no decline in porosity was noted at the longer residence times, suggesting that the decline resulted from pore plugging associated with sulfation. The porosities achieved in the CO-fired reactor without $\mathrm{SO}_{2}$ present were lower than those produced by calcining in an inert atmosphere under the same conditions, suggesting that $\mathrm{CO}_{2}$-activated sintering was responsible for some loss in porosity. Of the three sorbents tested, the Vicron $\mathrm{CaCO}_{3}$ exhibited the greatest loss in porosity and the lowest $\mathrm{SO}_{2}$ capture. The Mississippi $\mathrm{Ca}(\mathrm{OH})_{2}$ exhibited a greater porosity loss and lower $\mathrm{SO}_{2}$ capture than the Linwood $\mathrm{Ca}(\mathrm{OH})_{2}$. 
Peterson, J. R. and G. T. Rochelle. Aqueous Reaction of Fly Ash and $\mathrm{Ca}(\mathrm{OH})_{2}$ to Produce Calcium Silicate Absorbent for Flue Gas Desulfurization, Environ. Scl. Technol., 22 (1988).

Prevlous studies have shown that an improved sorbent for flue gas desulfurization (FGD) can be produced by reacting fly ash and $\mathrm{Ca}(\mathrm{OH})_{2}$ in a heated aqueous slurry. At temperatures of 65 to $85^{\circ} \mathrm{C}$, the sillica in the fly ash is slowly dissolved intis the water where it reacts with the $\mathrm{Ca}(\mathrm{OH})_{2}$ to form a calcium silicate absorbent with entanced effectiveness for capture of $\mathrm{SO}_{2}$. Because of the low dissolution rate of the sillica, this process normally requires a relatively long reaction time (ca $12 \mathrm{hr}$ ), a high temperature (ca $90^{\circ} \mathrm{C}$ ), and a high ratio of fly ash to $\mathrm{Ca}(\mathrm{OH})_{2}$ (ca $3: 1$ ). This study seeks to minimize these obstacles by using an additive, $\mathrm{NaOH}$, to increase the rate of silica dissolution. To investigate the effect of the $\mathrm{NaOH}$ additive, sorbents were prepared with $\mathrm{NaOH}$ concentrations of $0.0,0.08$, and $0.25 \mathrm{M}$ in the slurry. The fly ash to $\mathrm{Ca}(\mathrm{OH})_{2}$ mass ratio was $4: 1$, and the slurry was allowed to react for a period of $12 \mathrm{hr}$ at a temperature of $85^{\circ} \mathrm{C}$. The progress of the reaction was followed by monitoring the concentrations of calcium and silicon in solution by atomic absorption spectrophotometry (AAS). The reactivity of the calcium sillicate product toward $\mathrm{SO}_{2}$ was evaluated in a packed-bed reactor system.

The solids reactivity experiments showed that there was an optimum $\mathrm{NaOH}$ concentration in the slurry. The addition of $0.08 \mathrm{M} \mathrm{NaOH}$ increased the conversion of $\mathrm{Ca}(\mathrm{OH})_{2}$ to $\mathrm{CaSO}_{3}$ in the packed bed reactor from 41 to $52 \%$, while the addition of $0.25 \mathrm{M} \mathrm{NaOH}$ reduced the conversion from 41 to $36 \%$. The AAS analyses of the slurry samples showed that the addition of $0.08 \mathrm{M} \mathrm{NaOH}$ increased the solubility of the silica resulting in greater formation of the calcium silicate sorbent. The addition of $0.25 \mathrm{M} \mathrm{NaOH}$ also increased the silica solubility, but greatly reduced the concentration of dissolved calcium, resulting in a product with low calcium content and low reactivity toward $\mathrm{SO}_{2}$. This tradeoff between increased silica dissolution and reduced concentration of dissolved calcium leads to the optimum in $\mathrm{NaOH}$ concentration in the slurry. The product sorbent appears to be most reactive when formed in the presence of 10 to $100 \mathrm{ppm}$ dissolved calcium. This indicates that there is an optimum ratio of calcium to silica in the product sorbent, and this ratio can be controlled by adjusting the $\mathrm{NaOH}$ additive concentration. 
Pontius, D. H. and G. H. Marchant, Jr. Laboratory and Field Studies of Electrical Reentrainment Associated with Calcium-Based Sorbents, Presented at the Ninth Particulate Control Symposium, Williamsburg, VA, October 15-18, 1991.

The theories of electrical reentrainment and electrostatic decrepitation of agglomerates are developed, and recent laboratory and field studies relating to these phenomena are discussed. The theoretical criterion for electrical reentrainment is derived from a macroscopic balance of the electrostatic and cohesive forces acting on a dust layer. The theoretical criterion for decrepitation is derived in a manner analogous to Rayleigh's derivation for the disintegration of charged droplets in an electric field. The cohesive force is expressed in terms of the tensile strength of the agglomerate, in a manner analogous to the surface tension of a liquid droplet. The results of a recent field test of the E-SO, process are shown to provide evidence of electrical reentrainment and decrepitation. A significant degree of reentrainment is suggested by measured ESP fractional efficiencies that are considerably lower than predicted. The electrical resistivity measured under E$\mathrm{SO}_{x}$ conditions is shown to be low enough to suggest the possibility of electrical reentrainment. Evidence of electrostatic decrepitation is provided by size-dependent chemical compositions for inlet and outlet ash samples, which show much higher calciumto-silicon and calcium-to-iron ratios in the outlet samples. The authors also state that decrepitation was observed in agglomerates reentrained from an $\mathrm{E}-\mathrm{SO}_{\mathrm{x}}$ ash layer subjected to an electric field in a laboratory point-plane apparatus.

Sedman, C. B., R. E. Valentine, and N. Plaks. Evaluation of Pilot ESP Performance with Elevated Loadings from Sorbent Injection Processes, Presented at the Ninth Particulate Control Symposium, Williamsburg, VA, October 15-18, 1991.

The ESP computer model, ESPVI, was used to simulate the effect of the ADVACATE sorbent injection process on the performance of an ESP. Input data for the model were based on measurements made in EPA's 1000-acfm ESP test facility, which was modified to allow injection of high loadings of ADVACATE solids ahead of the ESP. The ADVACATE solids were prepared on site by slurrying a pre-ground Illinois fly ash with hydrated lime for $3 \mathrm{hrs}$ at $190^{\circ} \mathrm{F}$. The solids were pneumatically injected into a preheated air stream containing $1000 \mathrm{ppm}$ of $\mathrm{SO}_{2}$. The duct ahead of the ESP provided about $2 \mathrm{sec}$ of residence time for drying and reaction of the sorbent with $\mathrm{SO}_{2}$. With the sorbent injected at rates sufficient to produce inlet loadings of 1.7 to $11.5 \mathrm{gr} / \mathrm{scf}$, the loadings measured at 
the ESP outlet, with the ESP deenergized, varied from 0.7 to $3.7 \mathrm{gr} / \mathrm{scf}$. This suggested a large degree of dropout, which increased with increasing sorbent injection rate. The authors state that this is to be expected because of the large particle size in the ADVACATE sorbent, which is said to be over $100 \mu \mathrm{m}$. Therefore, the loadings used in the modeling were the lower values obtained after the settling. Presumably, this implies that hoppers would be installed in the duct between the sorbent injection point and the ESP.

Impactor measurements made at the ESP outlet, again with the ESP deenergized, showed a constant loading of submicron particles, regardless of the sorbent injection rate. This result is difficult to explain. The authors suggest that it may be a result of agglomeration, although it seems unlikely that this would produce a constant loading with increasing injection rate. In any case, the submicron loading is only $0.009 \mathrm{gr} / \mathrm{scf}$, which accounts for only 0.2 to $1 \%$ of the total mass loading that was actually measured. For an ESP with an SCA of $240 \mathrm{ft}^{2} / \mathrm{kacfm}$, the model predicted emission rates of 0.03 to $0.05 \mathrm{lb} / 10^{6} \mathrm{Btu}$ using the range of inlet loadings measured in the test facility (i.e., assuming considerable dropout ahead of the ESP and no increase in submicron particles). Allowing for the temperature reduction with sorbent injection $\left(300^{\circ} \mathrm{F}\right.$ to $\left.150^{\circ} \mathrm{F}\right)$, this size would correspond to a presorbent SCA of about $200 \mathrm{ft}^{2} / \mathrm{kacfm}$. If no credit is taken for the dropout, and the submicron mass is assumed to increase linearly with the sorbent injection rate, the predicted emission rate for the same scenario is about $0.16 \mathrm{lb} / 10^{6} \mathrm{Btu}$. An emission rate of about $0.04 \mathrm{lb} / 106 \mathrm{Btu}$ was predicted for the baseline (fly ash only) case at $300^{\circ} \mathrm{F}$ with the same ESP configuration. Thus, a high rate of sorbent injection will probably result in an increase in ESP emissions, but a low rate of injection may have little effect on the emission rate, if the ADVACATE sorbent contains no submicron particles.

Slaughter, D. M., S. L. Chen, W. R. Seeker, D. W. Pershing, and D. A. Kirchgessner. Increased $\mathrm{SO}_{2}$ Removal with the Addition of Alkali Metals and Chromium to CalciumBased Sorbents, Twenty-Second Symposium (International) on Combustion/The Combustion Institute, 22 (1988).

The promotion of high-temperature sulfur capture by chromium and alkali metal additives was studied in a $300 \mathrm{~kW}$, down-fired, boiler-simulator furnace. The promotion of both limestone and hydrated lime sorbents was studied at various levels of promoter addition and compared to baseline sorbent performance. Studies were done with five different types of coal and with $\mathrm{H}_{2} \mathrm{~S}$-doped natural gas to determine the effect of the coal mineral matter 
on promoter effectiveness. To provide an indication of temperature sensitivity, tests were done with the baseline and the promoted sorbents injected at temperatures of $2600^{\circ} \mathrm{F}$ and $2150^{\circ} \mathrm{F}$. A special phase-discrimination probe was used to separate reactive sorbent particles from the hot gas stream to avoid $\mathrm{SO}_{2}$ removal within the sampling system.

At a $\mathrm{Ca} / \mathrm{S}$ ratio of $2: 1$, the addition of 5 weight $\%$ chromium, as $\mathrm{Cr}_{2} \mathrm{O}_{3}$, to limestone was found to increase $\mathrm{SO}_{2}$ capture from $18 \%$ to $40 \%$ at $2600^{\circ} \mathrm{F}$ and from $25 \%$ to $38 \%$ at $2150^{\circ} \mathrm{F}$ with $\mathrm{SO}_{2}$-doped natural gas. Approximately the same degree of promotion was also observed when coal was fired and the promoted sorbent was injected at the same temperature. Electron microscopy revealed that the presence of the chromium converted the rough, angular, porous limestone particles to smooth spheres with fewer pores. BET measurements showed a reduction in calcine surface area from $12 \mathrm{~m}^{2} / \mathrm{g}$ to $4 \mathrm{~m}^{2} / \mathrm{g}$. The authors state that this suggests that the chromium combines with the sorbent forming a liquid phase, and they cite a study that identified a low-melting eutectic in the $\mathrm{CaO} / \mathrm{Cr}_{2} \mathrm{O}_{3}$ system. The authors speculate that the presence of the liquid phase allows faster diffusion of $\mathrm{SO}_{2}$ to reactive $\mathrm{CaO}$ sites. Carbonates of three alkali metals (sodium, potassium, and lithium) were also found to promote the capture by both limestone and hydrated lime in the $\mathrm{SO}_{2}$-doped gas system. However, the effectiveness of the these promoters was greatly reduced in the presence of coal mineral matter. The authors suggest that the mineral matter scavenges the vaporized alkali before it can reach the sorbent particles. Chromium is said to be less affected by the mineral matter because of its lower volatility.

Stouffer, M. R., H. Yoon, and F. P. Burke. An Investigation of Flue Gas Desulfurization by In-Duct Dry Sorbent Injection, Ind. Eng. Chem. Res., 28 (1989).

Pilot tests with steam and water spray humidification were conducted to study the effects of adsorbed moisture and water droplet collisions on the reaction of calcium hydroxide with $\mathrm{SO}_{2}$. The tests were performed in a pilot humidification chamber consisting of a vertical, 8in.-i.d., cylindrical duct equipped with a single two-fluid (air/water) spray nozzle mounted downstream from the hydrated lime injection point. The system used a simulated coal-fired flue gas produced by burning natural gas and injecting $\mathrm{CO}_{2}, \mathrm{H}_{2} \mathrm{O}, \mathrm{SO}_{2}$, and fly ash into the combustion gases. Measurements of $\mathrm{SO}_{2}$ removal efficiency were made across the chamber, which was $20 \mathrm{ft}$ in length, and across the entire system of chamber and downstream baghouse. A particle-discriminating probe and heated filter arrarigement were used to avoid $\mathrm{SO}_{2}$ removal in the sampling lines to the on-line analyzers. 
With steam humidification to an approach temperature of $25^{\circ} \mathrm{F}$ and a chamber residence time of $2 \mathrm{sec}, \mathrm{SO}_{2}$ removals of $12 \%$ and $23 \%$ were achieved at $\mathrm{Ca} / \mathrm{S}$ ratios of 1:1 and 2:1. The use of increased steam injection to decrease the approach temperature from $60^{\circ} \mathrm{F}$ to $10^{\circ} \mathrm{F}$, which corresponded to increasing the relative humidity from $20 \%$ to $75 \%$, produced an increase in $\mathrm{SO}_{2}$ removal from $12 \%$ to $40 \%$ at a $\mathrm{Ca} / \mathrm{S}$ ratio of $2: 1$. Based on previously published data on water vapor adsorption as a function of relative humidity, the authors show that the $\mathrm{SO}_{2}$ removals observed with steam humidification can be correlated linearly with the number of monolayers of water adsorbed on the sorbent. Pilot tests with water spray humidification clearly indicated that the presence of water droplets substantially enhances $\mathrm{SO}_{2}$ removal. At an approach temperature of $25^{\circ} \mathrm{F}$ and a $\mathrm{Ca} / \mathrm{S}$ ratio of $1: 1, \mathrm{SO}_{2}$ removal across the humidification chamber was $30 \%$ with a water spray, compared to $12 \%$ with steam injection. This suggests that sorbent-droplet collisions produce an increased degree of sorbent activation over that achieved solely by adsorption of water vapor. With the objective of maximizing the rate of sorbent-droplet collisions, tests were done with various droplet size distributions produced by adjusting the atomizing air pressure. The results showed that $\mathrm{SO}_{2}$ removal increased with increasing droplet size. With a Spraying Systems $\mathrm{J} 12$ nozzle, the removal at a $30^{\circ} \mathrm{F}$ approach was improved from $20 \%$ to $28 \%$ by reducing the atomizing air pressure from 115 psig to 55 psig. This result confirms that sorbent-droplet interactions enhance $\mathrm{SO}_{2}$ removal and suggests that sorbent injection prior to water spraying is important for maximum $\mathrm{SO}_{2}$ removal.

Volpe, L. and M. Boudart. Topotactic Preparation of Powders with High Specific Surface Area, Catal. Rev. - Sci. Eng., 27 (1985).

The authors present a review of our current state of knowledge concerning topotactic reactions of solids. Topotactic reactions are those in which the crystal lattices of the solid reactant and the solid product show a definite orientation relationship, and the reaction proceeds throughout the bulk of the solid reactant. Examples of topotactic reactions include the thermal decomposition of $\mathrm{Ca}(\mathrm{OH})_{2}, \mathrm{Mg}(\mathrm{OH})_{2}$, and $\mathrm{CaCO}_{3}$; the carburization of $\mathrm{MOO}_{2} \mathrm{~N}$ and $\mathrm{W}_{2} \mathrm{~N}$ in $\mathrm{CH}_{4}$ and $\mathrm{H}_{2}$; and the oxidation/reduction reactions of iron oxides. Topotactic reactions have wide-spread applications in the preparation of support materials for heterogeneous catalysts. Many topotactic reactions are characterized by a large increase in the specific surface area of the solid, which is frequently exploited in the preparation of catalytic solids or sorbents. 
For the purposes of this literature review, the topotactic reactions of greatest interest are the decompositions of $\mathrm{Ca}(\mathrm{OH})_{2}$ and $\mathrm{CaCO}_{3}$. The authors describe the $\mathrm{CaO}$ formed by these decompositions as a pseudomorph, meaning a crystal that has been converted into another substance without changing its external form. By virtue of this pseudomorphism, the $\mathrm{CaO}$ particles have the same external form as the parent $\mathrm{Ca}(\mathrm{OH})_{2}$ or $\mathrm{CaCO}_{3}$. particles. However, $\mathrm{CaO}$ has a substantially higher density, or lower molar volume, than either $\mathrm{Ca}(\mathrm{OH})_{2}$ or $\mathrm{CaCO}_{3}$. Therefore, there is an inevitable development of considerable porosity in the $\mathrm{CaO}$ produced from $\mathrm{Ca}(\mathrm{OH})_{2}$ or $\mathrm{CaCO}_{3}$. The authors assert that the measured porosity has been shown to be near the value predicted from the difference in molar volumes. The porosity and surface area of $\mathrm{CaO}$ produced by these decompositions depend upon particle size, dimensions of the bed of reactant solids, heat transfer rate, and the presence of water vapor and $\mathrm{CO}_{2}$. The authors report that water vapor concentrations as low as $1 \mathrm{ppm}$ have been shown to affect the rate of dehydration of $\mathrm{Mg}(\mathrm{OH})_{2}$, and $\mathrm{CO}_{2}$ concentrations as low as $2 \mathrm{ppm}$ have been shown to catalyze the sintering of high-surfacearea $\mathrm{CaO}$. The authors recommend the analysis of $\mathrm{N}_{2}$ adsorption-desorption isotherms to obtain information on pore size and surface area. A combination of several microstructural, crystallographic, and chemical techniques are recommended to understand a topotactic reaction. The authors also stress that the characterization should be done in situ at the reaction conditions to avoid structural changes caused by adsorption of water vapor and $\mathrm{CO}_{2}$. 

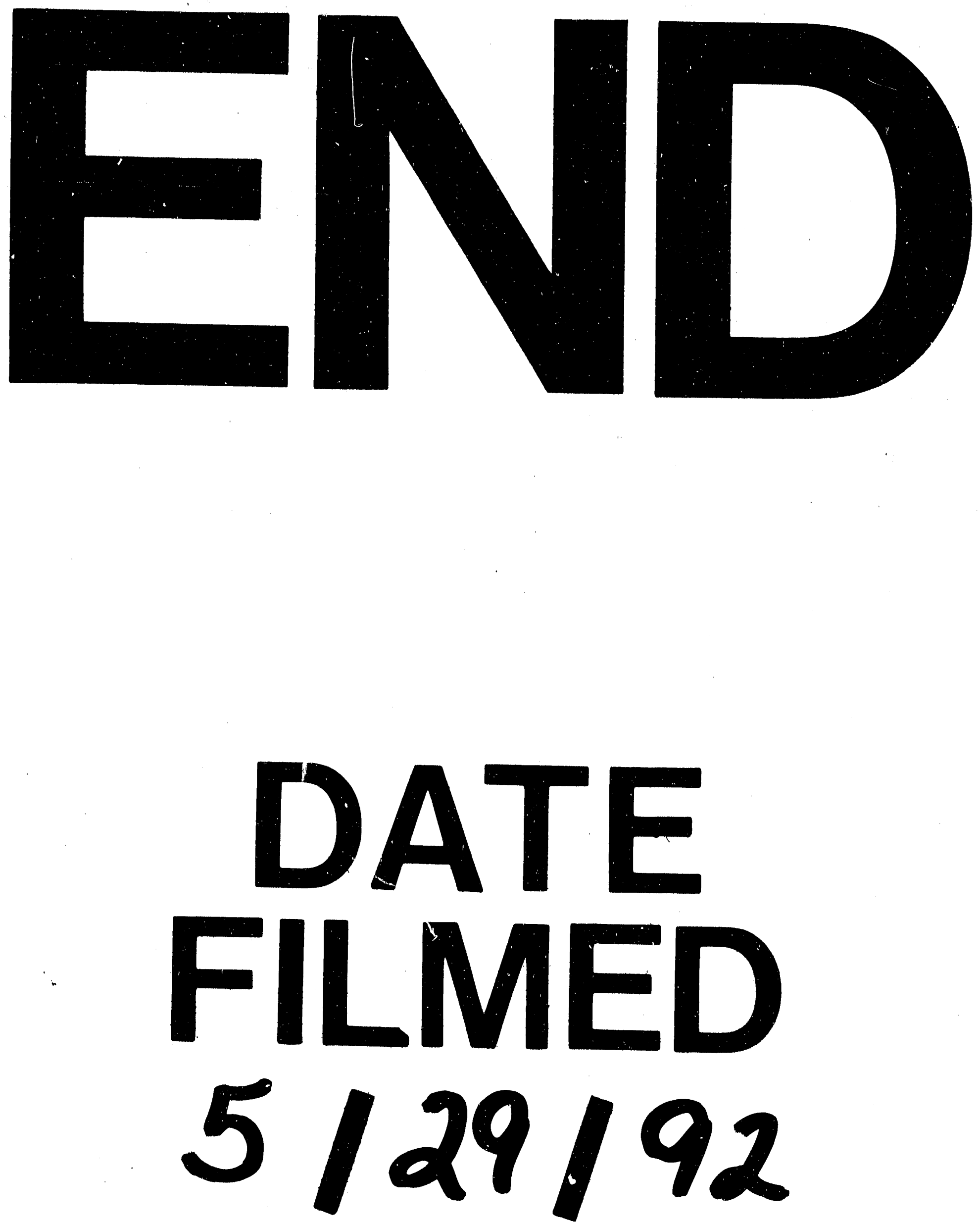
Cي 